\title{
Neural dynamics of visual selection
}

Citation for published version (APA):

van Aalderen-Smeets, S. I. (2007). Neural dynamics of visual selection. [Doctoral Thesis, Maastricht University]. Print Partners Ipskamp. https://doi.org/10.26481/dis.20070504sa

Document status and date:

Published: 01/01/2007

DOI:

10.26481/dis.20070504sa

Document Version:

Publisher's PDF, also known as Version of record

\section{Please check the document version of this publication:}

- A submitted manuscript is the version of the article upon submission and before peer-review. There can be important differences between the submitted version and the official published version of record.

People interested in the research are advised to contact the author for the final version of the publication, or visit the DOI to the publisher's website.

- The final author version and the galley proof are versions of the publication after peer review.

- The final published version features the final layout of the paper including the volume, issue and page numbers.

Link to publication

\footnotetext{
General rights rights.

- You may freely distribute the URL identifying the publication in the public portal. please follow below link for the End User Agreement:

www.umlib.nl/taverne-license

Take down policy

If you believe that this document breaches copyright please contact us at:

repository@maastrichtuniversity.nl

providing details and we will investigate your claim.
}

Copyright and moral rights for the publications made accessible in the public portal are retained by the authors and/or other copyright owners and it is a condition of accessing publications that users recognise and abide by the legal requirements associated with these

- Users may download and print one copy of any publication from the public portal for the purpose of private study or research.

- You may not further distribute the material or use it for any profit-making activity or commercial gain

If the publication is distributed under the terms of Article $25 \mathrm{fa}$ of the Dutch Copyright Act, indicated by the "Taverne" license above, 


\section{Neurale Dynamiek van Visuele Selectie}


ISBN: 978-90-9021720-8

Cover design: Joost van der Steen, O.K. Parking, Arnhem Printed by: Print Partners Ipskamp Enschede Copyright (C) 2007 by Sandra van Aalderen-Smeets. All rights reserved 


\section{Neural Dynamics of Visual Selection}

\section{PROEFSCHRIFT}

ter verkrijging van de graad van doctor aan de Universiteit Maastricht, op gezag van de Rector Magnificus Prof. Mr. G.P.M.F. Mols, volgens besluit van het College van Decanen, in het openbaar te verdedigen op vrijdag 4 mei 2007 om 12.00

door

Sandra Iris van Aalderen - Smeets geboren op 3 oktober 1976 te Eindhoven 


\section{Promotor:}

Prof.dr. R. Goebel

\section{Copromotores:}

Dr. P. Fries

(F.C. Donders Centre for Cognitive Neuroimaging, Nijmegen)

Dr. J.V. Schwarzbach

(Università Degli Studi di Trento, Rovereto, Italy)

\section{Beoordelingscommissie:}

Prof.dr. L. Boon

Prof.dr. E. Postma

Dr. O. Jensen

Dr. P. De Weerd (voorzitter)

(F.C. Donders Centre for Cognitive Neuroimaging, Nijmegen) 


\section{Table of Content |}

o.1 Introduction: The subject matter 7

1.1 The visual system 13

1.2 Visual masking $\quad 16$

1.3 Attention 18

1.4 Methodology 21

0.2 Investigating neurophysiological correlates of metacontrast masking with magnetoencephalography 29

2.1 Subjects and methods 33

2.2 Results 40

$\begin{array}{lll}2.3 & \text { Discussion } & 46\end{array}$

o.3 Beyond the forest and the trees: Local and global interference in hierarchical visual stimuli containing three levels

3.1 Methods $\quad 55$

$\begin{array}{lll}3.2 & \text { Results } & 59\end{array}$

$\begin{array}{lll}3 \cdot 3 & \text { Discussion } & 60\end{array}$

0.4 Activation patterns in visual cortex reveal receptive field size dependent attentional modulation $\quad \mathbf{6 5}$

$\begin{array}{llr}4.1 & \text { Methods } & 69\end{array}$

$\begin{array}{lll}4.2 & \text { Data analysis } & 72\end{array}$

$\begin{array}{lll}4.3 & \text { Results } & 75\end{array}$

$\begin{array}{lll}4.4 & \text { Discussion } & 76\end{array}$

0.5 Competative mechanisms subserve human visual attention 79

$\begin{array}{lll}5.1 & \text { Methods } & 88\end{array}$

$\begin{array}{lll}5.2 & \text { Data analysis } & 91\end{array}$

$5 \cdot 3$ Results 93

$\begin{array}{lll}5.4 & \text { Discussion } & 94\end{array}$

\begin{tabular}{ll|l}
0.6 & Summary & 97
\end{tabular}

Reference list $\quad 101$

Nederlandse samenvatting $\quad 111$

$\begin{array}{ll}\text { Dankwoord } & 115\end{array}$

$\begin{array}{ll}\text { Curriculum Vitae } & 119\end{array}$ 



\section{Chapter 0.1 |}

\section{Introduction: The subject matter}

Many people consider that what we see is what is truly there. Hence, the saying: "I do not believe it until I see it with my own eyes". However, this believe might not be entirely accurate. Visual perception is not a video camera that quietly records the outside world, but it is an active brain process by which certain parts of our visual world are emphasized, while others are ignored. Every percept we experience is created by the brain. Illustrating this active and constructive nature of perception is what is called the size constancy of perception; we are able to recognize an object as the same even though the actual image on the retina varies greatly. When somebody walks towards you, the image on the retina increases in size. Nevertheless, you perceive this person as coming closer; not that this person is growing in size. In order to accomplish this feature, the brain needs to actively integrate information from the person with information of the surroundings and with information from long term memory. The visual illusion shown in figure 1 demonstrates that this active mechanism can sometimes lead to a "wrong" percept. The processing and integration of information, which may lead to a distorted image 


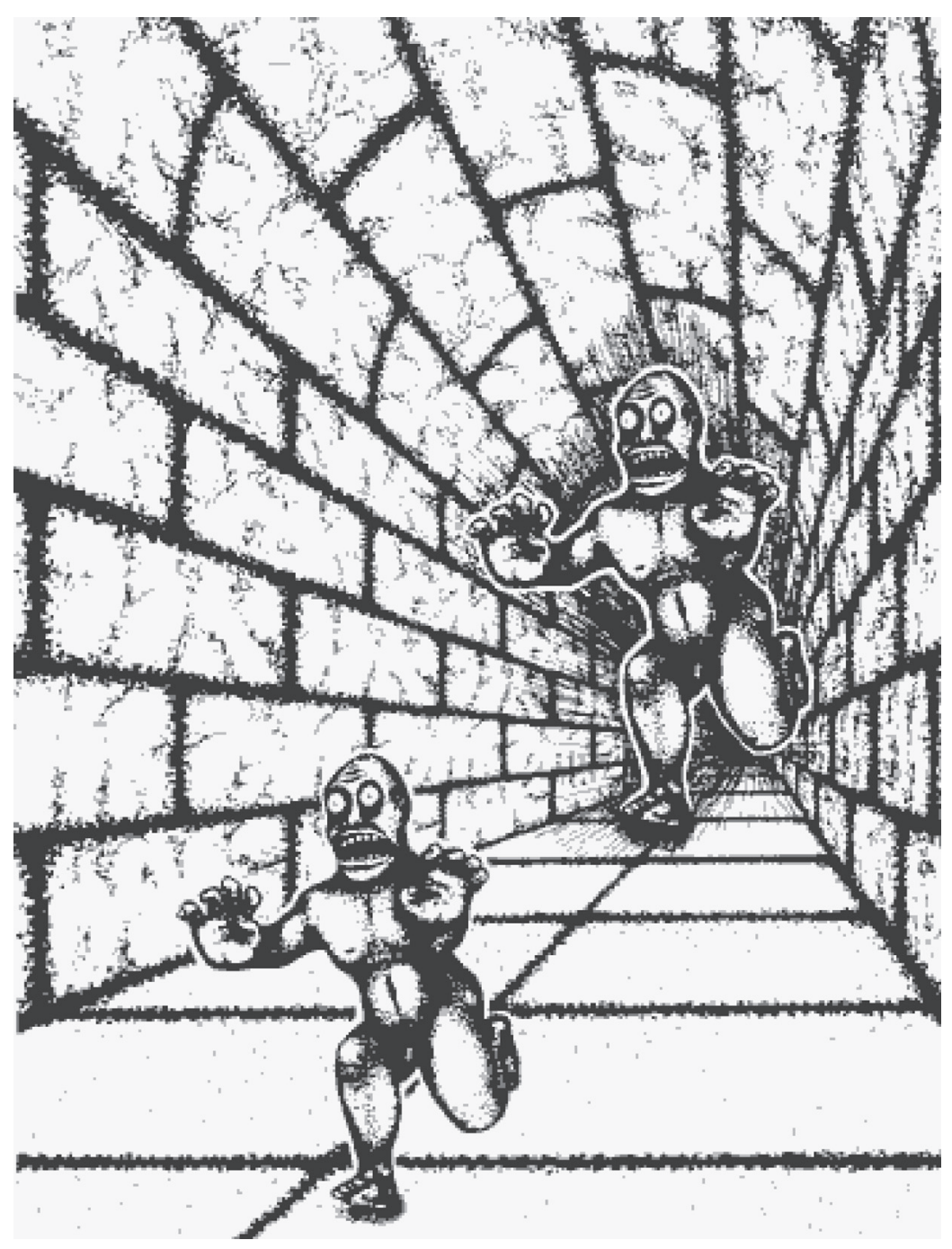

Figure 1. The hallway illusion.

It seems like the little man is chased by the large creature. However, both creatures are the same size. The creature in the back appears larger due to the surrounding information that is integrated with information from long term memory and with the information of the creature ( Illustration from Roger Shepard). 
of the "real world", is necessary to deal with the abundance of information we encounter each moment.

A very interesting phenomenon that results from this constructive nature of perception is visual masking. Visual masking refers to the decreased visibility of a target stimulus when a second stimulus is presented close in time and space. The interesting part of this phenomenon is not merely that the target stimulus is not seen. If this were the case it could be explained by early elimination of target processing. However, previous experiments have shown that the target information is processed up to a level where it can influence subsequent behavior, while the stimulus is still not seen by the subject (Neumann and Klotz, 1994; Dehaene et al., 1998). An example is illustrated in figure 2. When an arrow that is presented very briefly is followed by a masking stimulus, the subjects will respond at chance level when they have to report the direction of the arrow. This is visual masking. However, when they have to respond to the second arrow, i.e. the masking stimulus, reaction times will decrease when the masking arrow and the first arrow point in similar directions. Reaction times will increase when they point in opposite directions (Vorberg et al., 2003). This is called priming. The target information influences the reaction time of the subject without reaching the visual awareness of the subject. How can processing of a masking stimulus interfere with the perception of a target stimulus which is presented earlier in time, without completely eliminating processing of the target information? The neural mechanism of how target and mask information interact to yield visual masking is largely unknown. It is still an open question at which latency and in which visual brain area or areas visual masking takes place.

Our visual awareness (meaning that what we consciously perceive) is not just modulated by the timing and spatial characteristics of the input into the visual system but is also modulated by selective attention. Attention is the mechanism that selects parts of the input for enhanced processing. It is a prerequisite and necessity for visual perception. For example, patients suffering from hemispatial neglect (i.e. damage to the right parietal or parietal-occipital lobe) ignore one side of their body and of their surrounding. They fail to eat one side of their plate, to dress or undress one side of their body, or draw only one side of an object. An important contributor to this syndrome seems to be attention (Driver, 1995). Attention selects which part of the visual input reaches visual awareness in case there are multiple candidates. The allocation of attention is guided by the input itself (bottom-up processing) or by top-down modulation. Bottom-up attentional control occurs for example when a bright light is flashed, while top-down control is influenced by behavioral demands or long term memory. A fundamental issue concerns the allocation of attention to the overall structure of our visual field and its component parts. Our visual world can be thought of as being organized in 
a.

b.
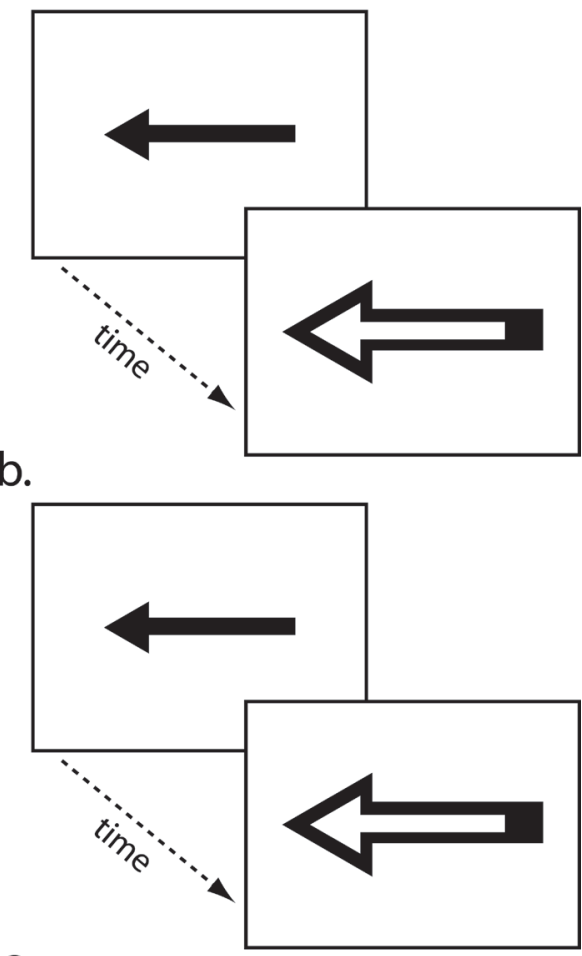

C.

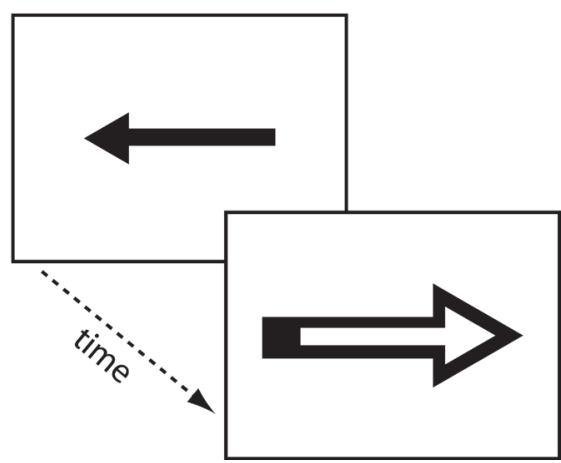

Figure 2. Visual masking and priming.

a. Visual masking. Subjects have to respond to the direction of the filled in arrow. When the second (open) arrow is presented close in time the subject reports not seeing the first arrow. b. and c. Visual priming. Subjects respond to the second (open) arrow. In b. subjects respond faster while in c. subjects respond slower compared to when only the open arrow is presented. When asked how many arrows they have seen subjects report having seen one arrow (figures based on Vorberg et al., 2003). 
a hierarchical way, like in the well-known metaphor of the forest and the trees (Navon, 1977). Allocating covert attention to different parts of a visual scene changes the perception of this scene while the visual input remains the same. There are many intriguing questions concerning how visual perception is changed by stimulus features or by attention. What are the neuronal correlates of visual masking? Does processing of the overall structure of an object precede processing of the component parts or are the parts perceived first and then combined to form the objects? How is visual processing influenced by attention? Or more specifically, what is the locus of attention? Does it operate from a single area, or does it operate on the level of processing that is relevant for behavior? Does attention merely enhance a neuronal response or is it a more complicated mechanism comprising both enhancing and inhibiting mechanisms?

This doctoral thesis investigates these open questions. The main research question is how a change in perception, brought about by task demand (visual masking) and behavioral modulation (attention) manifests itself in the neural dynamics of visual processing? This chapter will provide the necessary background information on visual masking and selective attention in order to introduce the topics of investigation. Furthermore, in this chapter I will formulate the research questions for each of the studies in this thesis more precisely. After a description of the visual system, I present a short overview of visual masking, emphasizing the discrepancy between our knowledge of the visual system and this striking phenomenon. Next, an overview of selective attention is given, which will zoom in on attentional modulation of neuronal processing. Since different research methods and brain imaging methods are used in the studies presented in this thesis I will present a short introduction into the methods in the last section.

The outline of the doctoral thesis follows the outline of this introductory chapter. Chapter 2 will present a study investigating the neuromagnetic correlates of visual masking using MEG. Unraveling the mechanisms behind visual masking can provide more insight into the mechanism of visual perception. The remaining chapters present studies regarding selective attention, starting off with an investigation of the allocation of attention to the global and local aspects of an object in chapter 3. Chapters 4 and 5 present neuroimaging studies investigating the neural dynamics of attention. The study in chapter 4 uses fMRI to relate the effect of attention to receptive field size of visual areas, while chapter 5 focuses on finding support for the biased competition model of attention in human visual cortex by trying to replicate single cell studies in monkey using MEG. 


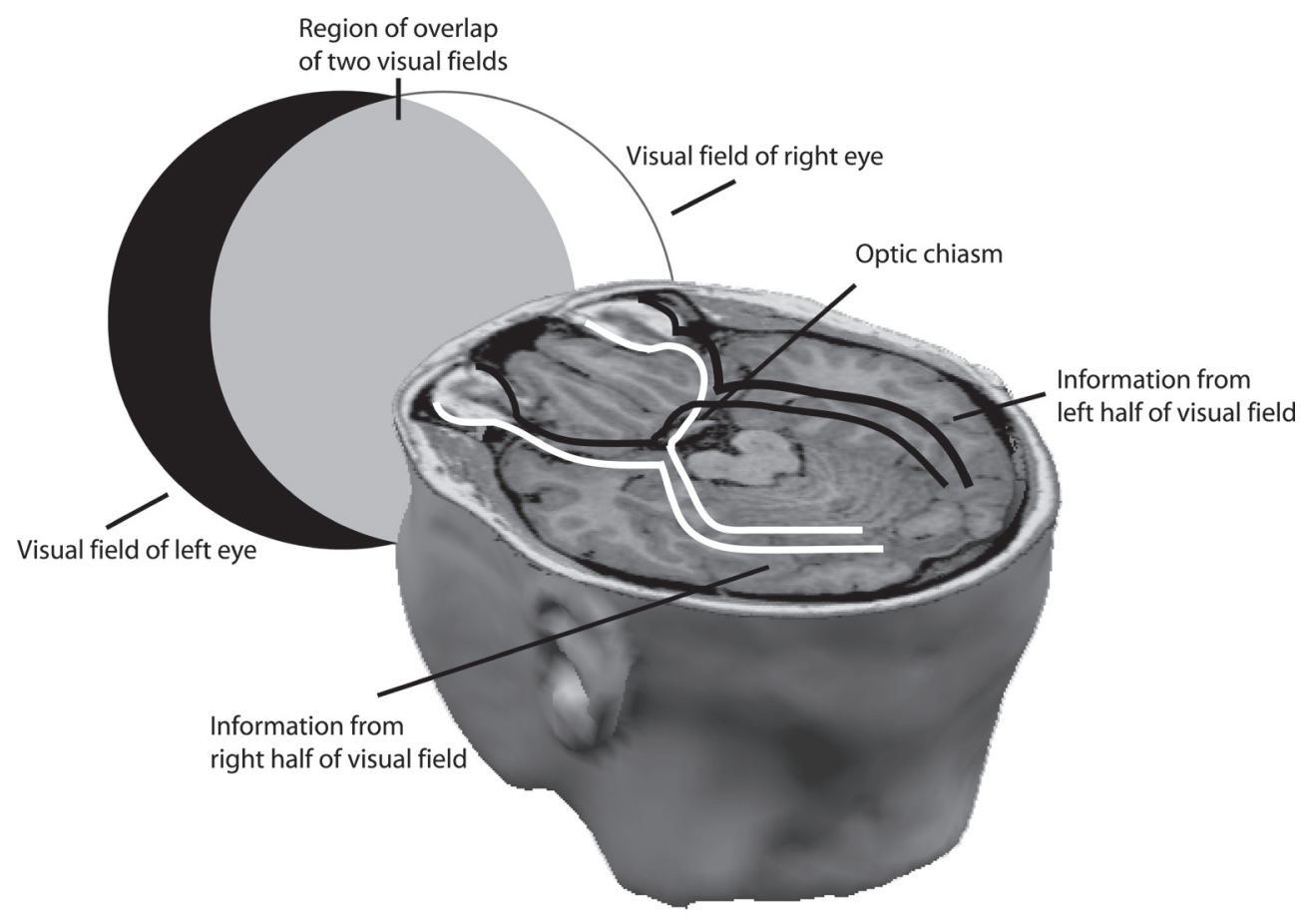

Figure 3. The primary visual pathway 


\subsection{The visual system}

The visual system of the human brain displays a marvellous architecture. The system is organized in a modular and a hierarchical fashion. The modularity means that different brain areas have a functional specialization. Different processes underlying vision, as for example low-level processes such as edge detection or higher level processes such as form-, color-, and motion detection are processed by different neural network elements and are distributed over the brain. Even higher level processing such as the perception of faces and places is located in distinct areas of the cortex (Kanwisher et al., 1997). Illustrating this functional organization are the more than 25 different visual areas that have been identified in the monkey brain (Sereno et al., 1995). The modularity reflecting functional specialization of brain areas arises from the feature specificity of neurons in different parts of the visual cortex. Next to being highly modular, information processing in the visual system is also hierarchical in the sense that low-level information is encoded and extracted at an earlier stage than high-level information. For example, edge detection occurs before object recognition and identification. This modularity and hierarchy is neither rigid nor very strong; there is interaction between the different modules and there are multiple feedback and recurrent connections in the hierarchy (Lamme et al., 1998). These characteristics of the organization of the visual system make this a flexible, dynamic, and fast system which can cope immediately with changes in the environment. In this section I will give a short overview of the visual pathway. Next, I will go deeper into the properties of neurons in visual areas and their implications for the organization of the visual system. This section will end with explaining a second organizational property of the visual system, namely retinotopy.

\section{The primary visual pathway}

Processing in the visual system starts when energy in the form of light waves is transformed into electrical signals by the rods and cones; the light sensitive cells in the retina at the back of the eye. These electrical signals leave the eye in a bundle called the optic nerve. Most of the fibers in the optic nerve coming from the retina travel through the geniculostriate pathway: from the retina through the lateral geniculate nucleus (LGN) to the visual cortex, located in the occipital lobe of the brain (see figure 3). Fibers from the medial part of the retina of both eyes cross hemisphere at the optic chiasm, while fibers from the lateral parts of both retinas stay in the same hemisphere. The result is that objects in one hemifield are processed by the contralateral hemisphere. The stream of visual information processing does not stop when it has reached the visual cortex, but extends well into the tem- 
poral and parietal lobe. The dorsal pathway, extending into the parietal lobe, is concerned with processing spatial information and is also called the "where" pathway. The ventral pathway, extending into inferotemporal cortex is crucial for identifying objects and is called the "what" pathway (Milner and Goodale, 1995). The stream of information does not only travel forwards, i.e. from the early visual areas to higher visual areas into the temporal and parietal lobe (feedforward processing), but also travels backwards from higher to lower areas (feedback processing), and within one area (recurrent processing). These feedback and recurrent connections make up for an equally important processing part of the visual system. The fast connections are both situated among neighbouring and non neighbouring areas. Feedback and recurrent connections are involved in all top-down processing in the visual system and are hypothesized to play a role in higher cognitive functions (Lamme and Roelfsema, 2000; Engel and Singer, 2001; Engel et al., 2001).

\section{Neuronal properties}

The hierarchical structure of the visual system is characterized by two properties of its neurons: an increase in receptive field size and an increase in receptive field complexity as one travels from early visual areas to higher areas. The receptive field of a neuron is the property of a neuron that drives the neuron to respond only to stimuli that impinge in a certain part of the visual field (Hubel and Wiesel, 1968). Studies in monkeys have shown that the size of receptive fields are smallest for neurons in central primary visual cortex (V1) and increase gradually for highertier areas and for areas processing peripheral parts of the visual field (Zeki, 1978; vanEssen et al., 1984; Maunsell and Newsome, 1987; Felleman and vanEssen, 1991; Boussaoud et al., 1991; Lamme et al., 1998; Gattass et al., 2005). This increase in receptive field size is due to convergence of feedforward connections from one cell to the next. In addition to an increase in receptive field size, the result of this convergence is that neurons in higher visual areas respond more selectively to a specific constellation of object features. For example, adjacent concentric on-off cells in the LGN converge on a simple cell in the primary visual cortex. The receptive field of this simple cell therefore becomes selective to edges with a specific orientation. The outputs of multiple simple cells converge onto one complex cell in a higher visual area, which then codes for a line in a particular orientation and a particular length, or a line that moves in a particular direction. Areas in parietal and temporal cortex that still process visual information are selective for very complex and abstract stimulus properties, which can span almost the entire visual field. 


\section{Retinotopy}

The feature specificity of neurons causes the functional specialization of the visual cortex and results in multiple separated visual areas. These striate and extrastriate visual areas are organized retinotopically (see chapter 4, figure 1c). Retinotopy refers to the preservation of spatial relationships of receptor input, i.e. neighboring locations in the visual field are represented by neighboring locations in the cortex. This means that each area contains a complete or partial representation of the retina and hence of the visual field. The visual areas are organized following a polar coordinate system; when a stimulus moves from the upper meridian to the lower meridian in the visual field, a traveling wave of activation in the cortex moves from the lower bank of the calcarine sulcus to the upper bank. A second dimension of the retinotopic organization is eccentricity. When a stimulus moves from the central visual field to the periphery, activation in the cortex moves concentrically from the occipital pole to more anterior regions of the visual cortex. Sereno et al. (1995) demonstrated that human visual areas could be mapped with a precision comparable to invasive studies in non-human primates. They used echo-planar fMRI to determine the borders between $\mathrm{V}_{1}, \mathrm{~V}_{2}, \mathrm{~V}_{3}, \mathrm{VP}$, and $\mathrm{V}_{4}$ in human subjects. The border between $\mathrm{V}_{1}$ and $\mathrm{V}_{2}$ is marked by the vertical meridians and the border between $\mathrm{V} 2$ and $\mathrm{V}_{3} / \mathrm{VP}$ is marked by the horizontal meridian. V1 represents the whole visual hemifield in a mirror representation. Higher areas (V2, V3, VP, and V4) are split into locations dorsal and ventral of the calcarine sulcus, where the dorsal part represents the lower visual field and the ventral part represents the upper visual field.

\section{2 | Visual masking}

Visual masking refers to a range of phenomena in which the visibility of a visual stimulus is reduced in the presence of a second stimulus. This thesis will focus on one type of masking, backward masking, in which the visibility of a visual target stimulus is reduced by the presentation of a second stimulus, the mask, presented later in time. Presenting different types of mask stimuli results in different behavioral masking functions, i.e. functions relating the visibility of the target to the length of the interval between the target and mask. A pattern or noise mask usually results in monotonically increasing visibility of the target stimulus with increasing latency of mask presentation (Breitmeyer, 1984). Metacontrast masking refers to conditions in which the inner contours of a mask stimulus do not spatially overlap with those of a preceding target stimulus (Breitmeyer and Ogmen, 2000). Figure 4 shows the non-monotonic U-shaped dependence of target visibility on Stimulus Onset Asynchrony (SOA) between target and mask resulting from metacontrast backward masking (Breitmeyer, 1984).

Several hypotheses concerning the mechanisms of masking have been 
postulated (for a review see Breitmeyer and Ogmen, 2000). The dual channel, sustained-transient theory of visual masking (Breitmeyer, 1984) postulates two hypothetical channels that are involved in the processing of a visual stimulus. A slow and sustained channel processes object features like brightness and color, while a faster transient channel processes coarse patterns and signals spatial location and motion of a stimulus. Accordingly, an interaction of these two channels is thought to give rise to metacontrast masking: The fast responding transient channel activated by the mask inhibits the slow responding sustained channel activated by the target, hence the target related activity is disrupted and the target is not processed any further (Breitmeyer, 1984). Another theory to explain backward masking is based on recurrent processing (Bridgeman, 1980; Enns and Di Lollo, 2000). A visual stimulus produces an early burst of activity in striate areas. After being carried to and processed by higher extrastriate visual areas through cortico-cortical connections the modulated information returns to early areas. It is thought that the architecture of re-entry searches for a match between the descending code and the low-level activity. This recurrent, or iterative, processing lasts until a match is made or new information is entered into the system. Consequently, the same cells in striate cortex encode different information about the same stimulus at different times. Recurrent processing is assumed to be necessary to group object features attentively and to make them available for

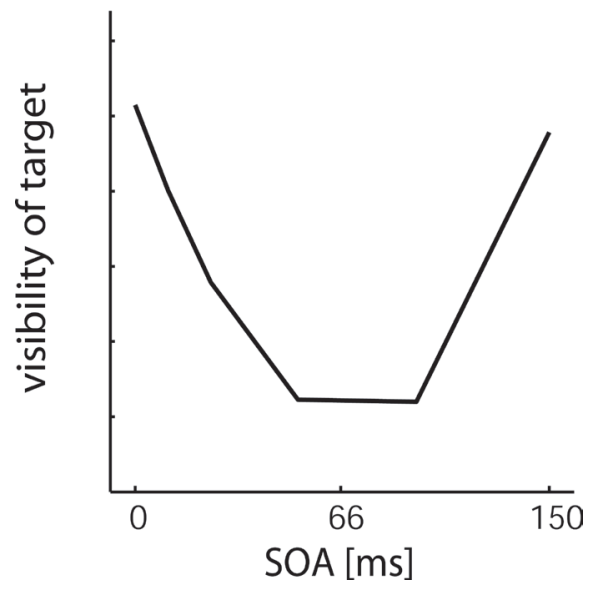

Figure 4. Metacontrast masking function. The visibility of a target depends on the Stimulus Onset Asynchrony between the target and a mask stimulus. 
conscious perception (Lamme and Roelfsema, 2000). In the case of metacontrast masking, activity related to the mask enters the early visual areas at the same time as target related information from recurrent loops is fed back to these same areas. In that case, feedback information does not match the activity from the first burst of activity, and the target stimulus is not consciously perceived.

Neurophysiological correlates related to the processing of masking stimuli can shed light on how processing of the target and mask stimulus evolves over time in the brain. These correlates provide information about the latencies at which the processing of the target is disrupted or modulated and might shed light on the underlying mechanism of visual masking and eventually might discriminate between the different models of metacontrast masking. This thesis will investigate the neural correlates of visual metacontrast backward masking using magnetoencephalography. The neuromagnetic response to the target followed by a mask at a certain latency is compared to the response to the target followed by a non-mask presented at the same latency but which does not decrease target visibility. We expect the evoked response to the target to correlate with visibility of the target and hope that the results will provide more insight into the neural mechanisms of visual backward masking.

\subsection{Attention}

A fundamental property of perception is attention: "Perception is what I agree to attend to", as said by W. James in Principles of Psychology (1890). The visual scenes we encounter are crowded with objects. From all these objects only a few reach visual awareness. The brain has a limited capacity for processing information and only a small amount of the sensory information impinging on the retina can be processed (Broadbent, 1953; Treisman, 1969; Desimone and Duncan, 1995). The mechanism by which the brain selects relevant information and filters out irrelevant information is attention (Broadbent, 1958; Treisman, 1969). Subjectively, one is aware of the stimuli one attends to and is unaware of unattended stimuli. However, this does not necessarily mean that the unselected information is not processed (Neumann and Klotz, 1994; Dehaene et al., 1998).

\section{Global-local attention}

An ongoing issue in vision research concerns the allocation of attention to the overall structure of our visual field and its component parts. Navon (1977) showed that the global aspect of a hierarchical visual stimulus is perceived more quickly than its local aspects (global advantage) and global processing interferes more with local processing than vice versa (global interference). These two effects are called the 
global precedence effect. Navon (1977) used dual layer stimuli for his experiments, which consist of larger figures (global forms) made up of smaller figures (local elements) to form hierarchical stimuli with layers that are equally complicated and identifiable and only differ in their level of globality (see figure 5). However, real world objects and visual scenes can be described as a hierarchical structure with many more levels. In the study presented in chapter 3, we use triple layer hierarchical stimuli to actually investigate the suggested global interference effects. In these stimuli the middle layer occupies a more global position in the hierarchical structure of the stimulus with respect to the local layer, and a more local position with respect to the global layer. In dual level stimuli the local-global relation between the two levels is obvious, both absolute and relative. In triple level stimuli however, both the middle and the global level occupy a more global hierarchical position relative to the local level. This allows us to test the hypothesis that the global interference effect will increase with increasing level of globality, as predicted by the global-to-local hypothesis. In chapter 3 we will test this hypothesis and thereby hope to gain more insight in visual perception and the allocation of attention to visual scenes.

Figure 5. Classical Navon figure; an $\mathrm{H}$ made out of the letter S. 


\section{Models of selective visual attention}

For a long time the dominant hypothesis to account for the neural mechanism of attentional selection has been the spotlight model of attention (Erikson and Hoffman, 1973; Posner et al., 1980; Treisman and Schmidt, 1982; Treisman and Gormican, 1988; Tootell et al., 1998). In this model, attention serves to enhance the responses of neurons reflecting stimuli in a restricted area of the visual field, like a spotlight enhancing vision on one part of the theater stage. However, the estimates of the spatial extend of the spotlight have varied dramatically (Eriksen and Hoffman, 1973; Hughes and Zimba, 1985). Furthermore, modified versions of the spotlight model propose that it can better be described as a zoom lens model of attention (Eriksen and St James, 1986; Müller et al., 2003b), be divided into two separate spotlights (Müller et al., 2003a), or that it is surrounded by an region of inhibition (Slotnick et al., 2002; Müller and Kleinschmidt, 2004; Müller et al., 2005; Hopf et al., 2006a). Therefore, the spotlight model of attention might be incomplete. An alternative account for selective attention which is gaining much support over the last years is the biased competition model (Moran and Desimone, 1985; Desimone and Duncan; 1995; Reynolds et al., 1999). Multiple objects presented within the same receptive field of a neuron located at any point in the visual processing stream compete for neural representation. Directing attention to one of these stimuli biases the response of the neuron toward the response elicited by the attended stimulus if presented in isolation. It has been suggested that this bias is the result of an increased weight of the synaptic input driven by the attended stimulus (Reynolds et al., 1999). The biased competition model of selective attention has been primarily based on neurophysiological studies in non-human primates. Single cell recordings from macaque V2 and V4 neurons show that in the absence of attention, the firing rate of a neuron is determined by the competitive interaction between two stimuli that are presented simultaneously within one receptive field. One stimulus is effective and one is ineffective in driving the neuron's response. The resulting firing rate is a weighted average of the responses to the individual stimuli. Directing attention to one of the stimuli biases the neurons response such that it reflects the response to the attended stimulus presented alone. The response increases if the effective stimulus is attended and decreases if the ineffective stimulus is attended (Reynolds et al., 1999). The effect of attention is maximal when there is competition between stimuli and this competition will only take place when stimuli are presented within one receptive field. Consequently, attention operates optimally when the scale of the presented stimuli and the size of a receptive field correspond, e.g. attention to stimuli spanning a larger part of the visual field will result in a response change in higher visual areas.

These results from single cell recordings indicate that attention does not merely facilitate neuronal processing within a restricted area, as suggested by the 
spotlight model of attention. Rather, attention filters out the influence of irrelevant stimuli on subsequent processing by biasing the competition between relevant and irrelevant stimuli. Note that attention does also facilitate object processing (e.g. when a single stimulus is presented), but that these effects of attention are much smaller than attention effects yielded by biased competition mechanisms (Motter, 1993; Treue and Maunsell, 1996; McAdams and Maunsell, 1999).

It has been hard to replicate the single cells studies investigating biased competition with human participants due to methodological limitations. In single cell studies the responses to pairs of stimuli within a receptive field and the effect of attention can be meaningfully compared to the responses of individual stimuli. Brain responses measured with MEG and fMRI, are usually not selective for different stimuli within one receptive field. Recent human neuroimaging studies have tried to provide support for biased competition in human visual cortex (Kastner et al., 1998; 1999; 2001; Pinsk et al., 1999; Bles et al., 2006; Hopf et al. 2006a; 2006b). Although these studies suggest that competition seems to play a role in the enhancing effect of attention and that the effect of attention is dependent on receptive field size of an area, these studies do not directly confirm the biased competition model. There are two problems with these studies. The first problem is that the used methods are not selective for different stimuli within one receptive field. Second, the studies have not measured receptive field size in those areas where the competitive interactions take place.

The studies in chapter 4 and chapter 5 present experiments that investigate the biased competition model and it predictions in human cortex. The methodology used in these studies will overcome the difficulties of the studies presented above. The fMRI study presented in chapter 4 investigates whether the attention effect is dependent on the receptive field sizes of neurons in visual areas. It will assess the effect of attention to a level of a hierarchical triple layer stimulus in different visual areas and will relate these findings to the size of the receptive fields in these visual areas. This study will show the relation between attended stimulus size and receptive field size. The study in chapter 5 will present results that show direct evidence for biased competition in human visual cortex. We use frequency tagging of individual stimuli in order to identify the corresponding responses. Two stimuli are presented in the same hemifield and these stimuli assumingly fall into the same receptive field. The response to an individual stimulus when attention is directed away is compared to conditions in which attention is directed to a target stimulus and when attention is directed to the competing stimulus. With this design we can directly assess the influence of attention on the competing stimuli. 


\section{4| Methodology}

The aim in cognitive neuroscience is to unravel the workings of the human brain. In order to do so, we need to investigate brain activity at such a spatial scale that response patterns of different cortical areas or neuronal groups can be separated and identified. At the same time, we would like to observe the timing of the response patterns on a millisecond timescale. The studies in this thesis make use of different methods each having specific strengths related to spatial location and timing of brain activity. The psychophysical study in chapter 3 draws conclusions about the mechanism of the visual system by observing a change in behavior in response to certain stimuli. The brain imaging methods used in chapters 2, 4, and 5, i.e. magnetoencephalography (MEG) and functional Magnetic Resonance Imaging (fMRI), go one step further and investigate how brain activity is modulated by changes in behavior and/or tasks. They provide an astonishing non-invasive insight into the human brain. fMRI and MEG have fundamentally different characteristics and measure different aspects of brain activity. These differences are most prominent in the signal that each method acquires and in the temporal resolution and the kind of spatial information each provides. Both methods will be introduced in the next sections.

\section{Magnetoencephalography}

MEG is a real-time functional imaging technique which measures magnetic fields arising from neurons in the brain (see figure 6). When a neuron receives input an intracellular current runs in the dendrites of the cell. These currents induce a magnetic field, also called magnetic flux, perpendicular to the direction of the current and can be described by the right hand rule. If the thumb of the right hand represents the direction of the current, the curled fingers represent the direction of the magnetic field. The main component of the currents measured with MEG is generated by synaptic ionic currents in the dendrites of mostly pyramidal cells (Hämäläinen, 1993; Nunez, 2000). These pyramidal cells are oriented in parallel and the corresponding induced magnetic field is therefore summated. The axonal currents are not directly reflected in the flux because their orientation is distributed randomly with respect to each other and the induced magnetic fields cancel each other out. Dendrites of pyramidal cells are oriented perpendicular to the brain's surface and it is therefore that their currents are mostly picked up by the coils located on the outside of the head. When the magnetic field in turn passes through a receiver coil on the outside of the head, it induces an electrical current according to the same physical law. The magnetic fields, in contrast to electrical currents, pass through tissues of the body with less distortion. When sufficient magnetometers are 


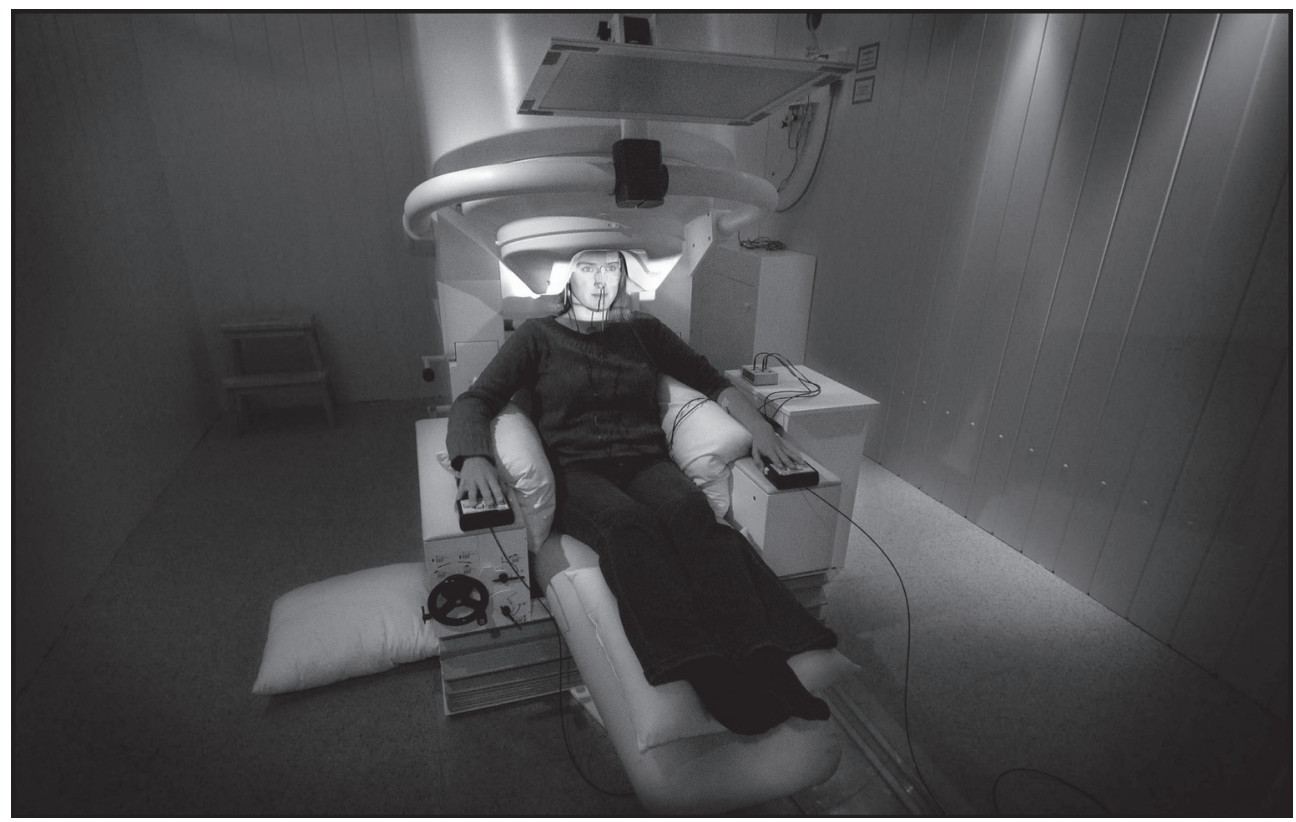

Figure 6. Magnetoencephalography. A picture of the MEG device situated within a magnetically shielded room

(Omega 2000, CTF Systems, Inc., Vancouver, Canada).

Photo by Raymond Rutting. Printed with permission. 
placed on the head surface, the shape of the surface magnetic flux distribution created by activated sources in the brain can be determined. The density of the magnetic flux, i.e. the strength of the field, is proportional to the strength of the current and decreases with distance from its source location.

The magnetic fields that emerge from the source currents are extremely small, about a million times weaker than the earth's magnetic field. To be able to record this "sound of a falling needle while standing on the moon", it is necessary to shield out all other possible sources of electromagnetic energy. In order for the magnetic flux to induce a current in a coil, super conducting sensors are used. They have an extremely low resistance, so that the tiniest magnetic fields can induce a current. To produce the superconductivity, the wiring of the MEG is cooled to about 4 degrees Kelvin by being immersed in a thermally insulated dewar filled with liquid helium. The weak magnetic field induces an extremely weak current in the coils and Superconductive Quantum Interference Devices or SQUIDs are used to detect this current. The dewar is placed in an electromagnetic shielded room so that signals from interfering magnetic sources are decreased. MEG is a direct measure of neuronal activity with a fine temporal resolution, which can track neural activation on a millisecond time scale. The direct analyses of the signals from each gradiometer can be very informative. However, since magnetic signals are minimally distorted by bodily tissues, MEG is also very suitable for localizing the sources of the activity and doing the analysis on the estimated signal of these sources, i.e. source-level analysis.

\section{MEG source analysis}

The mathematical analyses of the spatial distribution of the neuromagnetic field on the MEG sensors can offer accurate spatial localization of the neuronal sources generating these signals. The source of the measured signal can be modeled by a single source entity termed an equivalent current dipole. An equivalent current dipole represents the coherent intra- and extracellular current flow of a large number of pyramidal cells, which possibly extend over a few square centimeters of gray matter. A dipole is described by several parameters, i.e. location, orientation, and strength. When these parameters of a source in the brain are known, we can calculate the magnetic spatial distribution on the head surface. The solution to this forward problem is unique. Going back and calculating the source parameters given the magnetic field distribution on the head surface is called the inverse problem. From the magnetic distribution recorded on the head surface we have to infer the location in $\mathrm{x}, \mathrm{y}, \mathrm{z}$ coordinates, the orientation, and the strength of the dipole. The inverse problem does not have a unique solution. Slightly different values of the parameters or different arrangements of multiple dipoles can lead to the same shape of the distribution measured on the head. The validity of the solution computed 


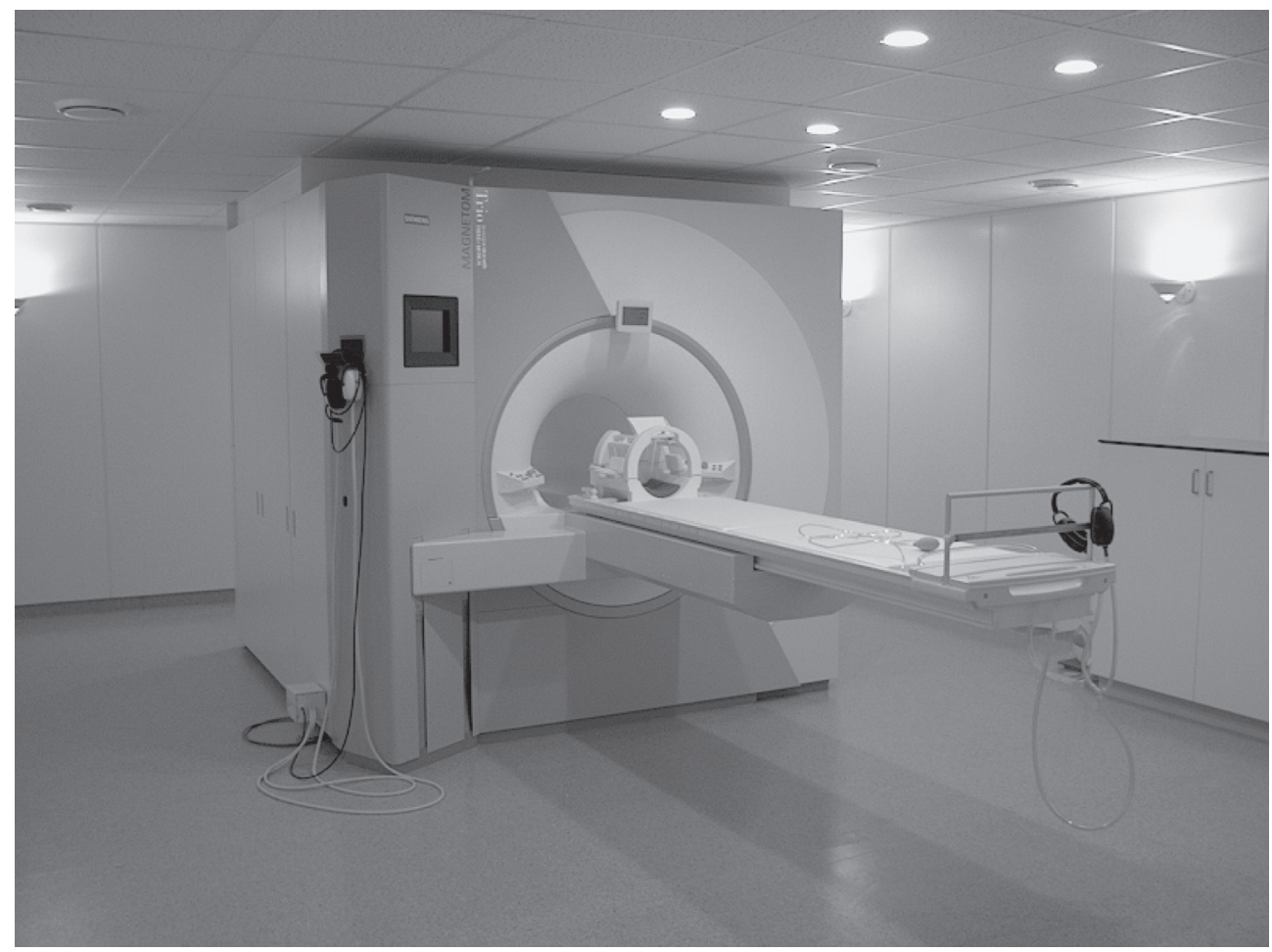

Figure 7. fMRI. The 3T whole body scanner from Siemens. 
is therefore ambiguous. However, some solutions are more sensible than others. Constraints from anatomy, physiology and other studies, for example fMRI, limit the number of possible source locations.

There are different methods for doing source modeling. The most common is to model a single dipole or multiple spatial-temporal dipoles at a specific location in the brain. This method models the generators of MEG signals by equivalent current dipoles and the resulting forward solution is compared to the actual spatial distribution (Scherg, 1990). Another method for source analyses is the beamforming technique, which uses an adaptive spatial filter to estimate the location of sources (for more detailed information on this beamforming method see the methods section of chapter 5). This filter has the property that it optimally passes activity from the location of interest, while activity from other locations is suppressed.

\section{Functional Magnetic Resonance Imaging}

Functional MRI (fMRI) is currently the major method for imaging the functioning human brain. It maps the neuro-anatomical localizations of dynamic brain changes during sensory, motor, or cognitive activities (Matthews, 2001). Functional MRI is a special case of Magnetic Resonance Imaging (MRI); a method which makes it possible to image the structure of the living brain. During MRI a subject is placed in the bore of a magnet which generates a strong static uniform magnetic field (see figure 7). The strength of the field of a 3 Tesla scanner (as used in chapter 4) is 60,000 times the strength of the earth's magnetic field (Bandettini et al., 2000) and 1,000,000,000,000,000 times the strength of the magnetic signals we try to pick up with MEG (Orrisson et.al, 1995). The nuclei of certain atoms possess the property of nuclear spin. When these nuclei are placed in a uniform magnetic field their behavior can be described as if they were tiny bar magnets (Orrisson et al., 1995). The atom that is most important for MRI is the hydrogen atom. This atom is found in $\mathrm{H} 2 \mathrm{O}$, or water, which is abundant in the human body. Thus, the protons in hydrogen are very abundant in biological tissue; i.e. the brain, and in addition, give a large Magnetic Resonance (MR) signal.

The energy state of the protons in the magnetic field can be changed by applying a radiofrequency (RF) pulse at the resonance or Larmor frequency. When this pulse is applied protons are excited and flip to a higher energy state. When the pulse is switched off, the protons relax to their low energy states by releasing $\mathrm{RF}$ energy. This constitutes the MR signal. The relaxation process of protons is characterized by a time constant, which is different for different tissues. In this way different tissues can be distinguished as for example the grey and white matter of the brain The MR signal is picked up by a receiver coil surrounding the head. 
To determine the exact location of the measured signal and to create an image of the brain, the location of each volume unit (voxel) is encoded during scanning using three functions: slice selective excitation, frequency encoding, and phase encoding. The resonance frequency of each voxel is changed by applying temporary magnetic gradients in the magnetic field in three directions. The frequency and phase information can be converted into a spatially informative image by inverse Fourier transformation. The sequence of gradients and RF pulses is the pulse sequence.

Functional MRI is designed to measure functional activity in the brain and can acquire whole-brain scans in a few seconds. The sequence mostly used in functional brain imaging is the echo planar imaging (EPI) sequence. Even though the acquisition using EPI is relative fast, the temporal resolution of fMRI stays fundamentally low. The MR signal measured by fMRI originates from the concentration of deoxygenated hemoglobin in the blood. This signal is called the Blood-Oxygenation-Level-Dependent response, or BOLD response. Deoxygenated hemoglobin differs from oxygenated hemoglobin in magnetic susceptibility. Lower ratios of paramagnetic deoxygenated hemoglobin decreases the measured BOLD signal. The BOLD response reflects a hemodynamic change in response to neural activation (Ogawa et al., 1992). One of the underlying assumptions of the BOLD response is that an increase in neuronal activity induces an increase in the metabolism of the corresponding cells. In turn, this triggers an increase in blood flow in the surrounding tissue bringing more oxygenated hemoglobin into that area, lasting for several seconds. This changes the ratio of deoxygenated and oxygenated hemoglobin and thus changes the intensity of the MR signal. When comparing the signal in a condition in which the subject has to perform, with a resting state condition, the increase neuronal activity causes increase in oxygenated hemoglobin close to the activated neuronal groups and thus an increase in signal intensity compared to the resting state.

The resolution of fMRI is determined by the characteristics of the vascular physiology. In addition to technical limitations, the spatial resolution of fMRI is determined by the spatial selectivity of the network of vessels, veins, and capillaries in response to an increase in neural activation. The temporal resolution is limited by the time it takes for the ratio of deoxygenated and oxygenated hemoglobin to change in the blood around that location. Although recently there has been provided evidence for the direct coupling of neuronal activation and the BOLD response (Logothetis et al., 2001), fMRI is an indirect measure of neuronal activity. 
Introduction | 0.1 
This chapter is based on:

Sandra I. van Aalderen-Smeets, Robert Oostenveld, and Jens Schwarzbach (2006).

Investigating neurophysiological correlates of metacontrast masking with magnetoencephalography, Advances in Cognitive Psychology, 2,1, 21-35. 


\section{Chapter 0.2}

\section{Investigating neurophysiological correlates of metacontrast masking with magnetoencephalography}

Backward masking refers to the phenomenon in which the visibility of a visual target stimulus is reduced by the presentation of a second stimulus, the mask, presented later in time. Metacontrast masking is a type of backward masking in which the inner contours of a mask stimulus do not spatially overlap with those of a preceding target stimulus (Breitmeyer and Ogmen, 2000). For certain durations of the stimuli, metacontrast backward masking results in a non-monotonic Ushaped dependence of target visibility on Stimulus Onset Asynchrony (SOA) between target and mask (Breitmeyer, 1984). Neurophysiological correlates related to the processing of masking stimuli can shed light on how processing of the target and mask stimulus evolves over time in the brain. They provide information about the latencies at which the processing of the target is disrupted or 
modulated. Previous studies have searched for physiological markers of masking using electroencephalography (EEG). This technique allows one to pinpoint the latency at which the target related brain activity is modulated by brain responses triggered by the mask. The motivation for the present experiment is based on an EEG study by Jeffreys and Musselwhite (1986) and the reanalysis of their data by Bridgeman (1988). Jeffreys and Musselwhite investigated whether the analysis of the target stimulus is suppressed at a pre-cortical or early cortical level, as the dual channel approach predicts (Jeffreys \& Musselwhite, 1986). They tested whether metacontrast related inhibition or suppression is reflected in early visual evoked potentials (VEPs), namely the $\mathrm{C} 1$ and $\mathrm{C} 2$ component. Scalp distributions of $\mathrm{C} 1$ and C2 reflect the respective sites of origin in the striate and extrastriate visual cortex (Jeffreys, 1971; Jeffreys \& Axford, 1972). They found no effect of metacontrast masking in the $\mathrm{C}_{1}$ or $\mathrm{C}_{2}$ amplitude when using either a single target flanked by four masks or multiple targets flanked by multiple masks spanning half of the visual field. However, both stimulus arrays did yield a clear U-shaped masking function in a separate psychophysical study. These results support an earlier EEG study of Schiller and Chorover (1966), which also did not find a modulation of early VEP components by metacontrast masking. The findings of Jeffreys and Musselwhite seem to rule out the early modulation of target related activity by the mask stimulus, but the authors did not address how their data might relate to alternative accounts of visual masking, for example, the influence of recurrent processes on later components of VEPs.

Bridgeman (1988) reanalyzed Jeffreys and Musselwhite's (1986) data to look for a modulation of the VEP at a later timepoint (250 ms) after stimulus onset. A modulation around this latency has been found in single neuron activity in cat and monkey striate cortex (Bridgeman, 1975, 1980). Bridgeman measured the VEP amplitude at this latency for all SOAs and showed a U-shaped modulation of the amplitude corresponding to the behavioral U-shaped masking function. He interpreted these modulations as reflecting visual masking due to recurrent processing.

We doubt that Bridgeman's conclusion is justified because mere temporal interactions between target and mask could produce such a U-shape without being related to visibility. The time it takes to process a stimulus is longer than the actual stimulus duration. When two stimuli are presented in close succession, the processing of these stimuli in visual cortex will overlap in time and will not necessarily sum up in a linear fashion. Hence, the VEP following two stimuli that are presented in rapid succession reflects the processing of both stimuli. If the time between the two stimuli varies, it will result in different VEP waveforms. In addition, the brain activity that is measured using EEG on the outside of the head reflects a summation of the signals from different brain areas. Bridgeman (1988) 
used only a single electrode, and, therefore, it is not possible to deduce how the different signals from different stimuli and different brain areas contributed to this VEP.

We therefore introduce a critical control for this temporal overlap in the present experiment. In addition to a standard masking procedure, we also present the target followed by a pseudomask at each SOA. This pseudomask is as similar to the mask as possible but is designed in a way that it does not lead to the behavioral effect of masking. For each SOA, we can compare trials of similar temporal characteristics (target, SOA, and mask) but with different behavioral masking effects, that is, masking versus nonmasking. If the U-shaped modulation that Bridgeman observed in the VEP amplitude is related to visibility, then the masking condition, which leads to U-shaped behavioral data, should also yield a U-shaped modulation of the VEP, while the pseudomask condition should yield flat (high) performance and produce no comparable change in VEP amplitude. In addition, the control condition can be used to determine whether an SOA interaction reflects perceptual or non perceptual processes. More specifically, we use the activity differences associated with the different physical masks to verify that a particular brain activity pattern has a perceptual origin. If we find a main effect of mask type, we can conclude that the corresponding activity reflects a perceptual process. If we do not find such significant main effects of masking on the brain responses, we must conclude that these brain activities are unspecific with respect to the visual appearance of the stimulus, and that they reflect processes at a post-perceptual level.

We used whole-head magnetoenchephalography (MEG) to measure the visual evoked fields (VEF) induced by the stimuli. The main benefits of MEG over EEG are that it is more sensitive to superficial sources in the brain and that MEG data contain less noise. In addition, MEG has a larger number of sensors and the signals are less spatially distorted by the skull. Otherwise, MEG and EEG are expected to produce very similar results. This is particularly true for the VEFs that occur at the same latencies as the corresponding ERPs. 
a.

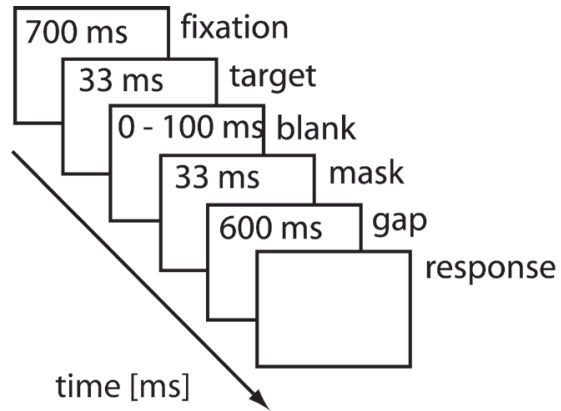

b.
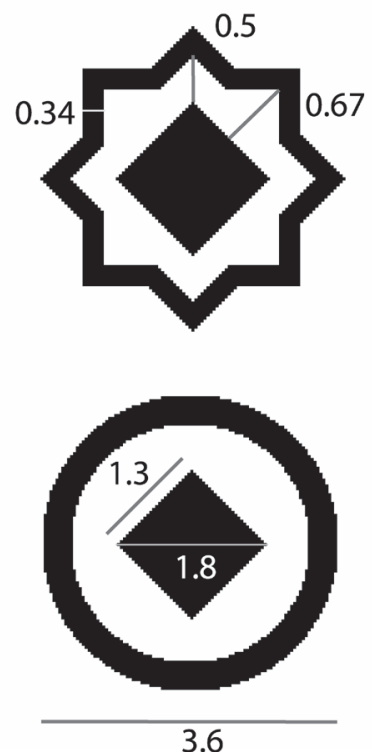

Figure 1. Stimulus Paradigm.

a. Schematic diagram of an example stimulus sequence. $b$.

Size of the target and mask stimulus in degrees. 


\subsection{Subjects and methods}

\section{Subjects}

Sixteen subjects (ages 19-38, mean 27 years, 11 women) took part in a behavioral practice session of 30 minutes (see Stimuli and Task section). Out of these subjects, 14 showed a U-shaped masking function in the masking condition and no masking in the pseudomask condition (more than $80 \%$ correct). These 14 subjects participated in a subsequent MEG experiment. All subjects were right handed and had normal or corrected to normal vision. The MEG protocol was approved by the local ethics committee and all subjects gave written informed consent according to the Declaration of Helsinki.

\section{Stimuli and Task}

The stimulus set consisted of two target stimuli and two mask stimuli. The target stimulus was either a diamond or a square figure, size $1.3^{\circ}-1.8^{\circ}$, presented in the lower right quadrant of the visual field at an eccentricity of $6^{\circ}$ from a small fixation cross at the centre of the screen. All stimuli were black, had equal illuminance (4 Lux), and were projected on a light grey background (409 Lux). The two conditions in the experiment were defined by the type of mask used. The mask in the masking condition consisted of an overlapping diamond and square, size $3.6^{\circ}$, which formed a star shaped figure with a similar star shaped figure cut out of the middle (Figure 1b). The size of the mask was such that the inner contour of the mask was separated by $0.5-0.67^{\circ}$ from the outer contour of the target stimuli. The mask in the pseudomask condition was a ring shaped figure with similar sizes of the inner and outer contours as the star shaped figure. Because the contours of this mask do not share similar features with those of the target stimulus, the target should be less masked (Alpern, 1953; Breitmeyer, 1984).

Trials started with the presentation of a fixation cross, which stayed on the screen during the whole trial. After $700 \mathrm{~ms}$, a sequence of target and mask stimuli was presented on the screen (Figure 1a). Both target and mask stimuli were presented for $33 \mathrm{~ms}$ with different SOAs $(0,33,50,66,83,133 \mathrm{~ms})$ between target and mask onset. At an SOA of o ms, the target and the mask were presented simultaneously. At longer SOAs the mask followed the target. Subjects had to indicate which of the two targets, diamond or square, they had seen by pressing a button with their left or right index finger, respectively. The response had to be made within a time window of two seconds, starting $600 \mathrm{~ms}$ after offset of the mask stimulus. This $600 \mathrm{~ms}$ delay prevents contamination of the VEFs with activity from motor execution as well as an overestimation of target visibility (Lachter, Durgin, 


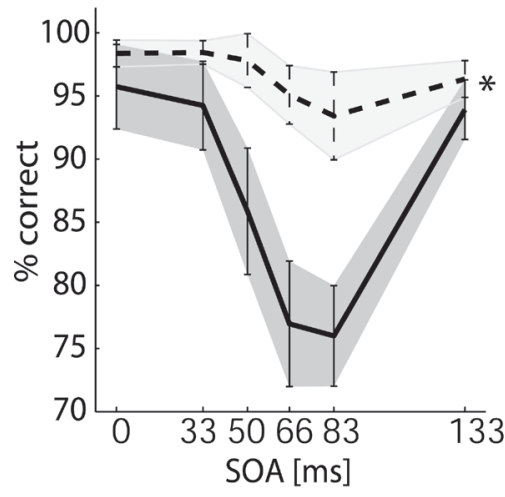

masking

- - - - pseudomask

I masking confidence interval

T pseudomask confidence interval

* target alone

Figure 2. Behavioral data.

Percent correct scores in the masking condition (solid line) and the pseudomask condition (dashed line) averaged over all subjects. The error bars as well as the shaded area in the background depict the $95 \%$ confidence interval. There is a significant interaction between mask type and SOA, which is reflected in the U-shaped function in the masking condition and a flat function in the pseudomask condition. 
\& Washington, 2000). If subjects responded within these $600 \mathrm{~ms}$, a visual warning signal appeared and the trial was discarded from further analysis. After a response, the screen turned blank until the next trial started. Inter-trial intervals varied randomly with a range between 1,000 and $2,000 \mathrm{~ms}$ and a mean of $1,500 \mathrm{~ms}$.

A total of 28 conditions [6 SOAs x 2 target types x 2 mask types, target presented alone (2 target types), mask presented alone (2 mask types)] were randomly presented with 40 repetitions each, resulting in 1,120 trials. The experiment was run in 8 blocks of 140 trials, each with a duration of about 8.5 minutes, depending on the subjects' response times. Subjects were free in deciding when to continue with the next block of trials.

\section{Recording Procedure}

Visually evoked fields were recorded in a magnetically shielded room using a whole-head MEG system (Omega 2000, CTF Systems, Inc., Vancouver, Canada) with 151 axial gradiometers. The data were sampled at $600 \mathrm{~Hz}$ with a lowpass filter of $200 \mathrm{~Hz}$. Subjects were seated comfortably with their head located within the helmet of the MEG system and were instructed to move as little as possible during the whole experiment. The distance of the eyes to the screen was $68 \mathrm{~cm}$. Lights were turned off during the measurement. To measure eye movements and blinks, bipolar electrode pairs were placed lateral to the outer side of the left and the right canthus and above and below the right eye. Impedance of all electrodes was below 10 $\mathrm{kOhms}$. Prior to and after the MEG measurement the subject's head position relative to the gradiometer array was measured using coils positioned on the subject's nasion and at the bilateral external auditory meatus.

\section{Analysis}

\section{Behavioral data}

Behavioral responses were recorded during the MEG measurement. Trials in which subjects responded too early were discarded (1.3\% on average, range $0.3 \%-5.3 \%)$. The percentage correct of the responses was calculated for each SOA in both the masking and pseudomask condition, pooled over square and diamond target trials. A two-factorial repeated measures ANOVA was performed on the behavioral data of all subjects with the variables mask type and SOA.

\section{MEG data}

During preprocessing, all trials in which subjects responded too early were excluded. The EOG was visually inspected and trials containing blinks or eye 
a.

occipital cluster masking condition


b.

\section{occipital cluster pseudomask condition}

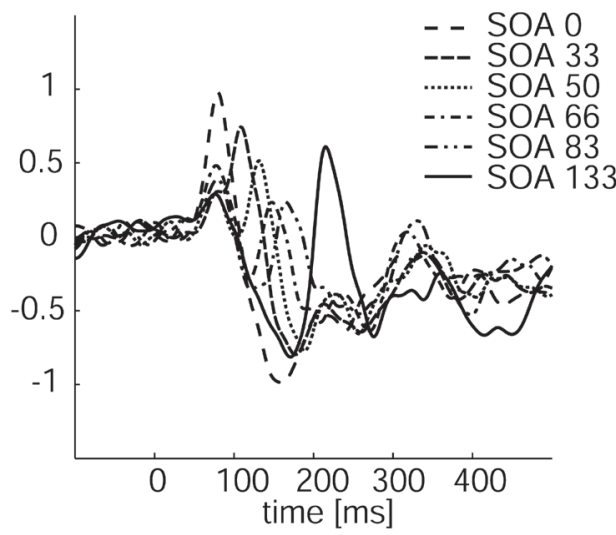

d.

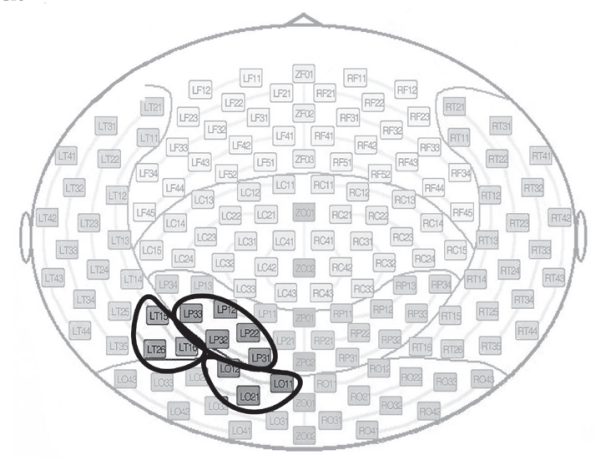

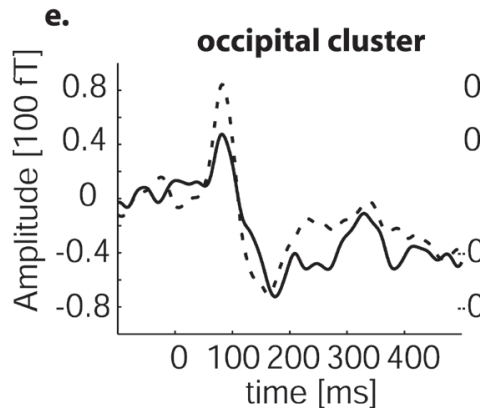



parietal cluster

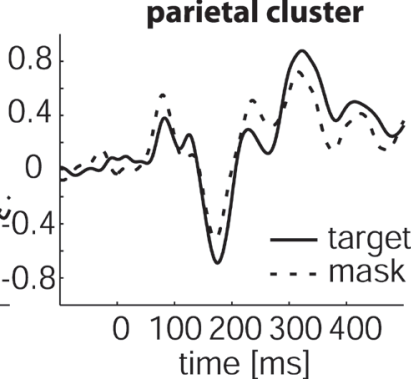

Figure 3. VEF of target locked averages.

Target locked VEFs. a. VEFs in the masking condition for each SOA of the channel cluster overlying occipital cortex. There is a clear VEF to the target as well as a VEF to the mask. The latency of the mask related peak shifts with the onset shift of the mask at different SOAs. b. VEFs in the pseudomask condition of the same cluster. These VEFs show the same pattern as the masking condition c. Difference waves for each SOA between masking condition and pseudomask condition of the same cluster. The shaded areas in the background are the $95 \%$ confidence intervals averaged over the whole epoch (no multiple comparison correction has been performed). There is no clear difference between 
Table 1.

Significance levels of effects in time intervals and clusters.

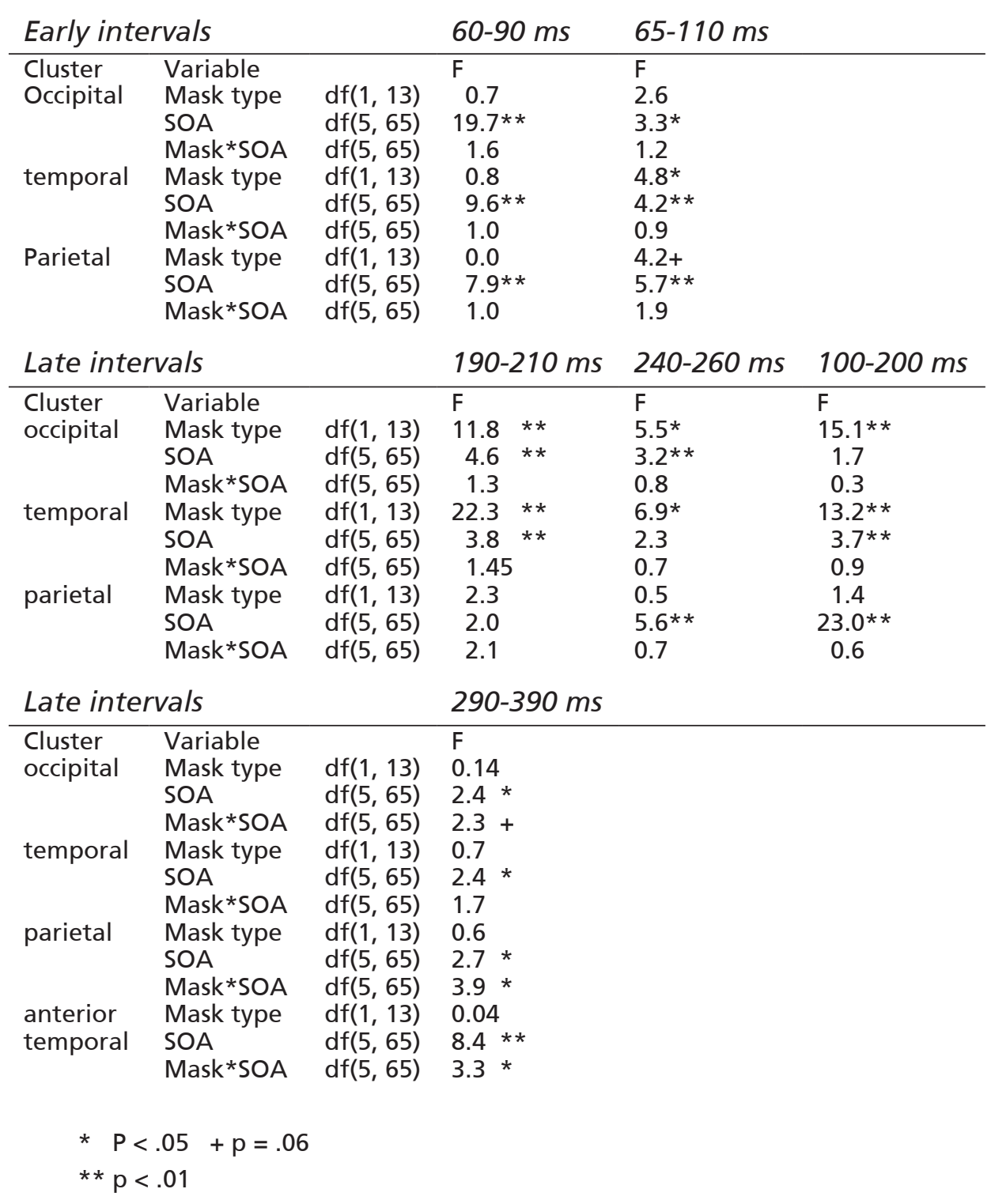

the masking and pseudomask condition which could be related to target visibility. There seems to be a small difference that shifts with SOA (thus being mask locked) between 100 and $200 \mathrm{~ms}$ after mask onset (100-333 ms after target onset). This difference is reflected in the significant effect of mask type in the $100-200 \mathrm{~ms}$ interval of the mask locked averages, see table 1. d. Topographical layout of the 151 MEG sensors. The location of the occipital, the temporal, and the parietal cluster are highlighted. e. VEFs of the target alone conditions (solid line) and the mask alone conditions (dashed line) for all three clusters. 



e.

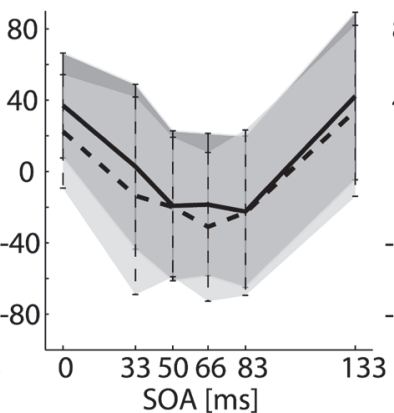

f.

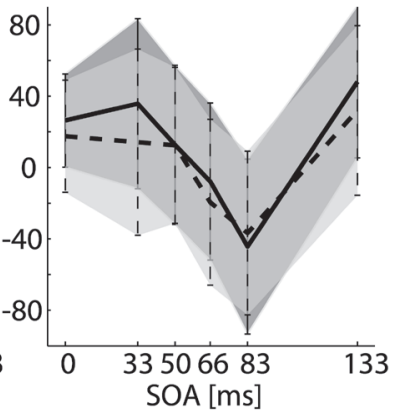

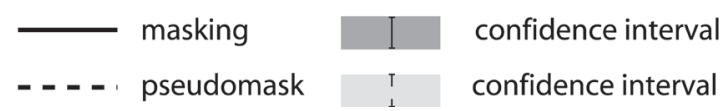

Figure 4. VEF amplitude in the early intervals for target and mask locked data.

Amplitude averaged over a time interval encompassing the early VEFs of the three clusters for both the masking condition (solid line) and the pseudomask condition (dashed line). a. Occipital cluster, target locked. b. Temporal cluster, target locked, c. Parietal cluster, target locked, d. Occipital cluster, mask locked, e. Temporal cluster, mask locked, f. Parietal cluster, mask locked.

None of the time intervals or clusters shows a significant interaction effect between mask type and SOA. 
movements were discarded. Trials containing muscle activity or jump artifacts due to MEG sensors were discarded using semi-automatic artifact detection routines. Between $3.9 \%$ and $6.8 \%$ of all trials were discarded on average per condition, and the percentage of trials discarded was evenly distributed over conditions. Data were filtered with a $40 \mathrm{~Hz}$ low-pass filter and baseline corrected using a $200 \mathrm{~ms}$ interval prior to the target onset.

For each channel, target locked averages were computed across trials containing square or diamond targets separately for masking and pseudomask conditions and SOAs. In addition, we computed mask locked averages, which provide the opportunity to look at components that are phase locked to the onset of the mask stimulus. Additionally, they allow for the contrast between the effect of the physical difference between the two masks and the effect of visibility. The effect of physical difference should result in a constant difference between VEF over SOAs, while the visibility effect is hypothesized to vary only corresponding to decreased visibility at certain SOAs.

To correct for subjects' head positions relative to the gradiometers, the target and mask locked averages were realigned using a spatial interpolation technique to a template gradiometer array that was constructed from the average position of the subjects relative to the helmet (Knösche, 2002). A grand average over subjects was computed for each SOA in the masking and pseudomask condition and for the target alone and mask alone conditions. To further increase the signal to noise ratio, we selected channels in three regions of interest contralateral to the stimulus, and averaged the VEFs within these channel groups. The channels in each region were selected according to the similarity of the VEFs, based on visual inspection. The channels showing opposite polarity to those channels included in the clusters showed opposite field VEFs. Due to the smaller amplitude of the VEFs in these channels compared to the channels in the clusters we did not include these in the analysis. Three channels located over the left occipital cortex formed the occipital cluster, three channels located over the left temporal cortex formed the temporal cluster and five channels overlying the left parietal cortex formed the parietal cluster (see Figure 3d).

For each respective SOA, the amplitude of the VEF in the masking condition was compared to the amplitude of the VEF in the pseudomask condition in both early and late intervals of the VEF. For the target locked averages, the first interval was a window selected around the first VEF component from 60 to $90 \mathrm{~ms}$. The latencies of later intervals were chosen according to intervals shown to reflect masking in earlier studies: The second interval was a window from 190 to $210 \mathrm{~ms}$ (Vaughan and Silverstein, 1968) and the third interval was taken from 240 to 260 ms (Bridgeman, 1988). These two late intervals, motivated by earlier EEG studies, fall within a period where mask related activation is present in some 

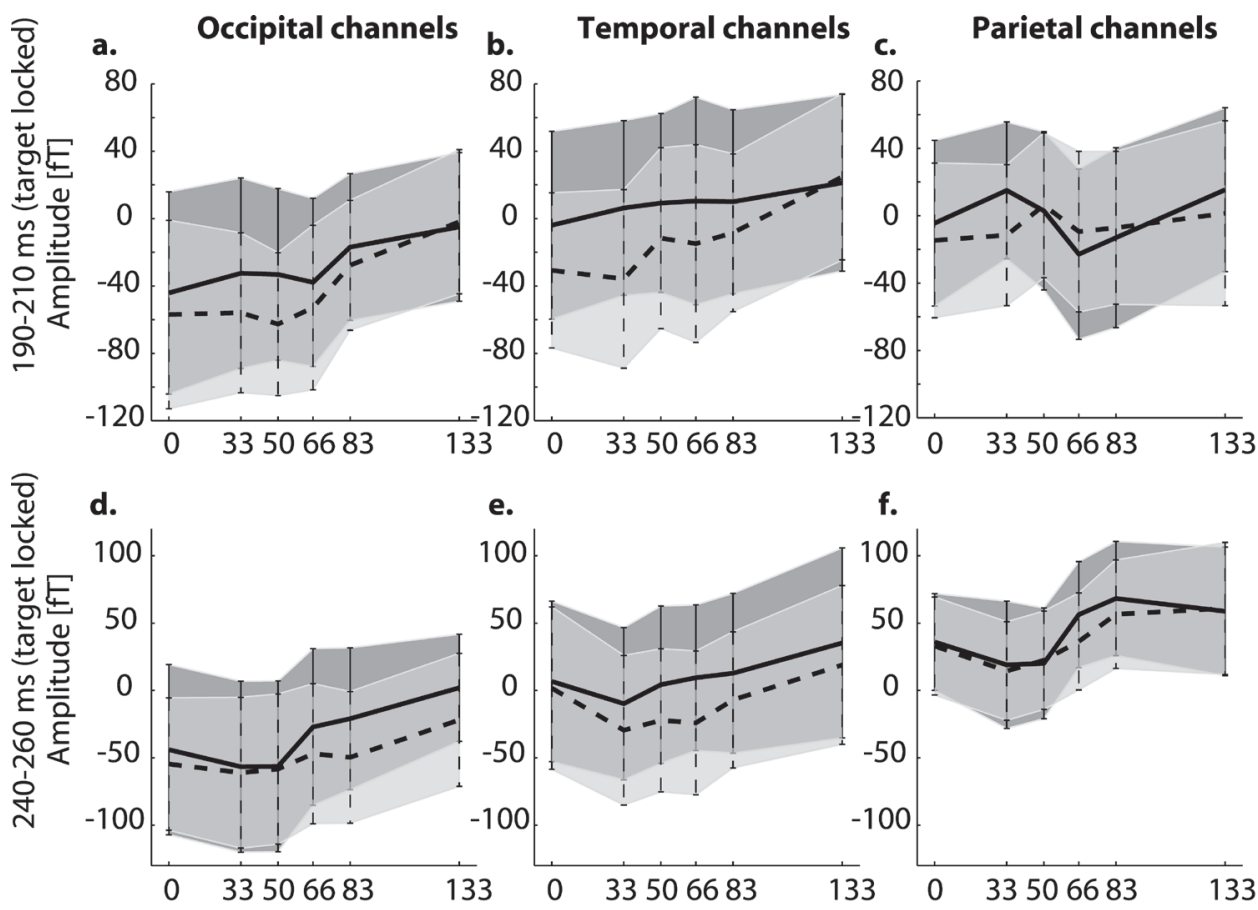

e.

f.
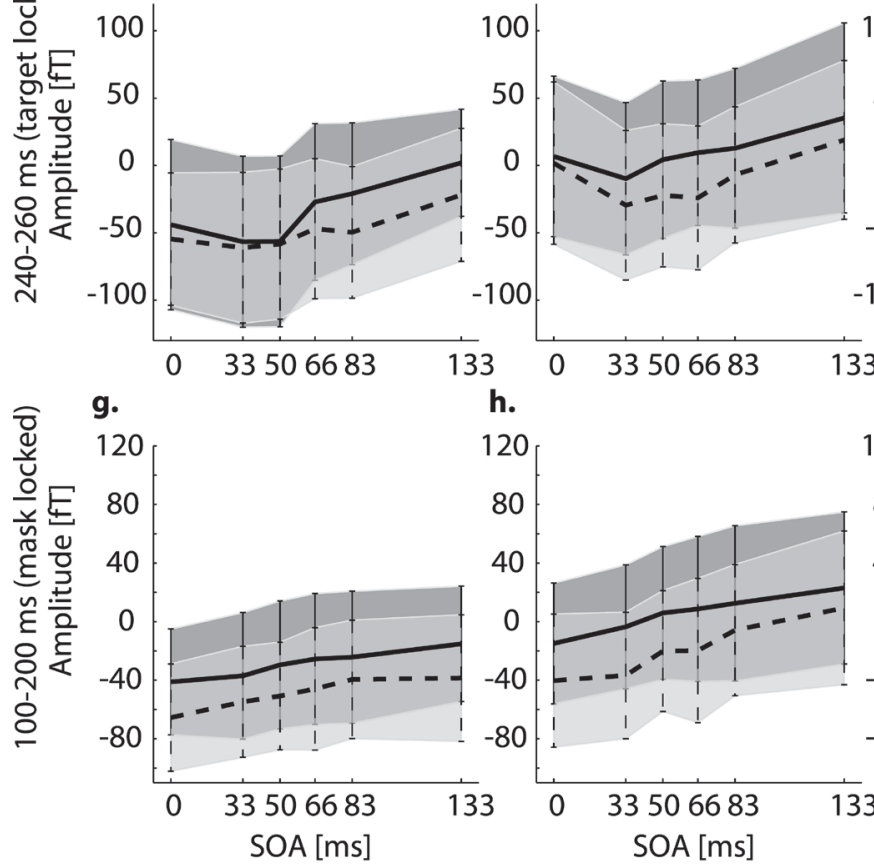

h.
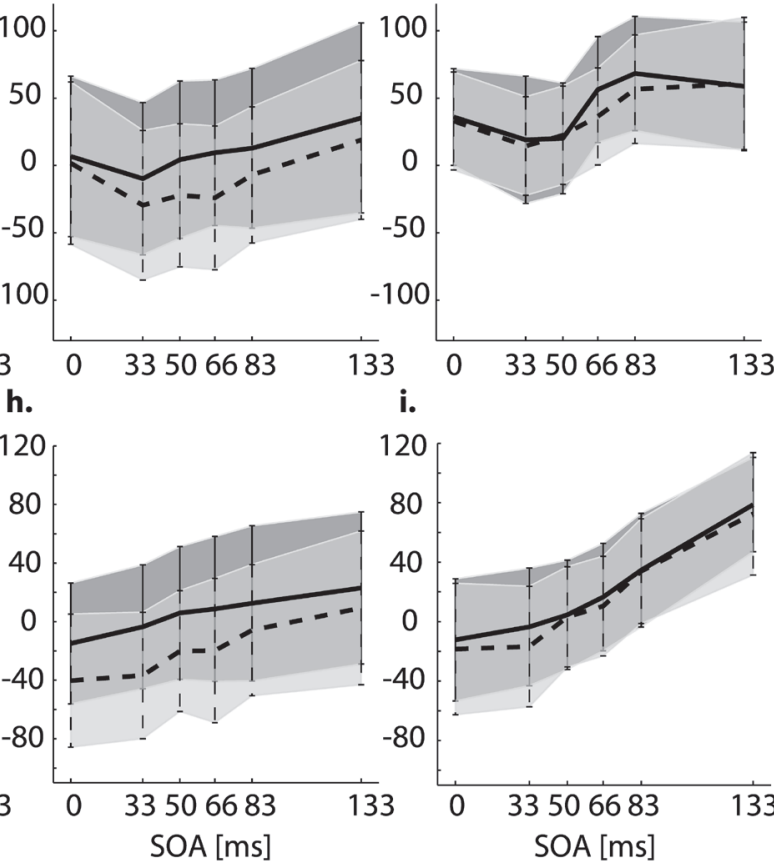

i.

- masking

confidence interval

- - - pseudomask

confidence interval

Figure 5. VEF amplitude in the 190 to $210 \mathrm{~ms}$ and 240 to $260 \mathrm{~ms}$ intervals for target and mask locked data.

Amplitude averaged over later time intervals of the three clusters for both the masking condition (solid line) and the pseudomask condition (dashed line). a./d. Occipital cluster, target locked. b./e. Temporal cluster, target locked, c./f. Parietal cluster, target locked, g. Occipital cluster, mask locked, h. Temporal cluster, mask locked, i. Parietal cluster, mask locked. None of the time intervals or clusters shows a significant interaction effect between mask type and SOA. 
conditions, but not in others. To circumvent this possible confound we choose a fourth late interval at a latency from 290 to $390 \mathrm{~ms}$, where mask related activity has decayed in all conditions, and hence would reflect higher cognitive, post perceptual processes. For the mask locked averages, the early interval was selected around the first peak component from 65 to $110 \mathrm{~ms}$. The late interval was a window from 100 to 200 ms containing the first downward peak in the VEF. A two-factorial repeated measure ANOVA with variables mask type and SOA was computed for evoked fields averaged over time within each time window and over clusters. If the amplitude is modulated differently across SOA for the masking and pseudomask conditions we expect an interaction effect between mask type and SOA. This would indicate that stimulus visibility is reflected in the VEF amplitude at that latency and cluster.

\subsection{Results}

\section{Behavioral data}

The masking condition produced stronger masking than the pseudomask condition, $\mathrm{F}(1,13)=154.3, \mathrm{p}<.01$. There is a clear U-shaped modulatory effect of SOA on visibility in the masking but not in the pseudomask condition, see Figure 2. This is reflected by a significant interaction effect between mask type and SOA, $\mathrm{F}(5,65)=26.3, \mathrm{p}<.01$.

\section{MEG data}

In visual evoked fields, we only found an interaction effect between mask type and SOA in the latest time window, $290-390 \mathrm{~ms}$, in the parietal cluster. For the other time windows, no interaction effect was found in any region of interest, despite the presence of clear visual evoked fields. Both target and mask evoke a clear response in channels overlying the occipital cortex, as can be seen in Figure $3 \mathrm{a}, 3 \mathrm{~b}$, and $3 \mathrm{e}$. The first peak, around $90 \mathrm{~ms}$, reflects target related activity (Figure $3 \mathrm{a}$ and $3 \mathrm{~b}$ ). The amplitude of the peak for SOA o is increased relative to the VEF at other SOAs due to the simultaneous presentation of target and mask. The second positive peak in all SOA bins reflects mask related activity. The peak amplitudes shift in latency, corresponding to the shift in onset of the mask at that particular SOA. Figure $3 \mathrm{c}$ shows the difference waves between the masking and pseudomask condition for each SOA and the $95 \%$ confidence interval of the difference averaged over the whole time epoch, which is plotted in the background. No correction has been performed for multiple comparisons over all latency bins. There seems to be 

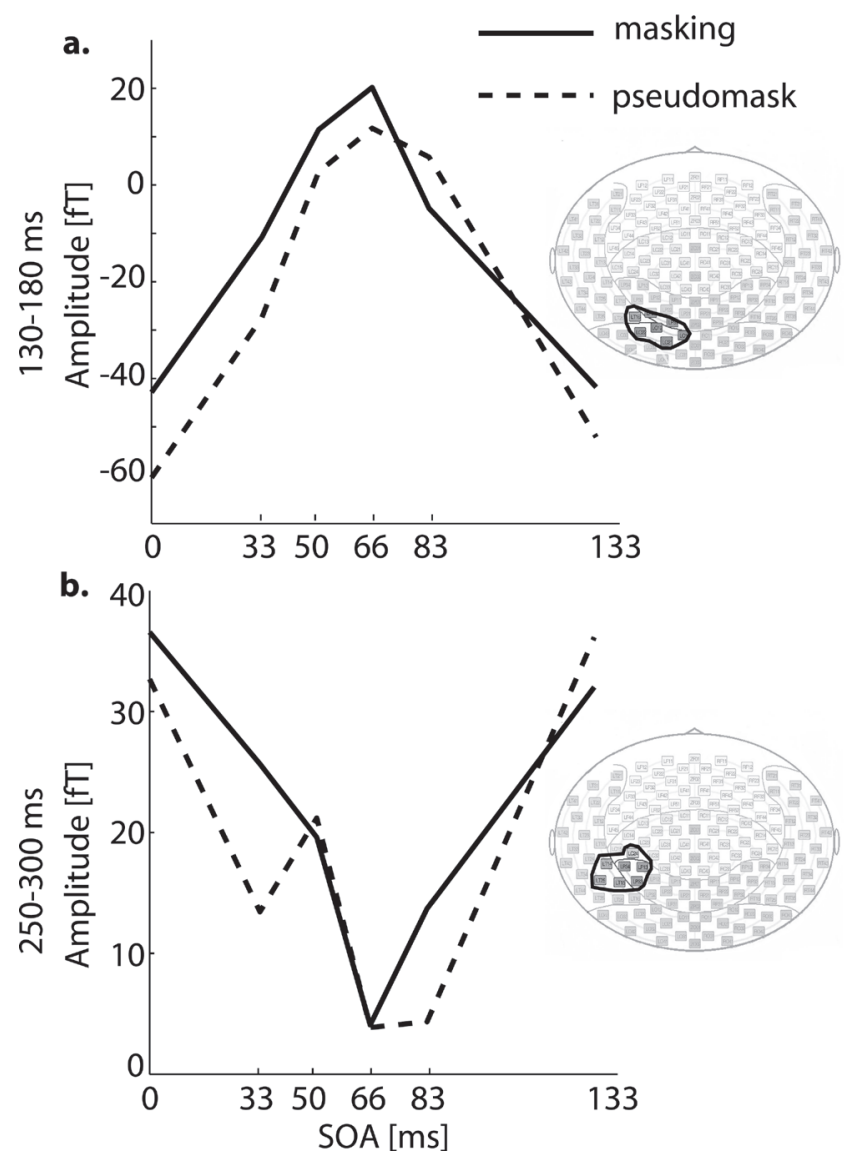

Figure 6. Correlation coefficients of the VEF amplitude in the 130 to $180 \mathrm{~ms}$ and 250 to $300 \mathrm{~ms}$ interval with the behavioral masking function.

Amplitude averaged over later time intervals of two

clusters for both the masking condition (solid line) and the pseudomask condition (blue line). a. 130-180 ms interval at a occipital cluster shown in the topographical plot to the right. b. 250-300 ms interval at a temporal cluster shown in the topographical plot to the right. Both the masking and the pseudomask condition show significant or nearly significant correlations with the behavioral masking function. 
a small difference between the masking and pseudomask condition that shifts with SOA between 100 and $200 \mathrm{~ms}$ after mask onset (100 - $333 \mathrm{~ms}$ after target onset). This effect shows up as a main effect of mask type in the mask locked $100-200 \mathrm{~ms}$ interval, see Table 1.

\section{Early intervals}

None of the early intervals $(60-90 \mathrm{~ms}$ and $65-110 \mathrm{~ms})$ show a modulation of VEF amplitude related to target visibility. This is reflected by the absence of interactions between mask type and SOA in the target locked components [occipital: $\mathrm{F}(5,65)=1.6, \mathrm{p}=0.2$, temporal: $\mathrm{F}(5,65)=1.0, \mathrm{p}=0.4$, parietal: $\mathrm{F}(5,65)=1.0, \mathrm{p}=0.4]$ and in the mask locked components for all clusters [occipital: $\mathrm{F}(5,65)=1.2, \mathrm{p}=0.3$, temporal: $\mathrm{F}(5,65)=0.9, \mathrm{p}=0.5$, parietal: $\mathrm{F}(5,65)=1.9, \mathrm{p}=0.1]$. The statistics are summarized in Table 1. Figure 4 shows VEF amplitudes averaged over a time window around the first visible peak for each SOA in both conditions.

The amplitudes of both the target and mask locked averages are modulated by SOA. Figures $4 \mathrm{a}$ to $4 \mathrm{c}$ show this main effect of SOA in the target locked data for all channel clusters [occipital: $\mathrm{F}(5,65)=19.7, \mathrm{p}<.01$, temporal: $\mathrm{F}(5,65)=9.6, \mathrm{p}<.01$, parietal: $\mathrm{F}(5,65)=7.9, \mathrm{p}<.01]$. This effect is due to the increased amplitude with the simultaneous presentation of target and mask at SOA o. Figures $4 \mathrm{~d}$ to $4 \mathrm{f}$ show the effect of SOA in the mask locked data [occipital: $\mathrm{F}(5,65)=3.3, \mathrm{p}=.01$, temporal: $\mathrm{F}(5,65)=4.2, \mathrm{p}<.01$, parietal: $\mathrm{F}(5,65)=5.7, \mathrm{p}<.01]$. The effect of mask type is only significant in the mask locked data for the channels overlying the temporal cortex $[\mathrm{F}(1,13)=4.8, \mathrm{p}=.05]$ and not in the target locked data, see Table 1.

\section{Later intervals}

The masking and pseudomask condition did not produce different modulations of VEF amplitude related to visibility during the $190-210 \mathrm{~ms}$ and the 240 $-260 \mathrm{~ms}$ interval in the target locked data, or during the $100-200 \mathrm{~ms}$ interval in the mask locked data. Figures 5 a to $5 \mathrm{c}$ show the averaged amplitudes over the target locked time window from $190-210 \mathrm{~ms}$ for all channel groups. There are no significant interaction effects in this interval [occipital: $\mathrm{F}(5,65)=1.3, \mathrm{p}=0.3$, temporal: $\mathrm{F}(5,65)=1.45, \mathrm{p}=0.2$, parietal: $\mathrm{F}(5,65)=2.1, \mathrm{p}=.08]$. However, for both the occipital and the temporal channels there is a main effect of both mask type and SOA [occipital: mask type: $\mathrm{F}(1,13)=11.8, \mathrm{p}<.01, \mathrm{SOA}: \mathrm{F}(5,65)=4.6$, $\mathrm{p}<$.01, temporal: mask type: $\mathrm{F}(1,13)=22.3, \mathrm{p}<.01$, SOA: $\mathrm{F}(5,65)=3.8, \mathrm{p}<.01$, parietal: mask type: $\mathrm{F}(1,13)=2.3, \mathrm{p}=0.2$, $\mathrm{SOA}: \mathrm{F}(5,65)=2.0, \mathrm{p}=.09]$. Figures $5 \mathrm{~d}$ to $5 \mathrm{f}$ show the averaged amplitudes over the target locked time window from 240 $-260 \mathrm{~ms}$. There is also no interaction effect in this interval for any of the clusters [occipital: $\mathrm{F}(5,65)=0.8, \mathrm{p}=0.5$, temporal: $\mathrm{F}(5,65)=0.7, \mathrm{p}=0.6$, parietal: 

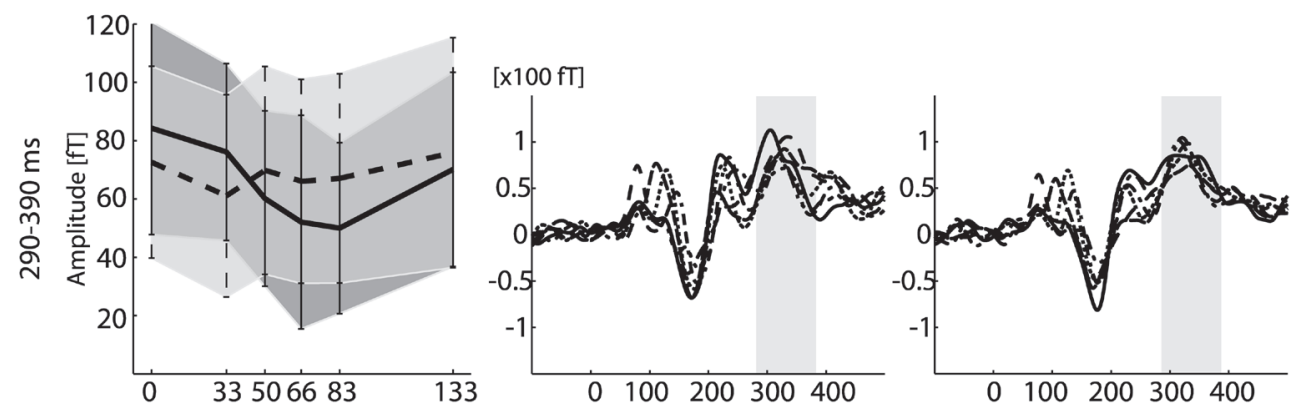

b Temporal cluster $B$

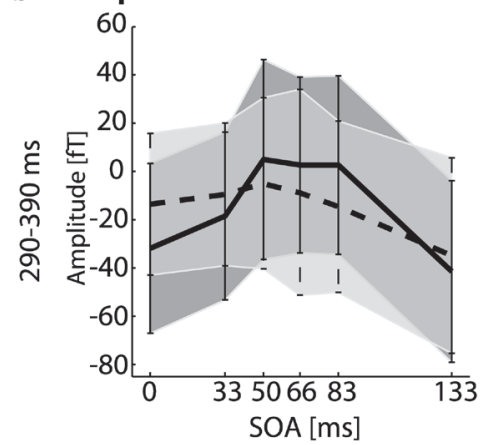

[x100 fT]
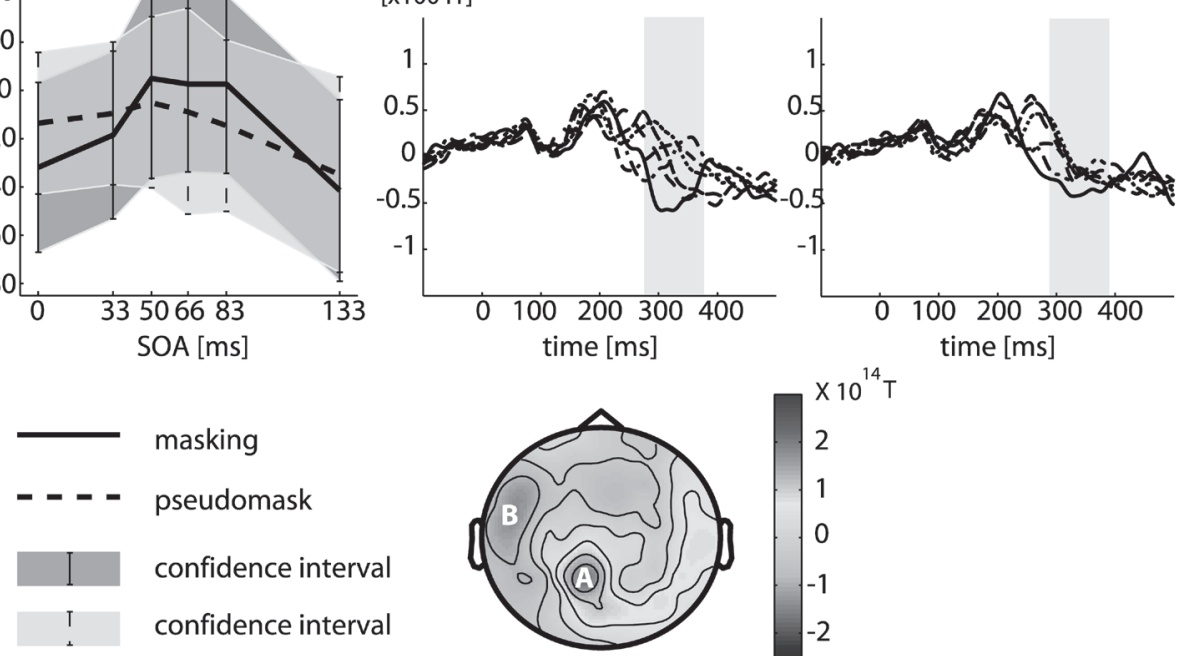

masking

pseudomask

confidence interval

confidence interval

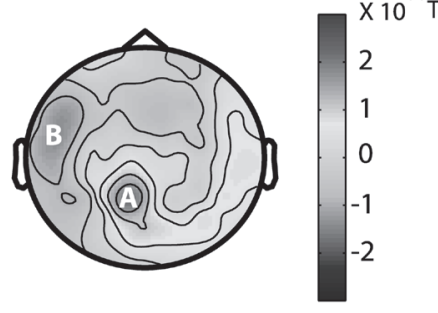

Figure 7. Interaction effect in the 290 to $390 \mathrm{~ms}$ interval for target locked data.

Amplitude averaged over a time interval from 290 to $390 \mathrm{~ms}$ for both the masking condition (solid line) and the pseudomask condition (dashed line). a. VEF amplitudes of cluster A (see figure $7 \mathrm{c}$ ) showing an interaction effect between SOA and mask type. The masking condition does correlate with the behavioral masking function while the pseudomask condition does not. This graph is flanked by the VEFs from the masking and pseudomask condition of the same cluster (for legend see figure 3a). The gray bar indicates the time interval. b. VEF amplitudes of cluster B showing an interaction effect between SOA and mask type. The masking condition does correlate with the behavioral masking function while the pseudomask condition does not. Also the corresponding VEFs of the masking and pseudomask condition of the same cluster are shown. The shape of the amplitude curve shows an opposite polarity pattern compared to the parietal cluster A. c. Topographical plot of the difference between the average of the SOA 50, 66, and 83 trials in the masking condition and the corresponding SOA trials in the pseudomask condition averaged over the 290 to $390 \mathrm{~ms}$ interval. 
$\mathrm{F}(5,65)=0.7, \mathrm{p}=0.6]$. There is a main effect of SOA in the occipital and parietal channels and a trend is seen in the temporal channels [occipital: $\mathrm{F}(5,65)=3.2$, $\mathrm{p}<.01$, temporal: $\mathrm{F}(5,65)=2.3, \mathrm{p}=.06$, parietal: $\mathrm{F}(5,65)=5.6, \mathrm{p}<.01]$. A main effect of mask type is shown in the occipital and temporal channels [occipital: $\mathrm{F}(1,13)=5.5, \mathrm{p}=.04$, temporal: $\mathrm{F}(1,13)=6.9, \mathrm{p}=.02$, parietal: $\mathrm{F}(1,13)=0.5$, $\mathrm{p}=0.5]$. Figures $5 \mathrm{~g}$ to $5 \mathrm{i}$ depict the averaged amplitude during the later time window of the mask locked averages. We also did not find significant interaction effects in this late interval of the mask locked average [occipital: $\mathrm{F}(5,65)=0.3$, $\mathrm{p}=0.9$, temporal: $\mathrm{F}(5,65)=0.9, \mathrm{p}=0.5$, parietal: $\mathrm{F}(5,65)=0.6, \mathrm{p}=0.7]$.

The occipital and temporal channels show an effect of mask type [occipital: $\mathrm{F}(1,13)=15.1, \mathrm{p}<.01$, temporal: $\mathrm{F}(1,13)=13.2$,

$\mathrm{p}<.01$, parietal: $\mathrm{F}(1,13)=1.4, \mathrm{p}=0.3]$. The temporal and parietal channels show an effect of SOA [occipital: $\mathrm{F}(5,65)=1.7, \mathrm{p}=0.1$, temporal: $\mathrm{F}(5,65)=3.7$, $\mathrm{p}<$.01, parietal: $\mathrm{F}(5,65)=23, \mathrm{p}<.01]$. This modulation is not even slightly Ushaped as in the target locked averages, but increases monotonically with SOA: the closer the target stimulus is to the mask in time, the more influence it has on the first downward component of the VEF.

Because the amplitudes of the VEF at each SOA in the $190-210 \mathrm{~ms}$ and 240 - $260 \mathrm{~ms}$ intervals do not show a very clear U-shape function, which we expected looking at Bridgeman's data (1988), we computed a Pearson correlation coefficient for broader time windows in the target locked data. Finding a significant correlation between the behavioral masking function and VEF amplitude of both the masking and pseudomask condition would show that a reported U-shape is not necessarily due to decreased visibility, but that it could be due to the temporal overlap between target and mask stimuli. We found significant correlations between the behavioral masking function and VEF amplitudes at different time intervals. During an interval between $130-180 \mathrm{~ms}$, in a cluster of channels overlapping with the left occipital cluster, the correlation coefficient is close to significance for the masking condition $[\mathrm{r}(6)=-0.76, \mathrm{p}=.079]$, and is significant for the pseudomask condition $[r(6)=-0.90, p=.015]$, see Figure 6 . For a later interval of $250-300 \mathrm{~ms}$ both the masking and pseudomask condition correlate significantly with the behavioral masking function in a cluster of channels overlapping with the temporal cluster, see figure $3 \mathrm{~d}$ [masking condition, $\mathrm{r}(6)=0.93, \mathrm{p}=.008$, pseudomask condition $\mathrm{r}(6)=0.82, \mathrm{p}=.045]$. However, during a later time window between 290 and $390 \mathrm{~ms}$, the masking and pseudomask condition yield different modulations of VEF amplitude in the parietal cluster. This is indicated by a significant interaction effect of SOA and mask type on VEF amplitude, see figure $7 \mathrm{a}[\mathrm{F}(5,65)=3.9, \mathrm{p}=.004]$. The occipital and the temporal cluster do not show this effect in this time interval [occipital: $\mathrm{F}(5,65)=2.3$,

$\mathrm{p}=.052$, temporal: $\mathrm{F}(5,65)=1.7, \mathrm{p}=0.14]$. In all three clusters we see a main 
effect of SOA [occipital: $\mathrm{F}(5,65)=2.4, \mathrm{p}=.05$, temporal: $\mathrm{F}(5,65)=2.4, \mathrm{p}=.048$, parietal: $\mathrm{F}(5,65)=2.7, \mathrm{p}=.03$ ], but not of mask type [occipital: $\mathrm{F}(1,13)=0.1$, $\mathrm{p}=0.7$, temporal: $\mathrm{F}(1,13)=0.7, \mathrm{p}=0.4$, parietal: $\mathrm{F}(1,13)=0.6, \mathrm{p}=0.4]$. The topographical distribution of the interaction effect in this time interval, calculated by subtracting the average of the SOA 50,66 , and 83 trials in the masking condition from the corresponding trials of the pseudomask condition, displays an additional cluster of three more anterior temporal channels, (Figure $7 \mathrm{c}$ ). The averaged VEFs over these channels in this time interval also show the interaction effect between mask type and $\operatorname{SOA}[\mathrm{F}(5,65)=3.3, \mathrm{p}=.01]$ and a main effect of SOA $[\mathrm{F}(5,65)=8.4, \mathrm{p}<.001]$, but no effect of mask type $[\mathrm{F}(1,13)=.04, \mathrm{p}=0.8]$. Figure $7 \mathrm{~b}$ shows that the polarity of the U-shaped effect is opposite in sign to the effect seen in the parietal cluster.

In addition to this significant interaction effect, we see a correlation between the behavioral masking function and the masking condition in this postperceptual interval, in both the parietal and the more anterior temporal cluster [parietal: $r(6)=0.96, p=.003$, anterior temporal: $r(6)=-0.84, p=.037]$. But, there is no correlation between the pseudomask condition and the behavioral masking data in the same clusters [parietal: $r(6)=0.308, p=0.55$, anterior temporal: $r(6)=-0.35$, $\mathrm{p}=0.5$ ], (figure 7).

\subsection{Discussion}

The aim of this study was to investigate whether modulations of early or late VEFs can be regarded as neurophysiological correlates of metacontrast masking. We compared behavioral data and evoked brain responses to masked and non masked target stimuli over a range of SOAs from o to $133 \mathrm{~ms}$. Visibility followed a U-shaped masking function in the masking condition, with the trough at 66 and $83 \mathrm{~ms}$, while staying above 90\% at all SOAs in the pseudomask condition. This was reflected in a significant interaction effect between the type of mask and SOA.

The analysis of the visual evoked fields focused on finding an interaction effect in early and late VEFs in both target and mask locked averages comparable to the effect seen in the behavioral data. This interaction effect, indicating a modulation of VEF amplitude over SOA in the masking condition, but not in the pseudomask condition, would reflect a neural correlate of stimulus visibility.

In the early timewindows we found that the evoked response to an initial stimulus is modulated by a second stimulus presented in close temporal succession, even though this modulation is unrelated to the visibility of the first stimulus. A differential response to the two mask stimuli was observed only in the mask locked averages of the cluster overlying temporal cortex. We interpret this as reflecting a 
difference in the processing of the physical properties of the two masks. Previous EEG studies also failed to find any modulation of early visual evoked components by visual masking (Bridgeman, 1988; Jeffreys \& Musselwhite, 1986; Schiller \& Chorover, 1966; Vaughan \& Silverstein, 1968). Given the present and previous results, it seems unlikely that the mechanism leading to the masking effect manifests itself in the first neural response to the stimulus.

Studies by Bridgeman (1988) and Vaughan \& Silverstein (1968) suggest that the modulatory effect of visibility should manifest itself in later timewindows. Therefore, we analyzed additional timewindows of 190 to $210 \mathrm{~ms}$ and 240 to 260 $\mathrm{ms}$ for the target locked averages, and a window between 100 and $200 \mathrm{~ms}$ for the mask locked averages. If backward masking leads to disruption of recurrent target activity, a modulation that reflects behavioral changes is expected at these latencies (Bridgeman, 1988; Vaughan \& Silverstein, 1968). In none of these intervals did we find an interaction effect reflecting the visibility of the target stimulus. However, we observed effects of SOA and mask type on several of the channel clusters, or intervals. In target locked averages on channels overlying occipital cortex, we found that SOA influences VEF amplitude, reflecting the different temporal overlap between the target and mask related activity at different SOAs. This effect of SOA on amplitude was obliterated by averaging data locked to the mask. Both the target and mask locked averages in these three intervals reflected differential perceptual processing of the two different mask stimuli shown by an effect of mask type. Thus, these late intervals on the occipital channels reflect the type of stimuli and their temporal organization, but show no modulation related to visibility. The same results also hold for the channels overlying part of temporal cortex. There is no effect of target visibility, but the data reflect the temporal overlap between target and mask processing and the differential response to the two masks. Also the channels overlying part of parietal cortex fail to show an effect of visibility. They show an effect of the temporal overlap of the stimuli in the 240-26o ms target locked interval and in the 100-200 ms mask locked interval, but do not show an effect of mask type.

In addition to these later intervals ( 190 to $210 \mathrm{~ms}$ and 240 to $260 \mathrm{~ms}$ ), a postperceptual time interval in the target locked averages was analyzed. Unlike in the two earlier intervals, the parietal cluster in the 290-390 ms interval shows an interaction effect between mask type and SOA. VEFs in the masking condition were deflected more strongly than those in the pseudomask condition. Further, only VEF amplitude in the masking condition showed a significant correlation with the behavioral data. This suggests that the VEF in this time interval reflects the visibility of the target stimulus. In addition, a main effect of SOA in all clusters was found. There was no effect of mask type, which indicates that the evoked response in this 290-390 ms interval is unaffected by differences in physical 
stimulation. Thus, this interval most likely reflects postperceptual processing. Bridgeman's (1988) observation of the effect of visibility is at a latency most likely to be perceptual in origin. Therefore, we can conclude that the effect we see is not comparable to Bridgeman's (1988) observations of the effect of visibility. The activities of both effects reflect different stages in visual processing. Furthermore, the absence of a main effect of mask type also shows that the behavioral performance is a genuine masking effect and not due to better target recovery in the pseudomask condition because of, for example, visible figural changes of the pseudomask that are produced by the target. If this were the case then one should also see an effect of mask type in this cluster.

An additional cluster of channels overlying the temporal cortex shows the interaction effect in opposite polarity. This bipolar pattern over temporal and parietal cortex suggests a source lying in the temporal-parietal cortex. However, source modeling of late components usually involves multiple sources. Our singlesubject data were not of sufficient quality to perform individual source analyses. In the grand averaged data, the interindividual differences between orientation and location of the individual sources cause a spatial blurring of the VEF topography, making it difficult to determine the appropriate number of sources required for the grand average, and thus leading to a potential mislocalization of the sources. Therefore we refrained from source analysis. This later component from 290 to $390 \mathrm{~ms}$, which could reflect target visibility, can be compared to the $\mathrm{P}_{300}$ component in ERP research. It is assumed that the $\mathrm{P}_{300}$ reflects a process related to attention and working memory (Kok, 2001; Vogel, Luck, \& Shapiro, 1998). Several attentional blink studies have shown that the P300 is suppressed or absent when a second target is not detected, compared to a present $\mathrm{P}_{300}$ when the second target is detected (Kranczioch, Debener, \& Engel, 2003; Rolke, 2001). It is concluded in these studies that the second target does reach the point of perceptual representation, but is not consolidated for subsequent report. This hypothesis can also be applied to the mechanism of metacontrast masking. We found a suppression of the amplitude of the VEF in those conditions showing the strongest masking, that is, SOA 50, 66, and 83 compared to those conditions in which the target was clearly visible. Assuming that this component is comparable to the $\mathrm{P}_{300}$, we argue that the masking of the target has taken place before the stimulus has formed a stable representation in working memory. There are several explanations for this failure to form a stable representation (Kranczioch et al., 2003). First, the information of the target is not successfully transferred into working memory. Second, the information is not selected by an attentional mechanism to enter working memory. Or third, it has failed to match with a template which is held in working memory.

This finding points to the conclusion that metacontrast masking is not due to 
a disruption of object identification, but rather occurs at a postperceptual phase when object related information is selected for, or enters, working memory. This account of metacontrast masking fits in with a broad range of priming studies in which a stimulus that is not consciously perceived nevertheless influences later behavior (Vorberg, Mattler, Heinecke, Schmidt, \& Schwarzbach, 2003). In contrast to the findings of Bridgeman (1988), the present data do not show a U-shaped modulation in the VEF amplitude at the $190-210 \mathrm{~ms}$ and $240-260 \mathrm{~ms}$ interval. However, when looking at broader time intervals we found significant correlations between the behavioral U-shaped masking function and the VEF amplitude over SOA in the masking condition of the MEG data. More interesting is the fact that this correlation is also present in the pseudomask condition. The VEF amplitude decreases at those SOAs where masking is strongest. This indicates that the overlap between target and mask related activity results in a U-shaped modulation of VEF amplitude that seems similar, but is unrelated to the visibility of the target stimulus. Even though the latencies at which we found these correlations are not directly comparable to the latency at which Bridgeman reports seeing a U-shape, we do want to question Bridgeman's interpretation that the U-shaped modulation he observed is a concomitant of metacontrast masking. The U-shaped modulation he observed could also be explained by the temporal overlap between the VEF of the target and the mask stimulus.

Our results do not seem to fit in with other earlier metacontrast masking studies using EEG. Vaughan and Silverstein (1968) compared the VEP of a condition in which masking occurred with the VEP of a comparable condition in which no masking occurred, and showed a reduction in size of the VEP component at $200 \mathrm{~ms}$ after target onset. But, as with the interpretation by Bridgeman (1988), it is unclear whether this reduction reflects behavioral performance, or if it is the result of different temporal overlap between target and mask related activity at different SOAs.

A study which did use a control condition to check for temporal overlap was conducted by Andreassi, De Simone, and Mellers in 1976. They contrasted the modulation of the VEP response for a target presented alone, an effective mask, and an ineffective mask. The attenuation of VEP amplitude with target alone versus effective mask was larger than the attenuation with target alone versus ineffective mask. They concluded that the attenuated VEP reflects visual masking. However, their data raise two questions. In the first place, the mask and nonmasking stimuli produce different VEPs. In the first condition, the data clearly show a target related peak and a second mask related peak that evolves with increasing SOA. This is also shown in Jeffreys and Musselwhite's (1986) data. In the nonmasking condition there is only one broad peak present, although it contains masks at the same latencies. Secondly, they present a second mask following the first one. In both 
the masking and non-masking condition this second mask effectively decreases visibility of the first mask (Breitmeyer, Rudd, \& Dunn, 1981). Following the reasoning of Andreassi et al. (1976), this should result in an attenuation of the VEP related to the first mask, which they did not observe.

In our view these EEG studies do not conclusively show a correlate of metacontrast masking. We believe that the modulation that Bridgeman (1988) and Vaughan and Silverstein (1968) observed is only due to temporal interaction between the processing of the stimuli, and is not a concomitant of stimulus visibility. The conclusions drawn by Andreassi et al. (1976) are debatable considering the aforementioned data issues. The present experiment has shown data that reflect the processing of the stimuli accurately with a high signal to noise ratio. Nevertheless, we observed no differential modulations between masking and non-masking conditions in time intervals around 200 and $250 \mathrm{~ms}$. Therefore, we conclude that the observed U-shaped modulations shown by these studies do not reflect stimulus visibility.

Other studies investigating object recognition with fMRI or cell recordings in monkeys also found changes in neural activity related to whether or not an object was recognized (Bar, et al., 2001; Grill-Spector, Kushnir, Hendler, \& Malach, 2000; Kovacs, Vogels, \& Orban, 1995; Rolls, Tovee, \& Panzeri, 1999). However, these studies used pattern masking in which the target and the mask stimuli are presented at the same retinal location and activate the same part of visual cortex. This paradigm yields a monotonically increasing masking function and is not comparable to metacontrast masking.

A recent study which did use a metacontrast masking paradigm showed that fMRI activity in early visual cortex did not reflect the visibility of a stimulus, but that activity in later visual areas and parieto-frontal regions are correlated with the visibility function (Haynes, Driver, \& Rees, 2005). We believe that the present results are consistent with these findings. Our results show a lack of correlation between early latency MEG components and the masking function, which indicates that the early visual areas are not involved in the masking mechanism, a finding which is comparable to the results of Haynes et al. (2005). We do see a correlation between visibility and a later VEF component on channels overlying the parietal cortex, which is consistent with the finding that fMRI activity in parieto-frontal regions correlates with the visibility of a stimulus. In addition to expanding the time range of interest in order to include postperceptual processing latencies, future studies investigating metacontrast masking might focus on a different aspect of brain activity. When computing stimulus locked averages, one assumes that the stimulus evokes an effect at a specific latency with the same phase (or polarity) in every trial. All other processes are considered noise and are averaged out. However, several studies have shown that brain activity related to visual awareness is not 
phase locked, but that it is induced. It is time locked to the stimulus, but with a phase that varies over trials (Engel \& Singer, 2001; Tallon-Baudry \& Bertrand, 1999). This type of activity can be revealed through a time-frequency analysis of the data. For metacontrast masking studies this means that the visibility of the target stimulus would be reflected in a modulation of the power in a specific frequency band. Studies on the role of oscillations in visual perception have shown that synchronous oscillations are important in the processes of selective attention and top-down modulation (Engel, Fries, \& Singer, 2001; Fries, Reynolds, Rorie, \& Desimone, 2001). If the mechanism of metacontrast masking is mediated by higher perceptual processes, like feedback or recurrent processes and attentional processes as suggested in several studies (Enns \& Di Lollo, 2000; Ro, Breitmeyer, Burton, Singhal, \& Lane, 2003), then designing metacontrast masking experiments suitable for time-frequency analysis could be an option for future masking studies. 
This chapter is based on:

M. Rijpkema, S. van Aalderen, J. Schwarzbach, and F.A.J. Verstraten (2006). Beyond the forest and the trees: local and global interference in hierarchical visual stimuli containing three levels. Accepted for publication in Perception. 


\section{Chapter 0.3}

\section{Beyond the forest and the trees: Local and global interference in hierarchi- cal visual stimuli containing three levels}

A fundamental issue in vision research concerns the allocation of attention to the overall structure of our visual field and its component parts. Our visual world can be thought of as being organized in a hierarchical way, like in the wellknown metaphor of the forest and the trees (Navon, 1977). The perceptual relation between the global level of an object (forest) and the local elements (trees) raises the question whether processing of the overall structure precedes processing of the component parts or whether the parts are perceived first and then combined to form the objects.

To test this question experimentally the local/global paradigm proposed by Navon (1977) has frequently been used. In this paradigm stimuli are used in which larger figures (global forms) are made of smaller figures (local elements) to form 
hierarchical stimuli with levels that are equally complicated and identifiable and only differ in their level of globality (see figure 1a). In psychological studies using these stimuli global precedence is usually observed (Navon, 1977; see Kimchi, 1992 for a review), which encompasses two effects: the global aspect of a hierarchical visual stimulus is perceived more quickly than its local aspects (global advantage) and global processing interferes more with local processing than vice versa (global interference).

Although typically reaction times are shorter when attention is directed to the global level than when directed to the local level, this global advantage can be altered by experimental manipulations of, for example, visual angle, eccentricity, shape, lateral masking, spatial uncertainty, number of local elements, and exposure duration (e.g. Kinchla \& Wolfe, 1979; Lamb \& Robertson, 1988; Kimchi, 1992; LaGasse, 1993; Amirkhiabani \& Lovegrove, 1996). Furthermore, several studies have shown that attentional manipulations can affect global and local processing (Ward, 1982; Kinchla, Solis-Macias \& Hoffman, 1983; Lamb \& Robertson, 1988; Robertson \& Lamb, 1991; Stoffer 1994). For example, Kinchla et al (1983) found that when targets were more likely to appear at a specific level, target detection at that level increased while detection of targets at the other level decreased. The same effect also occurred when participants were simply told that one level was more important than the other, without changing the probability of target appearance. This effect was argued to be due to the allocation of attention to one of the two levels. The finding that both perceptual and controlled attentional mechanisms have an effect on the processing of hierarchically organized stimuli was also demonstrated in studies using patients with brain damage to parietal and occipital cortical areas (Robertson \& Lamb, 1991).

In addition to the global advantage effect, reaction times are longer for processing the local level when the local and the global level are inconsistent (e.g. a different letter at the local and global level) than when these levels are consistent (e.g. the same letter for both levels). Usually, less interference is observed when attention is directed to the global level (Navon 1977, Kimchi, 1992; Yovel, Yovel, \& Levi, 2001), although studies have reported a large contribution from the local

level as well (e.g. Hoffman, 1980; Miller, 1981). Navon (1977) proposed that global advantage and global interference are indicative for global precedence in visual processing, suggesting that perception of the global level occurs before perception of the local level.

Whereas classical Navon stimuli contain two hierarchical levels, real world objects and visual scenes can be described as a hierarchical structure with many more levels. To investigate the order of visual processing in more detail, Stoffer (1991) and Greaney and MacRae (1992) used a triple level Navon stimulus. In these stimuli the middle level occupies a more global position in the hierarchical 
structure of the stimulus with respect to the local level, and a more local position with respect to the global level. Greaney and MacRae found no clear advantage for either the global, middle, or local level and hypothesized possible confounds of the physical characteristics of their stimuli and an effect of overall interference. In the present study we used triple level hierarchical stimuli (figure 1) to actually investigate these suggested interference effects. In two-level stimuli the local-global relation between the two levels is obvious, both absolute and relative. In triple level stimuli however, both the middle and the global level occupy a more global hierarchical position relative to the local level. This allows us to test the hypothesis whether global precedence is absolute or relative. If global precedence is absolute, the global interference effect will increase with increasing level of globality. In this case, the interference effect of the global level to the local level should exceed the interference effect of the middle level to the local level. Alternatively, global precedence may be relative and may only hold for the neighboring more global level in the hierarchical structure, and not necessarily for the absolute global level. In this case, the interference effect of the middle level to the local level should exceed the interference effect of the global level to the local level. By testing this hypothesis more insight will be gained in visual perception and the allocation of attention to visual scenes.

\section{1| Methods}

\section{Participants}

We tested 14 participants in the experiment ( 5 males, 9 females, aged 23-36). All had normal or corrected-to-normal vision.

\section{Stimuli}

The stimuli consisted of three letters out of the set E,O,U,C,F,H. We used this specific letter set instead of a set of only two letters because this set contains as many vowels as consonants, while letter features like straight and curved lines are balanced between both groups. To construct our stimuli, all possible combinations of three letters out of the letter set were used except for triple letter consistency (e.g. an F composed of Fs composed of Fs). The resulting stimuli were called inconsistent if the letter at the attended level of the stimulus did not occur at any other level (e.g. an F composed of Hs composed of Os), whereas in consistent stimuli the letter at the attended level also occurs at one of the other levels (e.g. an F composed of Fs composed of Os, with attention directed to an F). To construct 


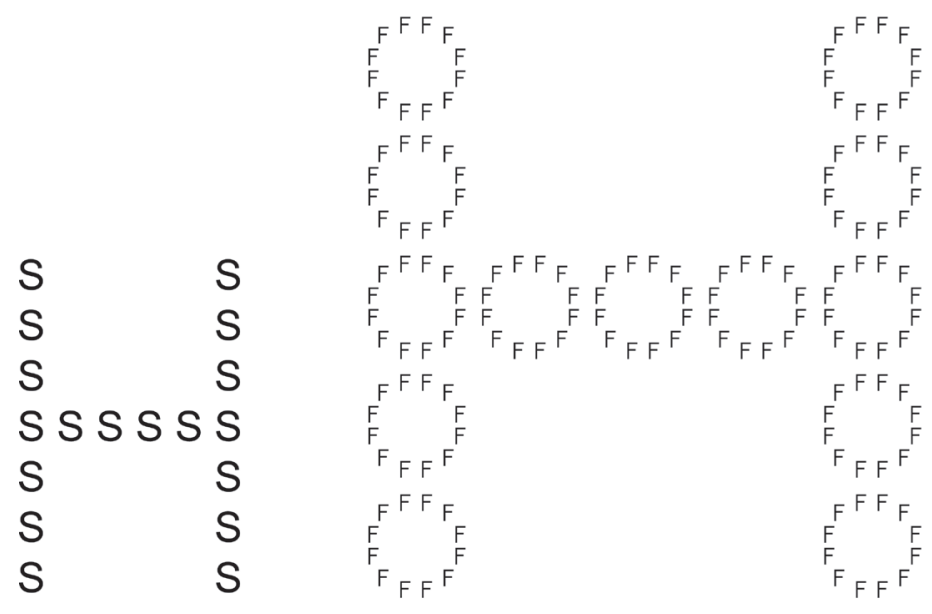

a.

b.

Figure 1. a: Classical Navon figure, an H composed of Ss. b: A triple level hierarchical stimulus, the $\mathrm{H}$ (global level) is composed of Os (middle level), which in turn are composed of Fs (local level). 
the middle level of the stimulus out of the local elements the letter shapes were drawn in a $5 \times 5$ grid. Global shapes were constructed from the middle level elements using these same letter shapes. The visual angles of the different levels were $9.8^{\circ}$, $1.77^{\circ}, 0.25^{\circ}$ of visual angle for the global, middle, and local level respectively. Stimuli were black on a white background.

\section{Procedure}

Stimuli were presented centrally for $100 \mathrm{~ms}$ under free viewing conditions and were shown at a mean intertrial interval of $1083 \mathrm{~ms}$ (range 750-1417 ms). We used a free vision paradigm because a fixation mark potentially creates a bias towards the local level of the stimulus. With no fixation mark present, we used short stimulus presentation to minimize eye movements, which can favor processing of the global level (Paquet \& Merikle, 1984). Although this could affect the global advantage effect, it cannot account for differences between consistent and inconsistent conditions (the global interference effect).

Blocks consisted of 50 trials in which participants had to attend to either the global, middle, or local level of the stimulus, as instructed by a text on the display before each block. The task was to respond differentially with a left or right button press to vowels or consonants at the level of the stimulus they were instructed to attend to. The response (vowels right, consonants left, or vice versa) was randomized among participants. The absence of a response or responses later than $1500 \mathrm{~ms}$ were excluded from analysis. The sequence of trials in a block was pseudo-randomized such that the same letter never appeared twice in a row at the attended level. Stimuli with letter consistency occurred in $40 \%$ of the trials. Although the elements of subsequent stimuli did fall in overlapping regions, there was no absolute spatial certainty for the middle and local level elements. This was done because the rationale of using hierarchical stimuli to study local and global processing is that the stimulus is perceived as an object at the moment of testing. This may not hold if an element of the stimulus is presented with spatial certainty (Navon, 2003). The total experiment consisted of 12 blocks ( 4 times global, middle, local) that were pseudo-randomized such that blocks with the same attended level never appeared twice in a row. Between blocks participants were allowed to take breaks for as long as they wanted. A session lasted about 30 minutes. Both reaction times and error rates were analyzed. To minimize learning effects, participants were trained the day before the actual experiment using the same experimental procedure. During the experiment participants were seated in a dimly illuminated booth. They were instructed to respond as quickly and as accurately as possible and presented with a short practice series of 3 blocks of 10 trials to get accustomed to the procedure again. 


\begin{tabular}{ccc}
$\begin{array}{c}\text { attended } \\
\text { level }\end{array}$ & $\begin{array}{c}\text { consistent } \\
\text { level }\end{array}$ & $\begin{array}{c}\text { effect } \\
(\mathrm{ms})\end{array}$ \\
\hline
\end{tabular}



b.
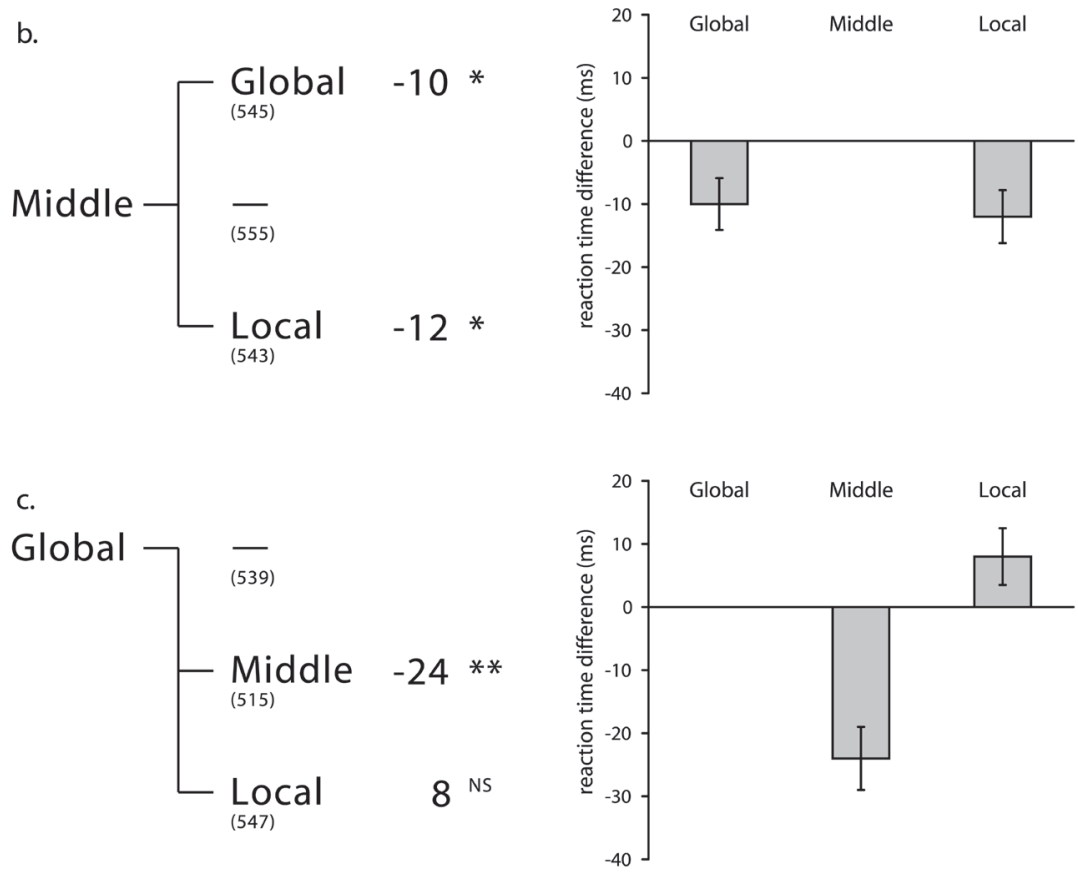

Figure 2. The effect of letter consistency on the reaction times for attending to the local (a), middle (b), and global (c) level of the stimulus. Numbers between brackets are reaction times (ms). The effect is visualized in gray columns (error bars are standard errors). Reaction times of attention to the local level were shorter when the middle level was consistent with the local level, but not when the global level was consistent with the local level. An analogous pattern was found for attention to the global level. For example (a), if at the attended local level a letter F would appear the reaction time was $33 \mathrm{~ms}$ shorter when the middle level was also an $\mathrm{F}$ compared to when the middle level was not an $\mathrm{F}$. In contrast, when the local and global level were consistent (e.g. both an F) no interference was found (o ms). See text for more details.

${ }^{*} \mathrm{p}<0.05,{ }^{* *} \mathrm{p}<0.001, \mathrm{NS}$ : not significant. 


\section{2| Results}

Reaction times for attending to the global, middle, and local level of the stimuli were $539 \pm 61,555 \pm 68$, and $575 \pm 66 \mathrm{~ms}$ respectively (mean \pm SD). Repeated measures ANOVA with attended level as factor showed a significant increase in reaction time from global to middle to local attention, $\mathrm{F}(2,26)=11.06, \mathrm{MSE}=412.84$, $\mathrm{p}<0.001$, all pairwise comparisons $\mathrm{p}<0.05$ (post-hoc Bonferroni analysis). The mean error rates for attending to the global, middle, and local level of the stimulus were $5.4 \% \pm 2.6,3.5 \% \pm 2.2$, and $4.6 \% \pm 2.5$ respectively (mean $\pm \mathrm{SD}$ ). None of the participants exceeded an error rate of $10 \%$.

To investigate whether performance of the participants was stable during the experiment, regression coefficients of reaction time over time were calculated for global, middle, and local attention separately for each condition. We observed large effects of learning in the training session in all conditions $(b=-0.75 \pm 0.54$, $\mathrm{b}=-0.41 \pm 0.19, \mathrm{~b}=-0.72 \pm 0.43$ (mean $\pm \mathrm{SD}$ ) for global, middle, and local attention respectively). During the experiment only a weak decrease in reaction times was observed: $\mathrm{b}=-0.19 \pm 0.18, \mathrm{~b}=-0.10 \pm 0.23, \mathrm{~b}=-0.19 \pm 0.22$ for global, middle, and local attention respectively.

The effect of letter consistency was analyzed by comparing reaction times to consistent stimuli with those to inconsistent stimuli. The results are shown in figure 2. Note that usually the baseline in measuring the global interference effect is performance when the unattended level is consistent with the attended level. Although this may work well in two-level hierarchical stimuli, in triple level stimuli the baseline would be a triple letter consistent stimulus (e.g. an F composed of Fs composed of Fs). This is a rather rare specimen in a set of triple level stimuli, making it hard to obtain a reliable baseline that can be used to calculate the global interference effect in the same way as in two-level stimuli. This is the reason why we decided to present the data relative to a baseline consisting of inconsistent stimuli. Hence, any interference from one level to another can be interpreted in terms of facilitation.

Reaction times for the condition in which participants were attending to the local level were shorter when the middle level was consistent with the local level, but not when the global level was consistent with the local level. An analogous pattern was found for attention to the global level. Attention to the middle level showed interference effects of both the global and the local level. Discarding the $2.5 \%$ fastest and slowest responses for each condition to get more stable means did not lead to statistically significant different results. 


\subsection{Discussion}

We addressed the hypothesis of global precedence by using triple level hierarchical stimuli to investigate the global interference effect. To characterize the stimuli used in this study we also analyzed reaction times for each level and found a significant reaction time increase from global to middle to local attention, indicating global advantage. This is consistent with results of many other psychological studies using the classical (two-level) Navon figures, although for stimuli larger than about 7-10 deg visual angle the global advantage effect was shown not to hold (Kinchla \& Wolfe, 1979; Lamb \& Robertson, 1990; Kimchi, 1992). However, this study was designed to investigate global interference and not global advantage (e.g. size was not corrected for) and one should be cautious in making inferences from just the processing advantage of the global level. Several factors affecting saliency of the different levels of hierarchical stimuli, size and eccentricity, texture, goodness of the shape, and spatial frequency may contribute largely to the global advantage effect (Navon, 1981; Kimchi, 1992; LaGasse, 1993; Fink, Halligan, Marshall, Frith, Frackowiak, \& Dolan, 1996; Grabowska \& Nowicka, 1996; Kimchi, 1998; Morrison \& Schyns, 2001).

Using triple level stimuli, Greaney and MacRae (1992) found longer reaction times to the middle level than to the local and global levels in their small visual angle condition. We did not find this in our study, but as Greaney and MacRae discussed the specific physical characteristics of the stimulus like the number of local elements or shape may completely dominate any advantage effect. Kim, Ivry \& Robertson (1999) added an extra level with letterlike components to their twolevel stimuli to investigate sequential priming. They found that the added level was processed as an additional distractor to the two-level letter stimuli. This has also been suggested by Stoffer (1991) in a study that compared the identification of twoand three-level compound letters. His results showed that the same stimulus was recognized faster when it was the global level of a two-level stimulus rather than the middle level of a triple level stimulus. In an exploratory analysis on triple level stimuli we also analyzed response compatibility, the effect that responses are faster when distracters (in the present study the unattended levels of the stimulus) are compatible with the response than when they are incompatible (Eriksen \& Eriksen, 1974). The results only showed a small significant effect when attending to the local level of the stimulus in the response compatibility condition with the middle level (repeated measures ANOVA, F(2,26) $=4.66, \mathrm{MSE}=345.68$, $\mathrm{p}<0.05$ ), suggesting that subjects mapped letters by identity rather than by response set.

By analyzing the effect of letter consistency we found an interference effect of the neighboring level only. While attending to the local level of the stimulus only the middle level showed an interference effect whereas the global level did 
not interfere at all. This suggests that the global precedence hypothesis only holds relative to the neighboring more global level in the hierarchical structure. The middle level is subject to interference from both the local and the global level, as Greaney and MacRae (1992) hypothesized. However, while global interference did not increase with increasing level of globality, global advantage did. This lack of covariation between global advantage and interference has frequently been reported (e.g. Lamb \& Robertson, 1988; LaGasse, 1993; Amirkhiabani \& Lovegrove, 1999; Blanca, Luna, Lopez-Montiel, Zalabardo, \& Rando, 2002) and shows that the global interference effect cannot easily be explained from global advantage alone. In addition to a global interference effect also a smaller local interference effect was found in this study. Several other studies have also shown this, especially when manipulating the relative visibility of each level (e.g. Hoffman, 1980; Blanca et al, 2002). Such bidirectional interference indicates that attentional filters include neighboring levels, whereas the global advantage indicates which level captures more attention depending on its relative salience.

Our finding that the global-to-local hypothesis only holds for the neighboring more global level in the hierarchical structure may have both perceptual and attentional sources. Firstly, hierarchical processing may still be global to local, but the interference effect may be strongest for the closest global level in the hierarchical structure of the stimulus. However, in this case still a small interference effect of the global level on the local level could be expected. Alternatively, if processing is global to middle to local, the absence of interference from the global level to the attended local level of the stimulus may be explained by cancellation: when attending to the local level of the stimulus, facilitation by a consistent global level may be cancelled by the interference of the inconsistent middle level. However, this explanation assumes a strict global to local processing, which is not supported by the observation of local interference. Consequently, the hypothesis that processing of a visual scene is global to local cannot account for the present data by simple extrapolation from two-level to triple level hierarchical structures. Secondly, a limited spatial attentional window would allow interference from other objects within this window and minimize interference from objects outside this window. This classical spotlight of attention model hypothesizes that information inside the spotlight is processed more quickly or more efficiently than information outside the spotlight (Posner, Snyder, \& Davidson, 1980). This model has been extended and developed further in the past two decades (e.g. see Cave \& Bichot, 1999; Brefczynski \& DeYoe, 1999) and also other neural mechanisms of selective visual attention have been proposed (e.g. Desimone \& Duncan, 1995). However, the basic idea of an attentional spotlight on hierarchical stimulus processing could very well account for our findings in this study. If attention is focused on the local level, covert attention to the middle level may 
0.3 | Chapter

cause interference effects, whereas the global level may be too far away from the attentional locus to interfere. This way, the global precedence hypothesis holds, but only within a limited window of attention. 

This chapter is based on:

Mark Rijpkema, Sandra I. van Aalderen-Smeets, Jens Schwarzbach, and Frans A.J. Verstraten (2006).

Activation patterns in visual cortex reveal receptive field size dependent attentional modulation.

(submitted) 


\section{Chapter $0.4 \mid$}

\section{Activation patterns in visual cortex reveal receptive field size dependent attentional modulation}

Because the visual world around us is cluttered with objects, we usually focus on a specific aspect of the visual world by paying attention to it (Treisman, 1969). Activation in brain areas corresponding to the attended spatial location is modulated by paying attention to these locations (Heinze et al., 1994; Maunsell, 1995; Posner and Petersen, 1990; Tootell et al., 1998). However, the attentional modulation may hold not only for the spatial organization of visual brain areas, but also for the receptive field size properties of our visual system (Kastner et al., 2001; Tootell et al., 1998). Visual attention enhances activation in different brain areas depending on the spatial scale of the relevant information (Bles et al., 2006; Hopf et al., 2006b), but the link of attended spatial scale to receptive field size has not been established. 

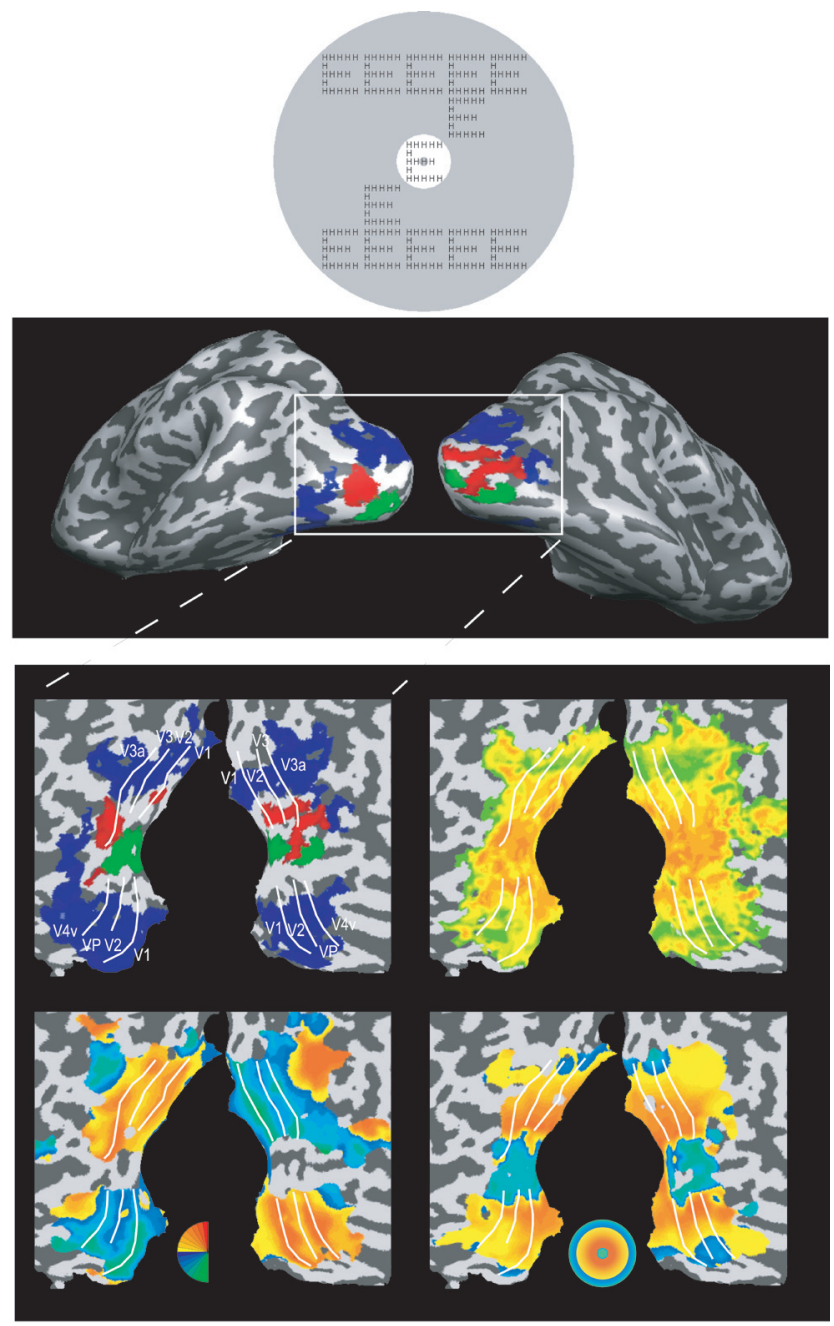

Figure 1. Example stimulus and brain activation patterns for a single subject.

a). an example of the stimulus used, a triple level hierarchical stimulus: a large letter $\mathrm{Z}$ composed of letters $\mathrm{E}$ (middle), which in turn are composed of small letters $\mathrm{H}$, projected onto a bullseye fixation mark (greyscale is adjusted for visualization purposes). Participants were instructed to attend to a specific level of the stimulus (the large letter, middle letter, or small letter) while a sequence of stimuli was shown. Differential activation of attention to the different levels was found in the visual areas of the left and right hemisphere, as is shown on an inflated representation of the brain of one participant (b, lateral-occipital view on both hemispheres). Activation of attention to the large, middle, and small letter is shown in blue, red, and green respectively. A flattened representation of the occipital part of the brain is shown in c-f. In d, the receptive field size map of this participant is shown. Receptive field size was calculated from the time an expanding ring stimulus passed through the receptive field at that location. Small receptive field sizes are shown in orange, large receptive field sizes in green. The receptive field size was smallest in the central parts of the lower visual areas and increased towards the higher-tier visual areas and towards the more peripheral regions. e and $\mathrm{f}$ show the retinotopic map and eccentricity map of this participant respectively. These data were recorded for each participant to characterize and chart the visual areas. The retinotopic map was constructed from data recorded using a rotating wedge stimulus. A color legend for the right hemisphere is shown at the bottom. The eccentricity map was constructed from data recorded using an expanding ring stimulus (see Method section for more details). The color legend for this map is also shown. 


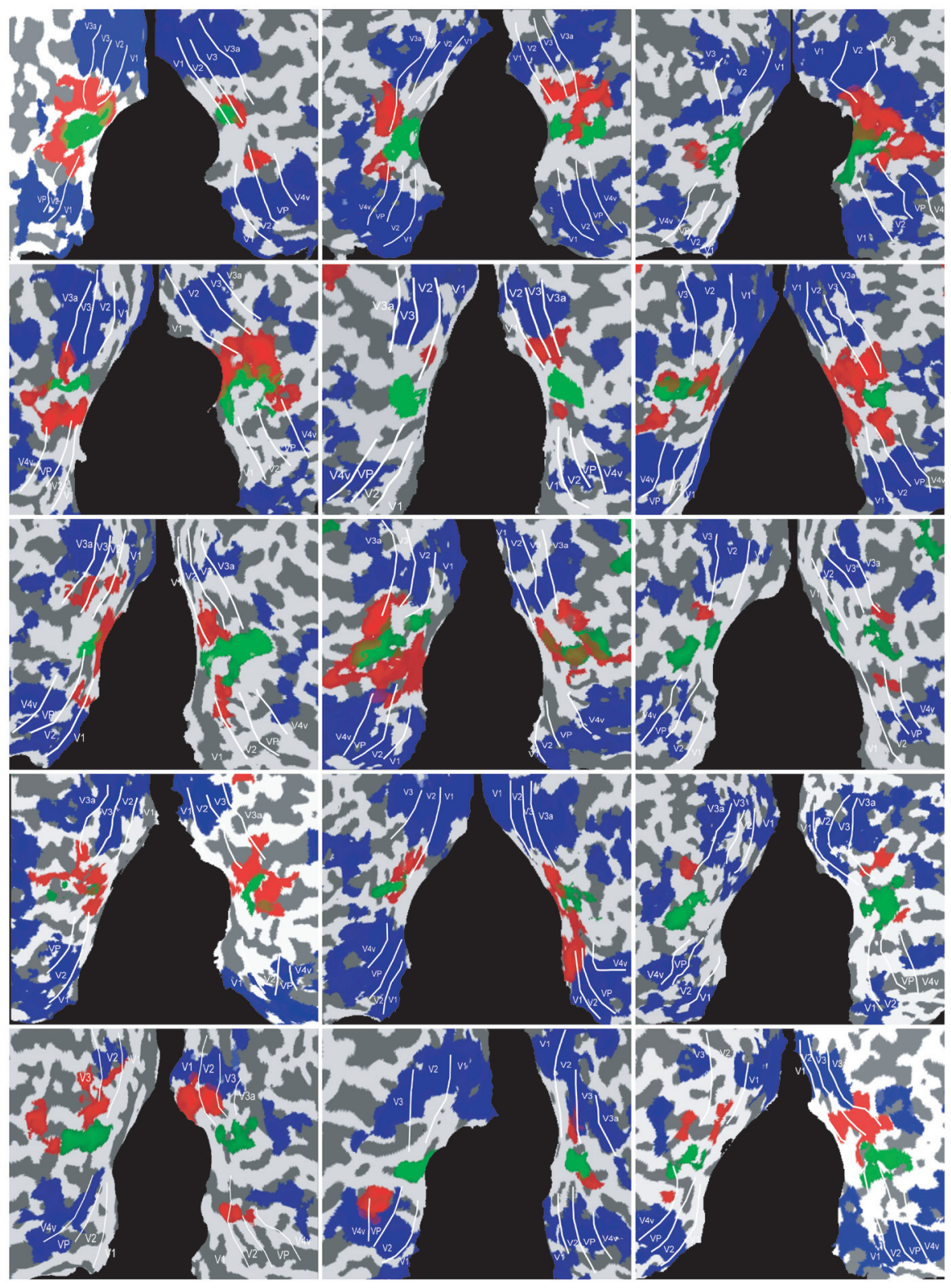

Figure 2. Single subject data showing the activation pattern of attention to the large (blue), middle (red), or small (green) letter of the stimulus for all 15 participants.

The boundaries between the visual areas $\mathrm{V}_{1}, \mathrm{~V}_{2}, \mathrm{~V}_{3} / \mathrm{VP}, \mathrm{V}_{3} \mathrm{a}$, and $\mathrm{V}_{4} \mathrm{~V}$ are also shown. In general, attention to the small letter differentially activated the central parts of the lower visual areas, attention to the large letter activated more peripheral region and higher-tier visual areas, and activation to the middle letter was located in between the activation loci of the small and large letter conditions. For each participant the most significant activated areas are shown. 
The receptive field size of a neuron in the visual cortex is the property that this neuron only responds to stimuli in a specific part of the visual field (Hubel and Wiesel, 1968). Studies in monkeys have shown that receptive field sizes are smallest in central primary visual cortex (V1) and increase gradually in both highertier and more peripheral parts of visual areas (Felleman and VanEssen, 1991; Gattas et al., 2005; Maunsell and Newsome, 1987; VanEssen et al., 1984; Zeki, 1978). Models of selective attention predict that attentional modulation of visual processing is dependent on the receptive field size of visual brain areas (Moran and Desimone, 1985; Desimone and Duncan, 1995; Pinsk et al., 2004). Both single unit recordings in monkeys and human neuroimaging studies suggest that the size of the attentional spotlight is directly related to the receptive field size in a visual area (Brefczynski and Deyoe, 1999; Conner et al., 1997; Luck et al., 1997; Moran and Desimone, 1985; Tootell et al., 1998). Models explicitly addressing the competition among multiple stimuli present at the same time in the visual field hypothesize that attention can bias this competition in favor of the attended stimulus (Desimone and Duncan, 1995). The degree, to which this competition occurs, crucially depends on the receptive field sizes of neurons across visual cortical areas. In humans, however, these models have not been confirmed by direct measurement of the receptive field size of visual brain areas in selective attention studies. In the current study, we estimated the neuronal receptive field size of visual brain areas from independently recorded neuroimaging data. We used selective attention to visual stimuli of different sizes to investigate whether attentional modulation of visual processing is receptive field size dependent. Our hypothesis was that attention enhances activation in brain areas with neuronal receptive field sizes corresponding to the attended object.

Participants had to attend to visual stimuli of different size while their brain activation was measured by functional Magnetic Resonance Imaging (fMRI). Instead of using different objects of varying size or eccentricity as stimuli, we used triple level hierarchical stimuli covering a wide range of spatial scales (see figure 1a). Attention to the different levels of the hierarchical letter stimulus led to three conditions: attention to the large letter, attention to the middle letter, attention to the small letter. Thus, we could isolate the effects of attention to different spatial scales, because the stimulus display remained unchanged over all conditions. Participants were instructed to attend to a specific level of the stimulus and respond to a target letter while stimuli of different letters were sequentially displayed (see Method section). We used a triple level hierarchical stimulus instead of just three letters of different size because all unattended elements act as distracters, which leads to more selective attention. 


\section{1| Methods}

\section{Subjects}

Seventeen participants were included in the study. One participant showed severe head motion ( $\geq 4 \mathrm{~mm}$ ) and one made too many errors ( $\geq 10 \%)$. In both cases more than 4 blocks of one condition had to be excluded from data analysis which led to exclusion of the complete dataset of these participants. The remaining 15 participants were aged 20-33 (mean 25.7), male/female 7/8, and had normal or corrected-to-normal vision. All participants gave written informed consent and the study was approved by the local ethics committee.

\section{Stimuli}

Stimuli were made from three letters out of the set $[\mathrm{Z}, \mathrm{H}, \mathrm{F}, \mathrm{M}, \mathrm{E}, \mathrm{N}]$ and were drawn on $5 \times 5$ grid. A triple level hierarchical stimulus always consisted of three different letters from this set and was projected over a bullseye fixation mark (figure 1a) to help the participants maintain their fixation in the center. This fixation mark remained on the screen during the entire experiment. The visual angles of the different levels were 9.8, 1.77, and o.25 degrees for the large, middle, and small letters respectively.

\section{Design}

Stimuli were presented centrally for $100 \mathrm{~ms}$ to minimize the effect of eye movements. The inter-stimulus interval was between 767-1433 ms. Stimuli were shown in blocks of 30 stimuli. At the start of each block, participants were instructed what level to attend to (large, middle, or small) by a green coloring of the corresponding ring of the bullseye. When the participant pressed a button the green color disappeared and after 4 seconds the sequence of stimuli started. During presentation of the stimuli the participant had to press buttons with the right and left index fingers simultaneously when the target letter appeared at the level they were attending to. The target letter was the ' $\mathrm{F}$ ' for all participants and appeared 3-7 times in a block of 30 stimuli. Other levels than the attended one never contained the target letter. In total 30 blocks of stimuli were presented, 10 times for all three conditions (attention to the large, middle, or small letter) in a pseudo-random order. Between the blocks a baseline of 16 seconds was recorded when only the bullseye was shown on the screen. 

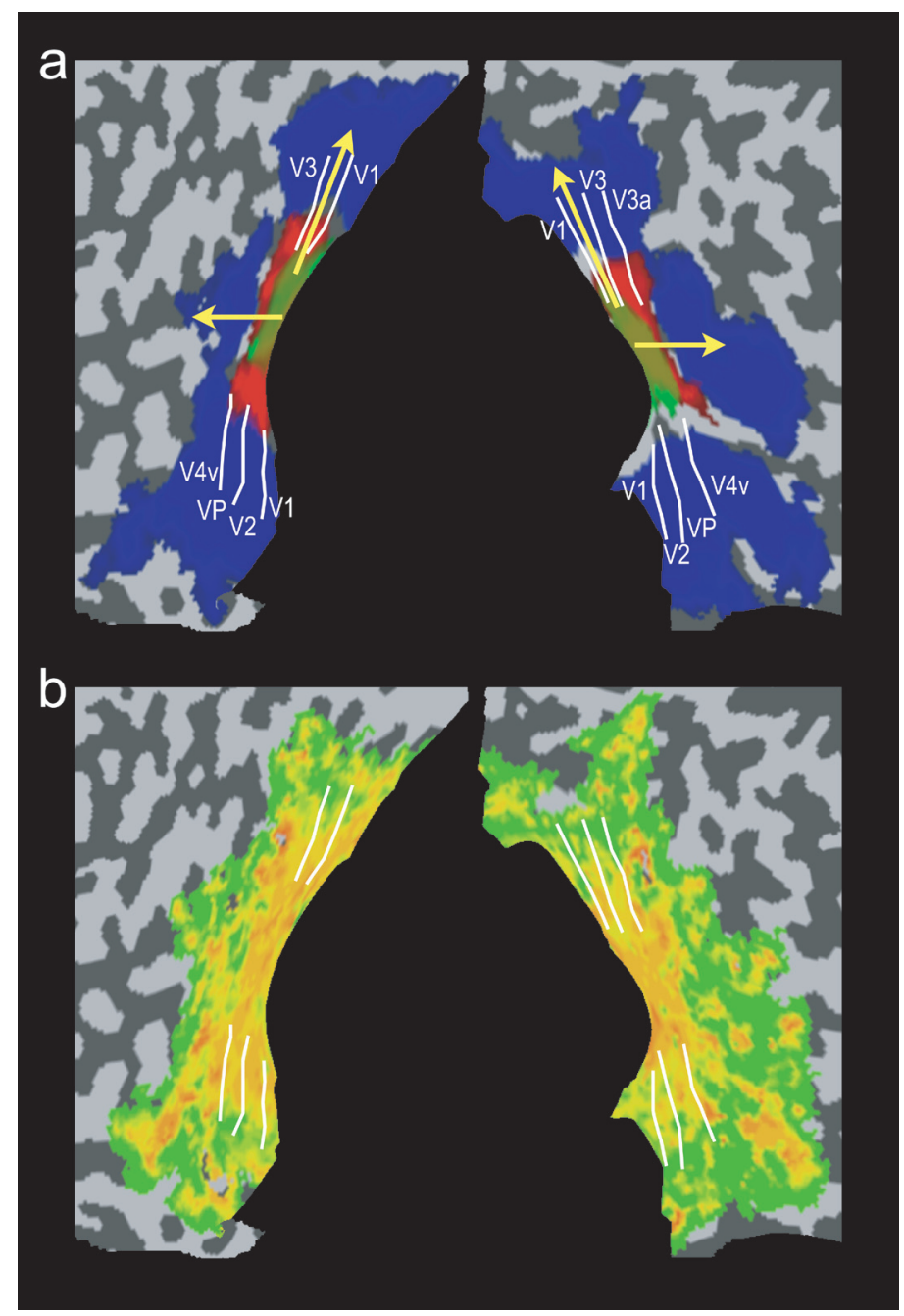

Figure 3. Group analysis results showing differential brain activation for the different attentional conditions.

a.) Flattened representation of the visual areas of the left and right hemisphere of one participant showing the results of the group analysis (fixed effects analysis, thresholded at $\mathrm{p}(\mathrm{FDR})<0.01$ ). The activation pattern of attention to the large, middle, or small letter of the stimulus (see figure 1a) is shown in blue, red, and green for the three conditions respectively. The white lines indicate the boundaries between the visual areas V1, V2, V3/VP, V3a, and V4V. Attention to the small letter differentially activated the central parts of the lower visual areas, whereas attention to the middle and large letter clearly shows a pattern of activation to more peripheral areas and higher-tier visual areas. The same pattern was found in the random effects analysis of the group data (figure 4) and in the single subject data of all 15 participants included in this study (figure 2). In b.) the RF size map of one participant is shown (small RF sizes are shown in orange, large RF sizes are shown in green), which shows a similar pattern as the functional data, with small RF sizes in the central parts of the lower visual areas and larger RF sizes in more peripheral and higher-tier visual areas. To explore this in more detail we analyzed the course of the beta weights (contrast estimates in the GLM analysis) along a trace in two directions, which are schematically indicated by the yellow arrows in both hemispheres. The first trace was drawn inside the dorsal part of visual area V2 from the central region to the peripheral region. The second trace was drawn within the central regions of the visual areas from V1 to the higher visual areas. The results of this analysis are shown in figure 6. 




Figure 4. Results of the random effects analysis showing the same activation pattern as the fixed effects analysis (figure 3) and the single subject data (figure 2).

Activation is thresholded at $\mathrm{p}$ (uncorrected)<0.01. Although the pattern of activation clearly emerges, these results are not significant at a higher threshold. The reason for this is that differences in the geometry of the visual cortex between participants cannot be accounted for in the analysis, although we tried to minimize this by using cortex-based alignment of all single subject data. Also, as we investigated small differential activation areas located close together in the visual cortex, no extensive spatial smoothing could be used which is usually applied to minimize the effects of anatomical differences between participants.
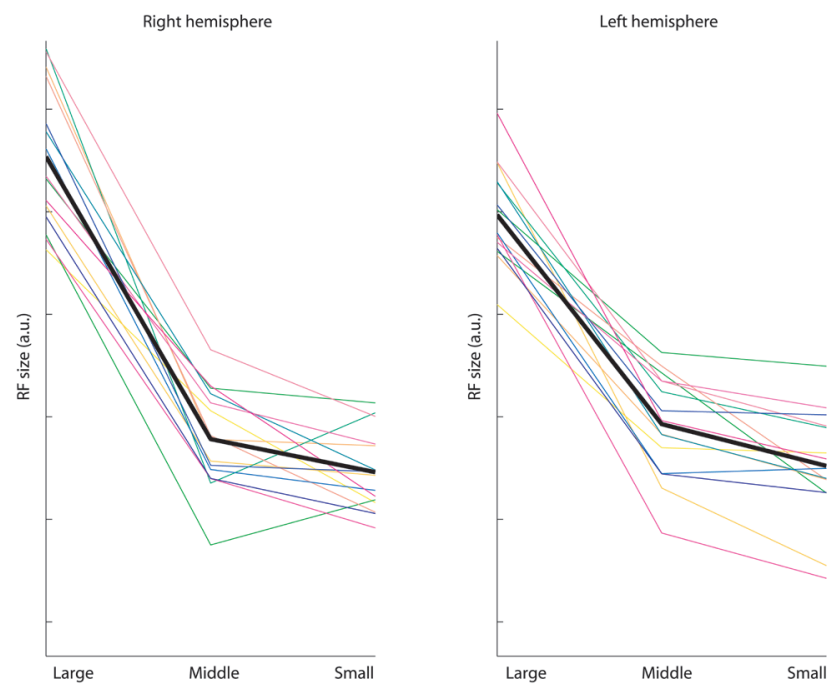

Figure 5. Receptive field sizes of the activated regions in the attention to the large, middle, or small letter conditions for both hemispheres.

Single subject data is shown in colored lines with the mean of all participants shown in black. Attention to the large, middle, or small letter led to activation in areas with significantly decreasing receptive field sizes. Note that receptive field sizes smaller than 0.9 degrees could not be detected with our method because the width of the expanding ring stimulus was 0.9 degrees. Since the visual angle of the small letters was 0.25 degrees, receptive field sizes in the regions activated in the attention to the small letter condition are overestimated, which may explain the small difference between the small letter and the middle letter conditions. 


\subsection{Data analysis}

\section{Data acquisition and image analysis}

Images of brain activity were recorded continuously using an echo planar imaging sequence (TR $2000 \mathrm{~ms}$, TE $30 \mathrm{~ms}, 3.5 \times 3.5 \mathrm{~mm}$ voxel size, 31 slices, slice thickness $3.5 \mathrm{~mm}$, slice gap $0.35 \mathrm{~mm}$ ) on a 3T Siemens Trio MRI scanner. All data was analyzed in Brainvoyager QX. Preprocessing of the data included 3D motion correction, slice scan time correction, linear trend removal, high pass filtering (3 cycles / time course), and coregistration with the recorded anatomical images of the participant. Blocks that showed severe head-motion of the participant ( $\geq 4 \mathrm{~mm}$ ) were excluded from further analysis. Also, blocks in which the participant made so many errors $(\geq 10 \%)$ that his or her attention to the instructed level could not be assured were excluded from the analysis. To visualize the visual brain areas more clearly, all brains were segmented, inflated, and flattened. Data was presented on these flattened representations of the brain. To analyze the functional data a General Linear Model (GLM) was used with 3 regressors for the three conditions (attention to the large, middle, or small letter) and 6 regressors of no interest (the $\mathrm{x}, \mathrm{y}$, and $\mathrm{z}$ rotation and translation motion correction parameters). For the group analyses (fixed effects analysis and random effects analysis) the data was mildly spatially smoothed (4 $\mathrm{mm}$

FWHM Gaussian filter) and cortex-based alignment was applied to minimize effects of inter-subject differences in brain anatomy. The differential effect of attention to the large letter condition was calculated using the t-contrast [2 $1-1]$ on the conditions [large middle small] in the GLM. The contrasts for the attention to the middle and small letter conditions were calculated in a similar way. The activated brain areas for each condition were thresholded to show the most significant activation only and were defined as regions of interest for each subject (see figure 2). The receptive field size of the activated brain regions for each condition was calculated as the average of all voxels in these regions of interest on the receptive field size map.

\section{Beta traces}

To further investigated differential brain activation in different areas of the visual cortex we obtained traces of beta weights by drawing a line from central V2 to dorsal peripheral V2, and from central V1 to the central region of higher visual areas (up to the Lateral Occipital cortex, LO). Visual area V2 was identified using the retinotopic map (see below) and the central line through the visual areas was drawn using the eccentricity map (see below). The visual region of the brain was 
defined by the total of activated areas in the retinotopic and eccentricity map, thresholded at $r>0.2$ and $r>0.25$ respectively. The traces of beta weights did not extend beyond this visually responsive region. To obtain a group average of the beta traces the individual data was resampled to 46 data points and the maximum value for beta for each condition was normalized to 1 before averaging over all participants.

\section{Retinotopic, eccentricity and receptive field size mapping}

Data for the retinotopic, eccentricity, and receptive field size maps were recorded with the same imaging parameters as the functional data (see above). Retinotopic areas were identified by polar angle mapping using a rotating wedge stimulus (7.5 Hz black/white flickering checkerboard, wedge size 33.75 degrees, 10 full rotations in 640 seconds, covering 18 degrees eccentricity, fixation point 0.9 degrees (Sereno et al., 1995)). Boundaries between visual areas V1, V2, and V3/VP could reliably be defined in the upper and lower visual field of both hemispheres in all participants. Depending on the data quality, also areas V3A and V4V could be identified and even visual responsiveness in higher-tier visual areas was observed. All retinotopic maps were thresholded at $r>0.20$. Eccentricity was mapped using an expanding ring stimulus $(7.5 \mathrm{~Hz}$ red/green flickering checkerboard, ring width 0.9 degrees, expanding in 60 seconds to 18 degrees visual angle, 10 cycles wrapped from fully expanded back to central state). All eccentricity maps were thresholded at $r>0.25$.

Besides the identification of central (foveal) and peripheral parts of different visual areas the expanding ring data was also used to explore receptive field sizes, adapted from Smith et al. (2001). Receptive field size at each cortical location was calculated from the functional activation as the expanding ring stimulus passed through the receptive field at that location. The length of the period a cortical location is activated is a measure for receptive field size. Compared to Smith et al. (2001) we used a shorter TR, more cycles, a thinner ring, and only an expanding ring stimulus for recording the data. Although in principle this method can calculate the receptive field size quantitatively, we used it as a qualitative measure only, because for this study we did not need the absolute value for the receptive field size. Also, a number of factors complicate the exact computation of receptive field size, which are summarized by Smith et al (2001). It is important to note that with this method one cannot detect very small receptive field sizes $(<0.9$ degrees, the width of the expanding ring) and very large receptive field sizes ( $>18$ degrees, the fully expanded ring). So, for an infinitely small receptive field the estimated receptive field size will be represented as 0.9 degrees, whereas receptive field sizes larger than 18 degrees will be underestimated. 
a.
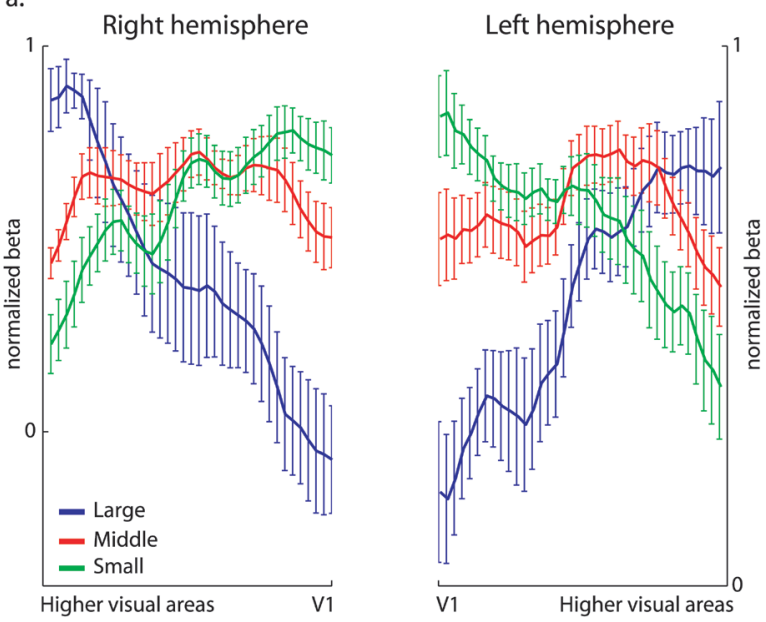

b.

Right hemisphere

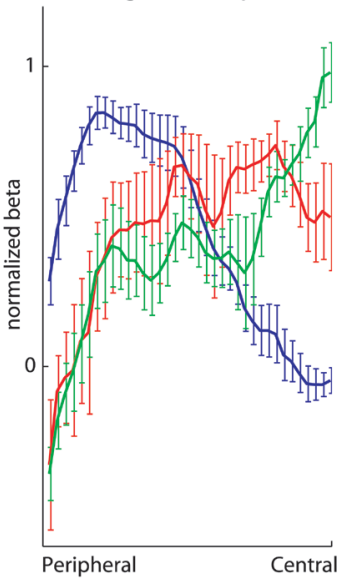

Left hemisphere

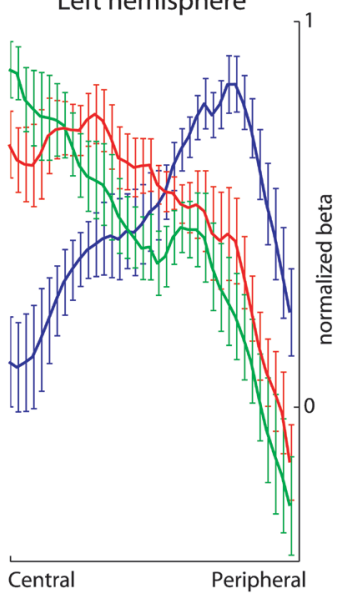

Figure 6. Normalized beta values along traces in different directions in the visual cortex.

a). Normalized beta values as a function of the location on the central line through the visual areas for both hemispheres. For each subject differential beta values of the contrasts for attention to the large, middle, or small letter were calculated along a line travelling from V1 to higher-tier visual areas. Before averaging over all subjects the maximum beta value was normalized to 1 for each condition. In a, the course of these normalized beta values is shown (mean of all subjects with standard errors). A typical pattern is observed with the highest activation for the 'large letter' condition in the higher-tier visual areas, and the highest activation for the 'small letter' condition in the lower visual areas. This clearly shows that attentional modulation of visual processing is receptive field size dependent, even at constant eccentricity. In b) the course of the beta values is shown within the dorsal part of visual area V2, travelling from the central region to the peripheral region. Activation for the attention to the 'large letter' condition is highest in the peripheral part of the visual field, whereas the activation for the 'small letter' condition decreases from the central to the peripheral region. These results may be explained by the increased eccentricity towards the periphery, as the larger letter also extents further into peripheral areas of the visual field than the smaller letters (see Method section for more details). Note that the $\mathrm{x}$-axis is swapped in the plots of the left hemispheres for visualization purposes. 


\subsection{Results}

Differential activation of attending to the large, middle, or the small letter was found in the visual areas of the left and right hemisphere (see figure 1b). More specific, an activation pattern emerged: activation of attention to the small letter was located in the central regions of the lower visual areas, whereas attention to the large letter led to activation in the higher-tier visual areas and more peripheral regions. Activation in the 'middle letter' condition was found between the activation loci of both other conditions. This pattern was even more robust in the group analysis of the data and follows the measured receptive field sizes of different visual brain areas (figure 3). The receptive field sizes of the activated regions in the condition 'attention to the large letter' were higher than in the 'middle letter' condition, which in turn were higher than in the 'small letter' condition (repeated measures ANOVA, $\mathrm{F}(1,14)=452.84$, $\mathrm{p}<0.001$ for right hemisphere large versus middle, $\mathrm{F}(1,14)=6.76, \mathrm{p}<0.05$ for right hemisphere middle versus small, $\mathrm{F}(1,14)$ $=133.16, \mathrm{p}<0.001$ for left hemisphere large versus middle, $\mathrm{F}(1,14)=15.00, \mathrm{p}<0.01$ for left hemisphere middle versus small, see figure 5). The pattern found in our receptive field size maps corresponds well with receptive field size estimations in humans (Bles et al., 2006; Kastner et al., 2001; Smith et al., 2001; Tootell et al., 1997; Tootell et al., 1998) and with receptive field size measurements in monkeys (Felleman and VanEssen, 1991; Gattas et al., 2005; Maunsell and Newsome, 1987; VanEssen et al., 1984; Zeki, 1978), showing that receptive field sizes increase gradually with progressively higher-tier visual brain areas and with increasing eccentricity. It is important to note though that receptive field size has been defined in monkeys at the level of single cells while in humans, neuroimaging is the most feasible technique at present. fMRI measurements to estimate neuronal receptive field size presume that information from voxels covering a brain area with a large population of neurons is representative for the average neuronal receptive field size in that area (discussed in more detail by Kastner et al., 2001).

In the next step of the analysis of our receptive field size dependent attentional modulation findings, we investigated the differential brain activation in different areas of the visual cortex. For this purpose, we traced in two directions the course of the beta weights (contrast estimates in the GLM analysis) as a measure of activation for our three conditions (figure 3). The first trace travels inside visual area V2 from the central region to the periphery and experiences both increasing receptive field size and increasing eccentricity, while the second trace travels from the central region of $\mathrm{V} 1$ to the central regions of the higher visual areas, experiencing increasing receptive field size at a constant eccentricity (Felleman and VanEssen, 1991; Tootell et al., 1996). This analysis is not only an important control of the previous findings, but also enabled us to explore the contribution of 
eccentricity effects to our main finding in more detail. Because receptive field size increases with increasing eccentricity (Gattass et al., 2005) and in our experiment the larger letters extended more into eccentric regions than the smaller letters, an effect of eccentricity may contribute to our results. The course of the beta weights along the two traces shows that the highest activation in the attention to the 'large letter' condition is found in the peripheral areas and in the higher-tier visual areas. In the attention to the 'small letter' condition the highest activation is found in the central regions of the lower visual areas, decreasing both in the direction to the higher-tier visual areas and the peripheral regions (figure 6). Thus, at a constant eccentricity, an attentional modulation is still observed consistent with the receptive field size of a visual brain area (note that the stimulus display was equal in all conditions and only selective attention varied between the conditions).

\section{4| Discussion}

The results in our study show that attention to large or small objects in a visual scene increases activation specifically in brain regions with correspondingly large or small receptive field sizes. This indicates that visual attentional modulation is receptive field size dependent, which extends existing views on spatial location specific neuronal activation. Hierarchical letter stimuli (also known as Navon stimuli (Navon, 1977)) like the ones used in the present study are very common in research on the perception and processing of local and global properties of visual stimuli. Psychophysically, the global level of the stimulus (large letter) is usually perceived more quickly than the local level (small letter) and global processing interferes more with local processing than vice versa, although saliency of the different levels may easily alter this (see Kimchi for a review (Kimchi, 1992)). A typical observation in neuroimaging studies using hierarchical letter stimuli is hemispheric lateralization, with local and global levels being processed predominantly in the left and right hemisphere respectively (Fink et al., 1996). However, not all studies have confirmed this observation (e.g. Fink et al., 1999; Sasaki et al., 2001; Han et al., 2004) and the direction of the lateralization has not always been observed consistent (Weissman et al., 2002). In our study, we did observe some degree of lateralization in the processing of the small versus the large letter stimulus in some participants. This effect, however, was not consistent over all subjects and did not hold in the group analysis of the data and therefore was not analyzed further.

Tootell et al. (1998) investigated the retinotopy of visual spatial attention and suggested that spatial attention uses the same receptive field mechanisms as the sensory-based retinotopic maps. Later studies confirmed that visual spatial 
attention is mapped consistently with the cortical retinotopy (Brefczynski and Deyoe, 1999; Gandhi et al., 1999; Sasaki et al., 2001). More recently, receptive field size of visual areas was estimated from the magnitude of the suppressive interactions among nearby stimuli (Bles et al., 2006; Kastner et al., 1998; Kastner et al., 2001). The estimated receptive field sizes in these studies are similar to the measured receptive field sizes in humans (Smith et al., 2001; Tootell et al., 1997) and correspond well with the areas of activation in the attention to the 'large', 'middle', and 'small letter' conditions found in our study: small letter (0.25 degrees): central V1-V2, middle letter (1.77 degrees): central V3/VP and peripheral $\mathrm{V}_{1}-\mathrm{V}_{3} / \mathrm{VP}$, and large letter (9.8 degrees): central $\mathrm{V}_{3} \mathrm{a}-\mathrm{V} 4 \mathrm{~V}-\mathrm{LO}$ and all peripheral regions. These values for receptive field sizes also match well with physiological recordings in homologous visual areas in monkeys (Felleman and VanEssen, 1991; Gattas et al., 2005; Maunsell and Newsome, 1987; VanEssen et al., 1984; Zeki, 1978).

Also, we confirm predictions of models of selective attention, in which attentional modulation of visual processing critically depends on the receptive field size of neurons across the visual cortex (Moran and Desimone, 1985; Desimone and Duncan, 1995; Pinsk et al., 2004). We conclude that selective visual attention modulates brain areas with specific neuronal receptive field size properties that are most suitable for the task at hand. This adds to the previously described spatially specific attentional effects and further enhances our understanding of visual attention. 
This chapter is based on:

Sandra I. van Aalderen-Smeets, Jan-Mathijs Schoffelen, Robert Oostenveld, and Pascal Fries (2006).

Competitive mechanisms subserve human visual attention. (in preparation). 


\section{Chapter 0.5}

\section{Competative mechanisms subserve human visual attention}

The visual system is remarkably flexible in recognizing objects in spite of variations in their size, position or appearance. This capacity is the consequence of response characteristics of neurons in higher visual areas. These neurons show selectivity for complex stimulus features and identify objects in a positionindependent manner. The response characteristic of a neuron arises from the converging input of multiple lower level neurons onto a single higher level neuron. The joined receptive fields of the input neurons result in larger receptive fields of neurons higher up in the hierarchy and in more complex response characteristics. Neurons in higher visual areas and in inferior temporal cortex commonly have receptive fields (RFs) that span much of the central visual field. In a typical visual scene, such an extended RF will contain multiple distinct objects. Because the visual system has a limited capacity to process information, these multiple objects will compete for neural representation in the absence of selective visual attention 
a.
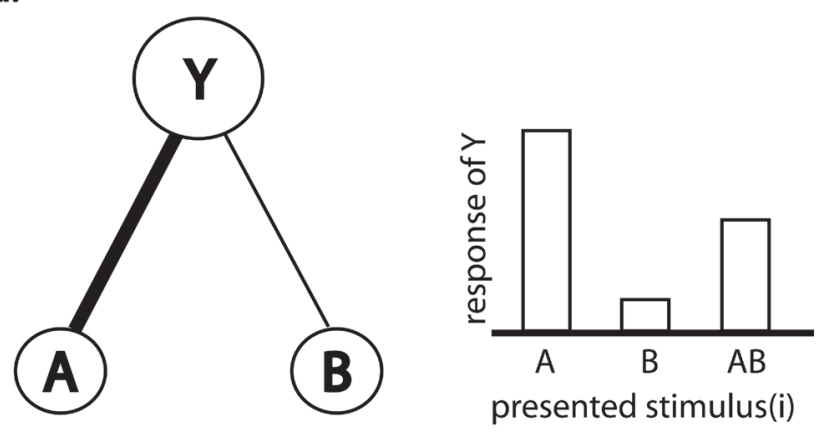

b.
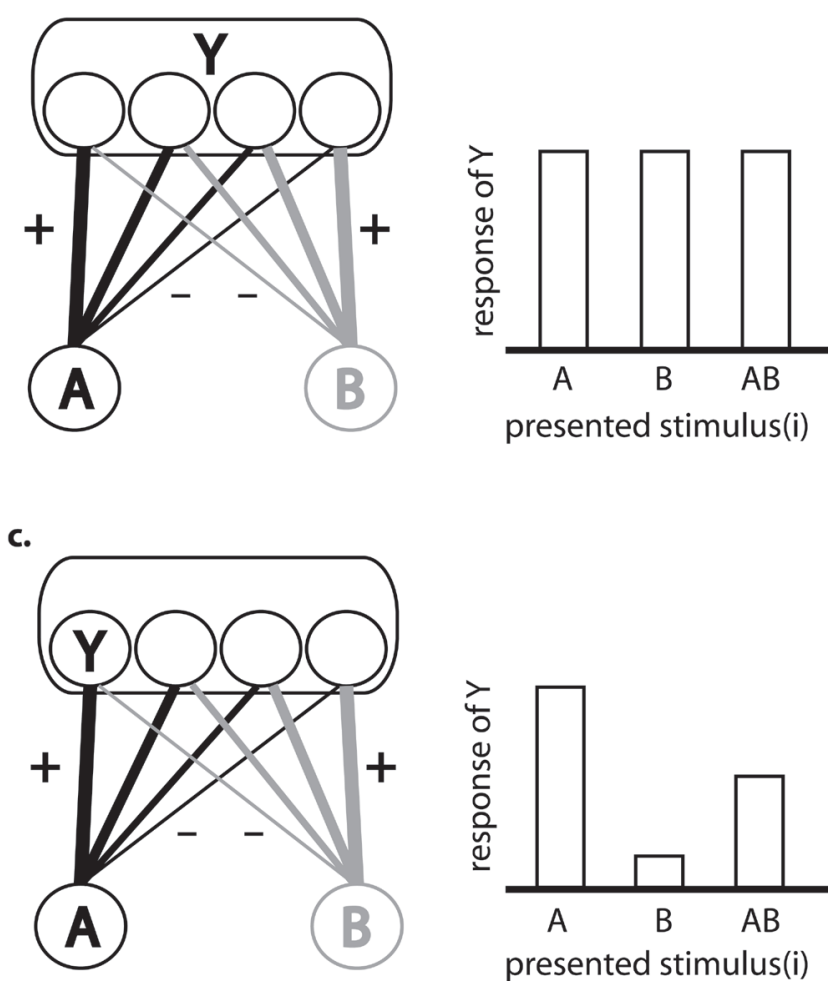

Figure 1. Circuit diagrams of biased competition model in relation to recording technique. In all diagrams attention is directed away. The shape termed Y represents the source of the recorded signals, i.e.: a neuron (a), a voxel, i.e. a group of cells generating a measured signal (b), or group of neurons within in a voxel (c). The variable $\mathrm{Y}$ is the response of this model node. The two circles A and B represent populations of input neurons that respond to either stimulus A or to stimulus B and project to the measured node. The thickness of the lines indicates the input weight, with thicker lines indicating more weight and thinner lines indicating less weight of the input cells to the recorded node. a.) Model circuit diagram of biased competition during single cell recording when attention is directed away. Neuron $\mathrm{Y}$ is selective for stimulus A and demonstrates a high response when stimulus A is presented alone, a low response when stimulus B is presented, and a weighted average of these responses when both stimuli are presented. b.) Model circuit diagram of biased competition in the BOLD response when attention is directed away. Voxel Y contains multiple neurons. The left 
average of the responses to the individual stimuli. In this case, the response would be just the same as the response to any individual stimulus presented alone (see figure 1b). We therefore argue that the used methodology precludes a convincing demonstration of competition between simultaneously presented stimuli. The reason why Kastner et al. (1998) observed a suppression of the BOLD response in the simultaneous condition as compared to the sequential condition is unclear.

The second consequence of not being selective for individual stimuli is that these studies cannot distinguish between a biasing effect of attention and attentional facilitation. The enhancing effect of attention Bles et al. (2006) observe is more likely to represent attentional facilitation, as shown in studies which present isolated stimuli in receptive fields (Motter, 1993; McAdams and Maunsell, 1999; Reynolds et al., 2000; Treue, 2003). Attentional facilitation increases the response to an attended stimulus, and this effect increases in higher areas (Motter, 1993; Treue and Maunsell, 1996; McAdams and Maunsell, 1999), as is observed in the study by Bles et al. (2006). If the increased response is subserved by attentional facilitation, Bles et al. (2006) would have observed the same results when only one stimulus would be presented instead of four. In contrast, the biased competition model predicts no change or even a decrease in BOLD response when one of the stimuli is attended. If attention is paid to one of the four competing simultaneously presented stimuli, the influence of the attended stimulus on the weighted average response is increased while the influence of the three unattended stimuli on the weighted average response is decreased (Reynolds et al., 1999). This would result in no net change or even a decrease in BOLD response. The results of stimulus separation reported by Bles et al. (2006) cannot be explained by attentional facilitation. This is an interesting finding we cannot explain, but which is hard to reconcile with biased competition due to aforementioned reasons.

There are several other studies claiming to demonstrate support for biased competition in human cortex using fMRI or MEG/EEG. These studies fall into one of two categories. The studies in the first category show that attention operates at the level of the visual system corresponding to the scale of the attended stimuli, as is predicted by the biased competition model (Hopf et al., 2006; Rijpkema et al., submitted). Studies falling into the second category show attentional suppression surrounding the area of attentional enhancement, which indicates that the influence of the competing surround is reduced (Slotnick et al., 2002;

most neuron is more selective for stimulus A than stimulus B and the other way around for the right most voxel. The response of the voxel when stimulus A is presented is an average of the response of all neurons in the voxel. This average is the same if stimulus A is presented or stimulus B is presented, even though the individual neurons show a different response pattern. When both stimuli are presented together, the response of each individual neuron is a weighted average of the response to each stimulus presented alone. The average of these responses as measured from the voxel is then the same as if the stimulus were presented alone. c.) Model circuit diagram of biased competition when measuring signals selective for a stimulus (frequency tagging) when attention is directed away. The circle termed Y represents a group of neurons within a voxel that represents the processing of stimulus A. The response is high when stimulus A is presented, low when stimulus B is presented, and weighted average when both stimuli are presented. 

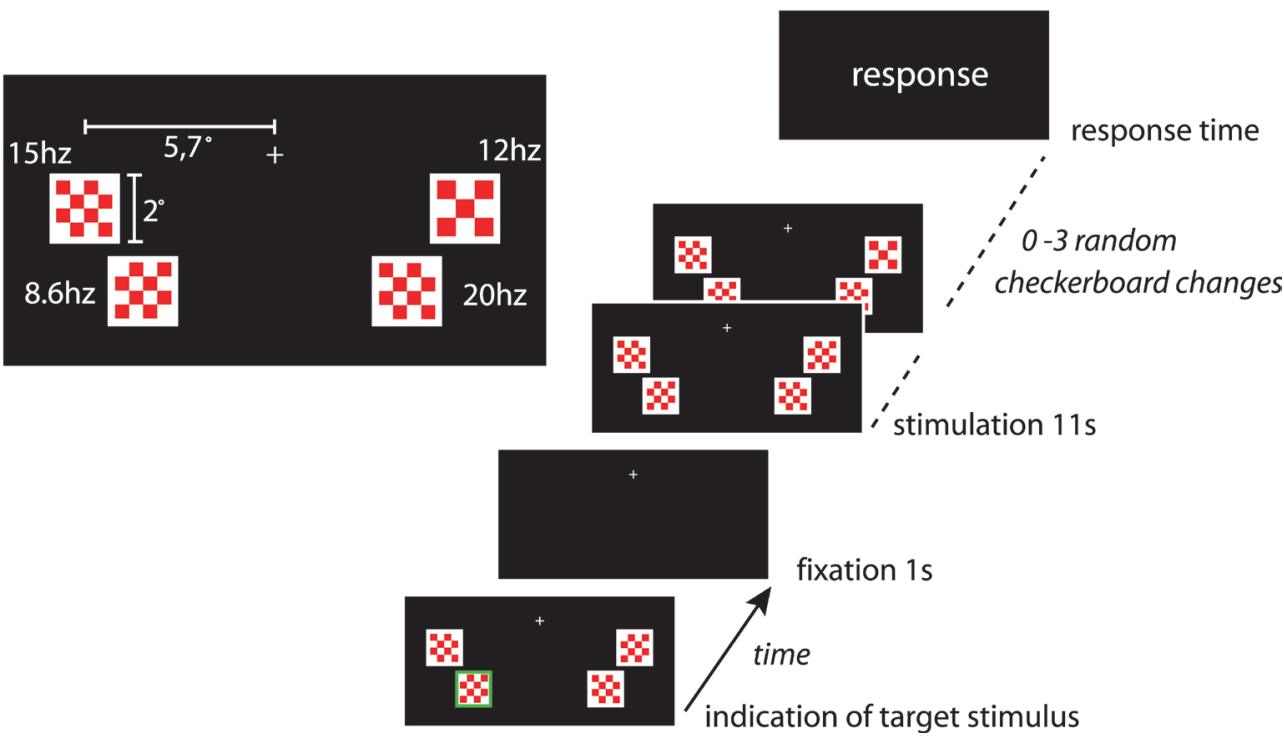

Figure 2. Experimental design.

a.) Displays of the four stimuli and the fixation cross on the screen. Each stimulus flickers with the indicated frequency.

The stimulus flickering at $12 \mathrm{~Hz}$ shows a checkerboard change. b.) Timing of the experiment. 
(Moran and Desimone 1985; Miller et al., 1993; Desimone and Duncan 1995; Reynolds, et al., 1999). A possible solution to this competition problem is provided by the biased competition model, which states that selective attention biases the response of the neuron in favor of the most relevant stimulus (Desimone and Duncan, 1995). Evidence for biased competition has come mainly from single cell recordings in extrastriate areas of monkeys (Moran and Desimone, 1985; Treue and Maunsell, 1996; Luck et al., 1997; Reynolds et al., 1999). When two competing stimuli are presented inside one receptive field, the firing rate of the neuron is a weighted average of the responses to the individual stimuli. Directing attention to one of two stimuli presented in the same receptive field biases the response of the neuron toward the response the attended stimulus elicits if presented in isolation. It has been suggested that the bias is the result of an increased weight of the synaptic input that is driven by the attended stimulus (Reynolds et al., 1999).

Several studies have tested the hypotheses derived from the biased competition account in human visual cortex, but so far none of these have provided direct evidence of biased competition (Kastner et al., 1998; Kastner et al., 1999; Kastner et al., 2001; Bles et al., 2006; Hopf et al., 2006a; Hopf et al., 2006b). We will quickly review the studies by Kastner et al. (1998; 1999; 2001) and Bles et al. (2006) and point out the drawbacks in their designs. Kastner et al. $(1998 ; 1999 ; 2001)$ presented subjects with four complex visual images presented simultaneously or sequentially while measuring the BOLD response with fMRI. They reasoned that competition between these stimuli was present only in the simultaneous condition, not in the sequential condition. The results show smaller BOLD signals for the simultaneous condition compared to the sequential condition and the authors interpret these findings as evidence for competitive interactions between stimuli during simultaneous presentation as compared to sequential presentation. Furthermore, the results show that directing attention to one of the four stimuli enhances the BOLD response to the simultaneous presented stimuli more than it enhances the BOLD response to sequentially presented stimuli. They conclude that these response increments demonstrate that the competition is biased in favor of the attended stimulus and that these findings support the biased competition model. Bles et al. (2006) have replicated and extended these findings. They improved the method used by Kastner et al. (1998) by no longer comparing simultaneously presented stimulation to sequentially presented stimulation. The drawback of this comparison is that in the sequential condition, more transient onsets are present than in the simultaneous condition. Since the BOLD response is dependent on the number of transient onsets, the higher response in the sequential condition could be explained by the higher number of onsets rather than by the reduced amount of suppressive interaction. Bles et al. (2006) presented four stimuli simultaneously in one visual quadrant, varying the locus of attention 
a.



b.

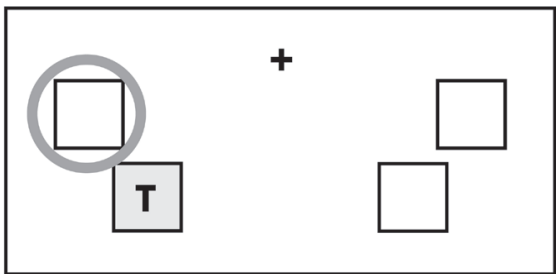

c.

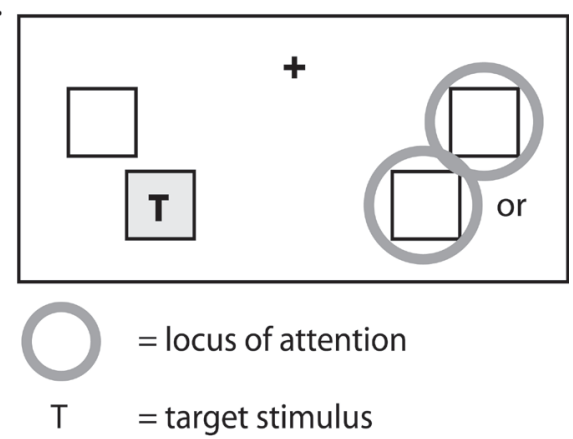

Figure 3. Attentional conditions.

The target stimulus is the stimulus of which the flicker frequency is being analyzed. The target displayed here is an example, all flicker frequencies are analyzed. a.) The target condition; the target stimulus is being attended. b.) The near-distracter condition; the nearby stimulus which is presented in the same hemifield is being attended. c.) The attend-away condition; one of the stimuli in the opposite hemifield is being attended. 
(attention to stimulus or attention to fixation cross) and the separation between the four stimuli. According to the biased competition model, the presence of sensory interactions depends on the relation between the size of the receptive field of a neuron and the scale of the presented stimuli, e.g. two stimuli spaced far apart will not fall into the same receptive field of neurons in area V1, while they will fall into the larger receptive field of a neuron in area V4 (Reynolds et al., 1999). Therefore, the difference in BOLD signal between attended and unattended conditions was hypothesized to be scaled with receptive field size and stimulus separation. Indeed, they found no attention effects in lower visual areas where receptive fields are small. An effect of attention was observed in higher visual areas and this effect increased with visual area. The largest increase in BOLD signal with attention was present in area TEO and significant for all stimulus separations. In area V4, the attention effect was only present for the smaller two separations, suggesting that the receptive fields of neurons in area $\mathrm{V}_{4}$ are too small to encompass the stimuli presented with the largest separation. The authors conclude that attentional mechanisms cancel the suppressive interactions caused by simultaneous presentation of multiple stimuli and that this effect is scaled with receptive field size as the biased competition model predicts.

The main drawback of these studies is that the BOLD signal is not selective for the individual stimuli. As a consequence, these studies don't fulfill the prerequisites for demonstrating sensory interaction and correspondingly for demonstrating biased competition as do single cell studies. Single neurons recorded from microelectrodes show differential responses to individual stimuli presented in their receptive field. Therefore the response to a single stimulus can be meaningfully compared to the sensory interaction arising from presenting a second stimulus in the receptive field. The effect of attention on the firing rate can be related to the firing when the stimulus is presented alone. By contrast, the BOLD signals recorded in these fMRI studies are not selective for individual stimuli presented in close proximity, but represent the weighted average response of a group of neurons contained in one voxel. This has two consequences for the conclusions drawn from these fMRI studies. First, the studies cannot demonstrate sensory interaction convincingly. Sensory interaction is demonstrated in the single cell studies by using a preferred stimulus, eliciting a large response, and a non-preferred stimulus eliciting a small response. When both stimuli are presented to one receptive field and attention is directed away, the resulting firing rate of this neuron is a weighted average of the responses to the individual stimuli, the hallmark of sensory interaction (see figure 1a). In these human neuroimaging studies, no such distinction between preferred and non-preferred stimuli is used. All four presented stimuli elicit a comparable BOLD response in the recorded voxel (see figure $1 \mathrm{~b}$ ). Presenting all four stimuli simultaneously elicits a response which is a weighted 


\section{a. 8.6 and $15 \mathrm{~Hz}$}

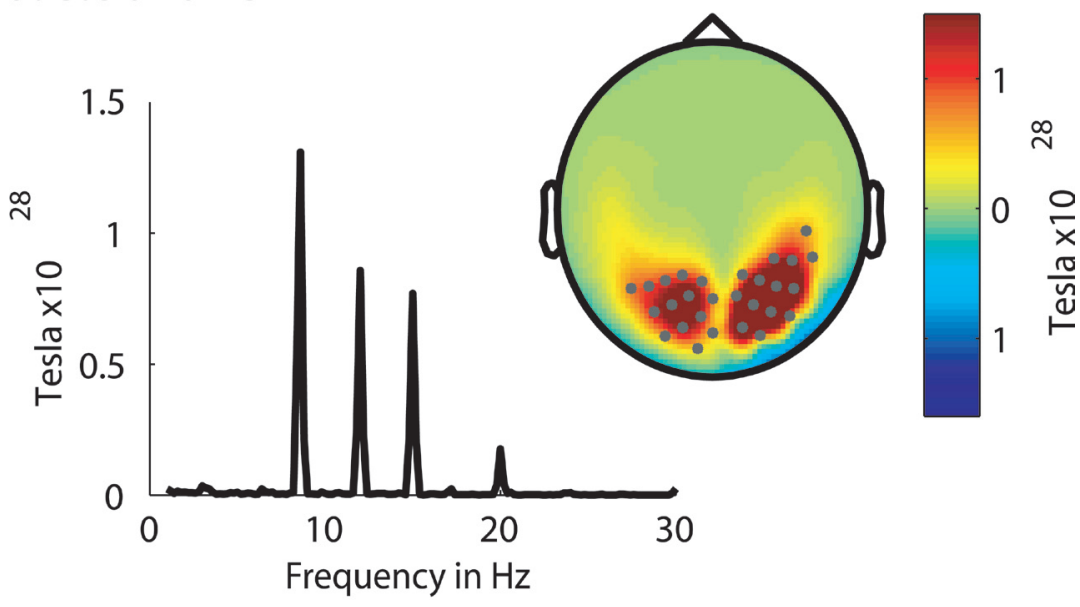

\section{b. 12 and $20 \mathrm{~Hz}$}

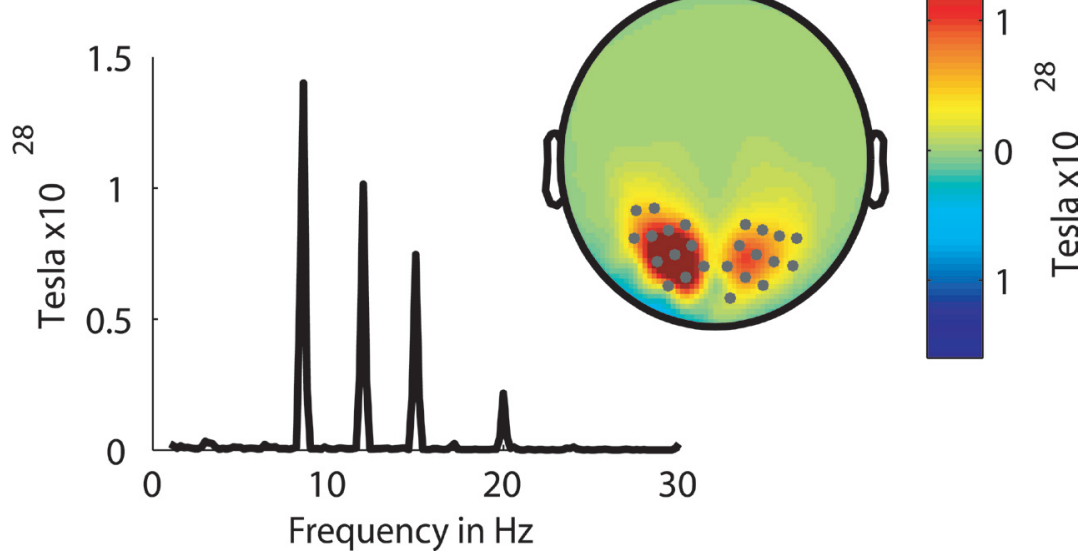

Figure 4. Phase-locked power spectra of an individual subject.

a.) The phase-locked power spectra to the 8.6 and $15 \mathrm{~Hz}$ stimulation accumulated over those channels. This representative subject shows entrainment to these frequencies. Entrainment is defined as an increase in power amplitude of at least a $100 \%$ compared to the mean phase-locked power over all channels and frequencies. The selected channels are highlighted on the topographical distribution plot. The entrainment is located in channels over parieto-occipital regions with the largest entrainment on the hemisphere contralateral to side of stimulation. b.) This plot shows the same pattern for the 12 and $20 \mathrm{~Hz}$ stimulation frequencies. 
Müller and Kleinschmidt, 2004; Müller et al., 2005; Hopf et al., 2006a). However, none of these studies provides direct evidence for biased competition in human visual cortex due to similar methodological problems as in aforementioned studies (Kastner et al. 1998; 1999; 2001; Bles et al., 2006).

There has been one convincing study showing evidence for a biased competition mechanism present in humans (O'Craven et al., 1999). This study successfully measured BOLD signals selective for individual stimuli. Houses and superimposed faces were presented while subjects paid attention to either one of them. These stimulation conditions were compared to a baseline period where only a fixation cross was present. Signals recorded from the fusiform face area (FFA) and the parahippocampal place area (PPA) showed a larger increase in BOLD response when the preferred stimulus was attended for that particular area compared to the increase in BOLD response when the non preferred stimulus was attended. Note however that the increase in BOLD reflected a difference between a baseline period and the stimulation period. Therefore a smaller increase was expected when comparing the two conditions, and no decrease in response. These findings provide support for the biased competition model by demonstrating a higher BOLD response when the preferred stimulus was attended and a smaller BOLD response when the non-preferred stimulus was attended. This indicates that attention biases the selective response of a group of neurons towards a BOLD response that would be elicited by either stimulus alone. Since no direct comparison of attention to and no attention to a stimulus has been performed, attentional facilitation cannot be ruled out. However, attentional facilitation seems an unlikely explanation since it would predict to facilitate both preferred and non preferred stimuli equally well. In the current study, we hope to extend these findings by showing direct support for biased competition in the earlier visual areas of human cortex, more comparable to the single cell study of Reynolds et al. (1999).

We will measure MEG signals selective for individual stimuli by means of frequency tagging the stimuli which are presented simultaneously and in close spatial proximity. Frequency tagging has been shown to be a useful tool to study the effect of attention, as demonstrated by increased power for the frequency corresponding to the attended stimulus (Morgan et al., 1996; Muller et al., 1998; Muller et al., 2003a; Chen et al., 2003). In the present study, four stimuli flickering at different frequencies will be shown (see figure 2). The stimuli presented in one hemifield are more likely to fall within one receptive field than stimuli presented in different hemifields and these stimuli are therefore more likely to show competitive interactions. The response to a target stimulus is measured in three different conditions depending on the location of attention: attention directed to the target, attention directed away and attention directed to a nearby distracter (see figure 3). According to the biased competition model, the stimuli presented in 
one hemifield (read receptive field) will compete for neural representation when attention is directed away and the response of the group of neurons selective for the target stimulus will be the weighted average of the responses to the individual stimuli. When attention is directed to the target stimulus, the competition will be biased in favor of the attended stimulus and the influence of the competing stimulus will be reduced. As a consequence, we expect the entrained response to the attended stimulus to be increased compared to when attention is directed away. When attention is directed to the nearby distracter stimulus, the influence of the target stimulus is decreased and hence the entrained response to the target will be decreased compared to when attention is directed away. If attention would be mediated by a facilitation process then only an increase in response amplitude would be expected with attention and no decrease in response amplitude in the near-distracter condition.

\section{1| Methods}

\section{Subjects}

Twelve subjects ( 7 male, 5 female, mean age 27.1 year, range $23-34$ year, 1 left handed) participated in the study. All had normal or corrected-to-normal visual acuity. Before the experiment, informed consent was obtained from each subject according to the Declaration of Helsinki. We had to exclude one subject from analysis due to technical problems with the MEG system.

\section{Stimuli and paradigm}

Stimuli were presented against a black background at four different locations in the lower visual field, see figure 2. Each stimulus consisted of a white square flickering at a certain frequency and a superimposed 4x4 checkerboard with the alternate checks being either red or transparent. At a viewing distance of 57 centimeters each white square subtended a viewing angle of $2^{\circ} \times 2^{\circ}$, which was slightly larger then the checkerboard, which subtended a viewing angle of $1.5^{\circ} \times 1.5^{\circ}$. All stimuli were presented at same eccentricity $\left(5.7^{\circ}\right.$ from centre of square to fixation cross). The distance between the two squares in the same hemifield was $2.8^{\circ}$ (centre to centre) and $7.3^{\circ}$ between the two lower squares. The four stimuli flickered at rates of $15 \mathrm{~Hz}, 8.6 \mathrm{~Hz}, 20 \mathrm{~Hz}$, and $12 \mathrm{~Hz}$ respectively (see figure 1). With a refresh rate of $60 \mathrm{~Hz}$, each white square was on for one frame (16.67 ms) and off for the respective number of frames needed to achieve the appropriate frequency, i.e. $4,7,3$, and 5 frames respectively. 
The duration of one trial was 12 seconds, consisting of a 1 second fixation period followed by 11 seconds of stimulation. A white central fixation cross was presented during the whole trial. Before the start of the trial the subject was instructed to pay attention to one of the squares by the presentation of the stimulus array with the target square displaying a green outer lining. During the trial, zero to three checkerboard changes could occur in this target square (the change encompassed a transformation from a $4 \times 4$ to a $3 \times 3$ checkerboard for the duration 11 frames, i.e. $183 \mathrm{~ms}$ ). The subjects were instructed to count the number of checkerboard changes in the target square and to report the number after the end of the trial. The zero to three checkerboard changes could also occur in each of the three non-target squares serving as distracters. Subjects had to respond on the number of changes by pressing one of four buttons ( $0,1,2$, or 3 changes) with their left and right index and middle fingers.

Each location had to be attended 36 times. Also 36 fixation trials were included in the experiment for potential baseline subtraction. A total of 180 trials were presented random in five blocks of 36 trials. Since data analysis is done within each frequency band $(8.6,12,15$, and $20 \mathrm{~Hz})$, conditions are defined with respect to this particular frequency (see figure 3 ).

\section{Data acquisition}

Magnetic fields were recorded in a magnetically shielded room using a wholehead MEG system (Omega 2000, CTF Systems, Inc., Vancouver, Canada) with 151 axial gradiometers. The data were low pass filtered at $300 \mathrm{~Hz}$ and digitized at 1200 Hz. Subjects were comfortably seated with their head located within the helmet of the MEG system and were instructed to move as little as possible during the whole experiment. Lights were turned off during the measurement. An electro-oculogram (EOG) was recorded simultaneously during the MEG experiment and was used for offline artifact rejection. Impedance at all electrodes was below $10 \mathrm{kOhms}$. Prior to and after the MEG measurement, the subject's head position relative to the gradiometer array was measured using coils positioned on the subject's nasion and at the bilateral external auditory meatus.

Structural magnetic resonance images were obtained using a 3D MPRAGE sequence with $1 \mathrm{~mm}$ isotropic resolution on a 1,5T whole body MRI scanner (Siemens, Erlangen, Germany). 
a. Attend target vs attend near-distracter
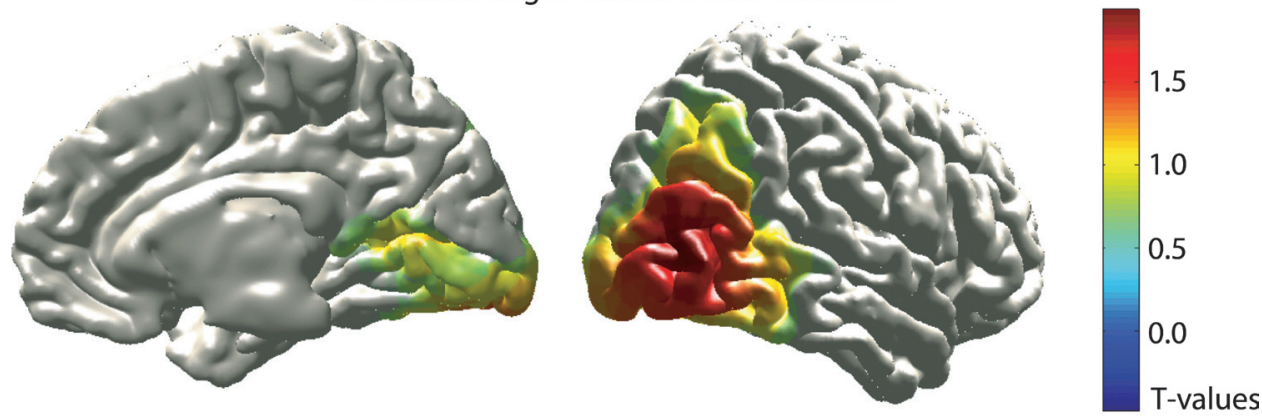

b. Attend target vs attend away
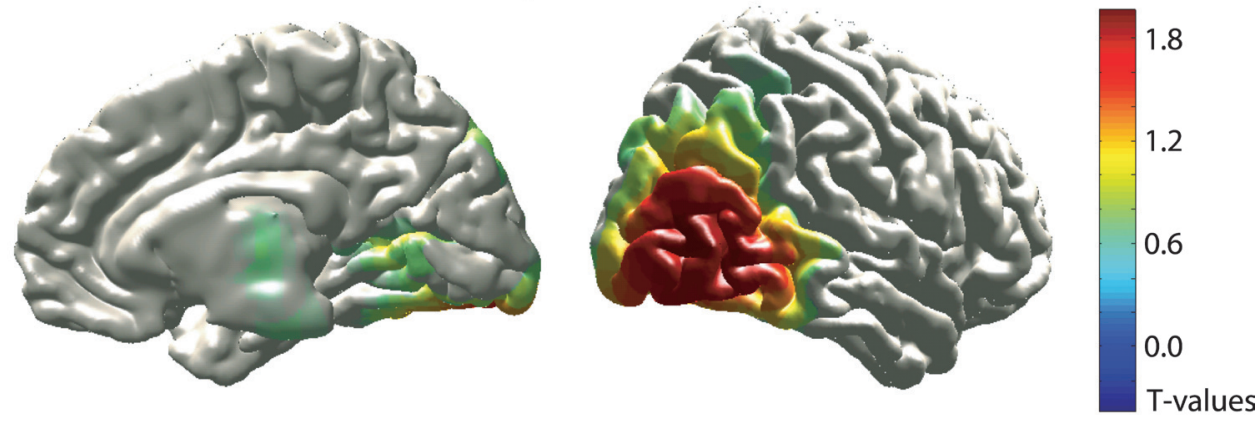

\section{c. Attend away vs attend near-distracter}
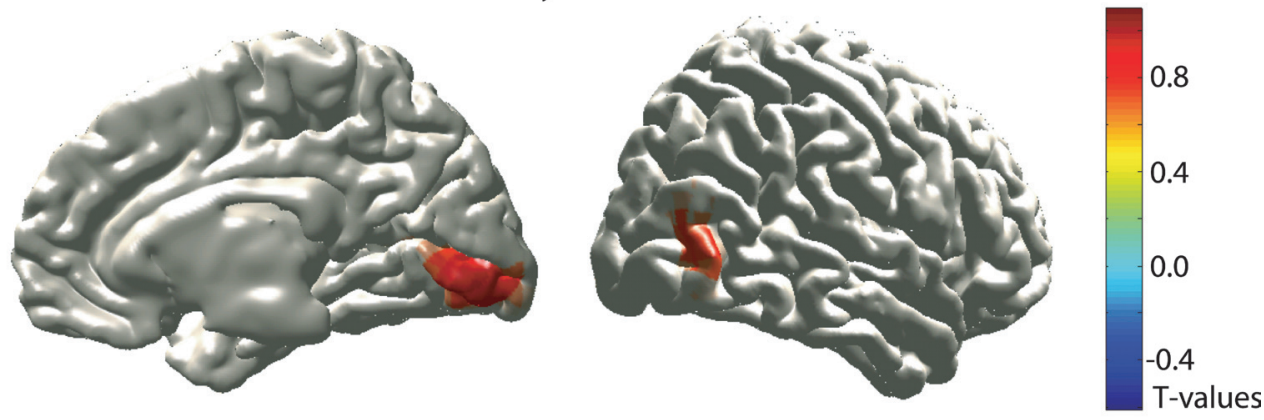

Figure 5. Results of statistical testing showing both increasing and decreasing attention effects.

Statistically significant clusters projected onto a template brain. Figure $5 \mathrm{a}$ and $5 \mathrm{~b}$ show the increasing effect of attention on response amplitude when the target stimulus is attended directly. a.) Representation of the increase in response amplitude when the target is attended compared to when attention is directed to a nearby distracter. b.) Representation of the increase in response amplitude when the target is attended compared to when attention is directed away. c.) Representation of the decreasing effect of attention on the response amplitude of the target stimulus when attention is directed to a stimulus located in close proximity. These findings provide evidence for biased competition in human visual cortex. 


\subsection{Data analysis}

All MEG data analysis was done in the Fieldtrip open source Matlab toolbox (http://www.ru.nl/fcdonders/fieldtrip/) that was developed at the F.C. Donders Centre for Cognitive Neuroimaging. Data epochs of interest were defined from the continuously recorded MEG. A timewindow from $500 \mathrm{~ms}$ after stimulus onset until 10.5 seconds after stimulus onset was selected in each trial. Data epochs containing eye movements or jump artifacts in the SQUIDs were discarded using semi-automatic artifact detection routines, accepting clean data epochs only if they were at least 5 seconds long. For subsequent data analysis we cut the trials into 5 seconds. To obtain epochs of this length we cut those trials being 10 seconds in two equal parts. From those trials with a length between 5 and 10 seconds, we selected only the first 5 seconds of the trial.

\section{Spectral analysis}

The frequency content of the signal was computed with the fast Fourier transform (FFT). To this end, the 5 -second data epochs were first Hanning-tapered. This yielded a spectral resolution of $0.2 \mathrm{~Hz} / \mathrm{bin}$. To quantify entrainment to the stimuli, we estimated the phase-locked power for each frequency bin centering around each stimulation frequency. This is equivalent to estimating the stimulus-locked amplitude in the time domain. The phase-locked power was estimated by aligning the phase of the estimated single epoch activity to the phase of one of the stimuli. These aligned Fourier transforms were subsequently averaged across all observations. The absolute value of this average was squared to obtain the phase-locked power.

For each subject we included only those frequency bins that showed entrainment to the stimuli. Entrainment was defined as a relative increase in phase-locked power of $100 \%$, with respect to the phase-locked power, averaged over all channels and frequencies ( 1 to $30 \mathrm{~Hz}$ ).

\section{Sourceanalysis}

For the analysis of the neuronal sources of the four spectral components, we used an adaptive spatial filtering technique (Gross et al., 2001). Each subject's brain volume was divided into a regular $5 \mathrm{~mm}$ grid and for each grid location, a spatial filter was constructed. This filter has the property that it optimally passes activity from the location of interest, while activity from other locations is suppressed. It is calculated by taking into account the forward model at the location of interest (the leadfield matrix) and the cross-spectral density between all MEG signal pairs 
at the frequency of interest. To compute the leadfield matrices, we used a singleshell headmodel, based on the shape of the inside of the skull (Nolte, 2003). The shape of the inside of the skull was derived from each individual subject's structural MRI, which was spatially aligned to the MEG sensors. We excluded the most silent direction from each leadfield, since this direction potentially picks up a lot of noise. The cross-spectral density matrix between all MEG signal pairs was computed from the single data epoch Fourier transforms. At each location in the grid, we estimated the activity by projecting the sensor level Fourier transforms through the spatial filter for that location. This yielded an estimate of the activity in three orthogonal directions. We estimated the orientation in which the activity was maximal and then projected the Fourier coefficients on this direction.

To quantify the effect of attention on the frequency tagged activity, we computed t-statistics of the phase-locked power in each voxel for three different contrasts. The variance estimate for the phase-locked power at each voxel was estimated using a jackknife procedure (Efron and Tibshirani, 1993). For each frequency we tested the three contrasts. To assess the effect of directing attention on the target we tested target versus near-distracter and target versus attend-away. To test the effect of attention on the competing stimulus we contrasted attendaway versus near-distracter. The attend-away condition contained twice as many trials as the other conditions. Due to the experimental paradigm, a given stimulus is defined in the attend-away condition in $50 \%$ of the trials, whereas it is a target or near-distracter only in $25 \%$ of the trials. To avoid a potential confounding effect of number of trials on the t-values, we split the distant condition into two equal subsets and computed two sets of t-values, for the contrasts containing the distant condition. All resulting t-values were transformed into Z-values, and the Zvalues of the contrast containing the distant condition were pooled. For each of the contrasts, we obtained a single volume of Z-values by accumulating the data of all selected frequency bins. Prior to accumulation, the Z-values corresponding to the two stimuli presented in the right visual field were mirrored in the sagittal plane. This was done to spatially align the attended locations. Each individual subject's volume of Z-values was smoothed with a $10 \mathrm{~mm}$ Gaussian kernel and normalized to a template brain, using SPM2 (http://www.fil.ion.ucl.ac.uk/spm/software/spm2).

\section{Group statistics}

The normalized volumes were accumulated across subjects, and we tested for each contrast whether the Z-values in the accumulated volumes differed significantly from zero. A statistical interpretation of the accumulated Z-values is not straightforward because of the large number of voxels to be tested and because the spatial correlation among them is not known precisely. Therefore, to 
identify source locations that were significantly different across the conditions, we adopted a non-parametric randomization approach (Nichols and Holmes, 2002). This procedure does not rely on an underlying distribution, and it allows for a solution to the multiple comparisons problem. For a given contrast, the null hypothesis states that there is no difference between the phase-locked power in the two conditions. Under this null hypothesis, flipping the sign of the Z-values of a random subset of the subjects before accumulating, leads to an alternative observation that belongs to the null-distribution. By repeating this procedure multiple times, a reference distribution of a test-statistic can be created for each voxel. We corrected for multiple comparisons by applying a weighted clusterstatistic. This cluster-statistic increases sensitivity by increasing the signal-to-noise ratio. For each randomly permuted volume, clusters of neighboring voxels were identified in which the individual voxels' p-value, as obtained from the voxellevel reference distribution, exceeded an a priori threshold. For each cluster we computed the weighted cluster mass (Hayasaka and Nichols, 2004) and we created a cluster mass reference distribution by taking the "heaviest" cluster for each randomization. The clusters in the observed data were tested against this reference distribution, yielding the probability of observing such a cluster of voxels under the null hypothesis. The choice of the a priori individual voxel threshold determines the shape and spatial extent of the voxel clusters in both the observed and the randomized data. To some extent, this choice is an arbitrary one. We used an a priori treshold of $\mathrm{p}<0.05$. It is important to note that the a priori threshold does not affect the false alarm rate of the statistical test (Nichols and Holmes, 2002). For visualization, the clusters of statistically significant voxels were projected onto a high resolution template brain, obtained from the Montreal Neurological Institute (Collins et al., 1998).

\section{3 | Results}

We measured MEG in 10 subjects while they directed attention to one of 4 presented stimuli flickering at different frequencies $(8.6,12,15$, and $20 \mathrm{~Hz})$. After artifact rejection, an experimental session yielded 296 (range 256 -327) five-second artifact-free data epochs on average. Subjects were asked to count the number of checkerboard changes that they observed in a target stimulus and to report this at the end of a trial. The average percent correct scores ranged from 50.0\% to $90.3 \%$, with a mean of $70.0 \%$ correct. This apparently low mean percent correct score can be explained by the accumulating difficulty of having multiple changes (zero to three) within one trial.

We observed clear entrainment of brain activity to the frequencies of 
stimulation. Figure 4 shows the lateralized distribution of phase-locked power on the MEG sensor array for one representative subject. The phase-locked power is averaged over the frequencies corresponding to stimuli presented in the same hemifield. All subjects showed entrainment to 8.6, 12, and $15 \mathrm{~Hz}$ stimulation. Four out of the ten subjects failed to show entrainment to $20 \mathrm{~Hz}$ stimulation and for these subjects this frequency bin was excluded from further analysis. The lack of showing $20 \mathrm{~Hz}$ entrainment might depend on task parameters, flicker frequency, position of the stimulus, or the cortical networks involved (Chen et al., 2003; Ding et al., 2006). One subject showed ipsilateral entrained brain activity over the occipital hemisphere when stimulating the right side of the visual field. With further inquiring, this subject turned out to be the only left handed subject in the experiment. We therefore cannot assume similar lateralization mechanism and excluded this subject from further analysis.

To assess the effect of attention on brain activity we analyzed the data on the source level using a beamformer technique. Figure 5 shows the results of the analysis of the contrasts between the target and near-distracter condition, the target and attend-away condition, and the attend-away and near-distracter condition. The figure shows the projection of the statistically significant clusters that show a difference between the conditions that is different from zero onto a template brain ( $\mathrm{p}<0.05$, corrected for multiple comparisons). The effect of directing attention to the target is shown by figures $5 \mathrm{a}$ and $5 \mathrm{~b}$. The amplitude of the response to the target is increased when attention is directed to it compared to when attention is directed away (see figure 5a). A similar increase in response amplitude to the target is found when this condition is compared to the neardistracter condition (see figure $5 \mathrm{~b}$ ). The location of the increase in response amplitude is mainly focused in extrastriate visual areas (figure $5 \mathrm{a}$ and b, lateral representation), but smaller response changes are also seen in the early visual areas (figure 5a, medial representations). Figure $5 \mathrm{c}$ demonstrates a significantly larger response amplitude to the target stimulus when attention is directed away as compared to when attention is directed to a nearby stimulus. The response difference is located in striate and extrastriate visual areas.

\section{4| Discussion}

This study investigated the presence of biased competition mechanisms in the human visual cortex by presenting two stimuli within one receptive field of a neuron in human visual cortex and measuring the response to each individual stimulus separately. We demonstrate that the response amplitude to a target stimulus is increased when this stimulus was attended compared to when attention 
was directed away. More interestingly, we observed a decrease in response amplitude to the target when a nearby distracter stimulus was attended compared to when attention was directed away. This indicates that the response to the target is suppressed when attention is directed to a nearby distracter. These findings can only be explained if we assume that there is competition between the two stimuli presented in the same hemifield. Directing attention to one of these stimuli will bias the response towards the response when the stimulus presented alone and will thereby - in this study - always increase the response to this stimulus. However, directing attention to the nearby competing stimulus biased the response to this nearby stimulus and decreased the influence of the target (non attended) stimulus, resulting in a decreased response amplitude compared to when attention was directed away.

The attention effect (both the increase and the decrease in response amplitude) was observed in visual brain areas contralateral to the side of stimulation. The maximal difference between the conditions in each contrast was located in extrastriate areas. This fits well with the hypothesis that attention modulates different brain areas depending on the scale of the relevant information (Reynolds et al., 1999). The stimuli presented in one hemifield span at least $5^{\circ}$ of visual angle, corresponding to the estimated RF size of neurons in area V4 in humans (Tootell et al., 1997; Kastner et al., 2001; Smith et al., 2001). The increase in response amplitude when attention was directed to the target stimulus is extended over a larger area than the decrease in response amplitude. This could be explained by a superposition of the effects of biased competition and attentional facilitation. Attention biases the response only in those areas containing neurons with a receptive field large enough to contain both stimuli. Attentional facilitation increases in addition response amplitudes to the attended response in those areas containing neurons who's receptive fields are too small to encompass both stimuli. The study presented here is not able to disentangle the response increments effects due to bias effect and attentional facilitation. This would only be possible when using more or less preferred stimuli and measuring the response to each of these stimuli. Nevertheless, we can conclude that these findings can be explained by biased competition. The inhibitory effect of the attentional bias on the competing stimulus can only be explained by biased competition, not by attentional facilitation.

In addition to activating extrastriate areas, the inhibition of attention on the response to the competing stimulus is also located in early visual areas. This was not expected since the stimuli are too large to fall into one receptive field of an area V1 neuron. One explanation for this finding is that the facing corners of both stimuli presented in one hemifield are spaced close enough to fall into one receptive field of a V1/V2 neuron. The minimal distance between the two stimuli 
was $0.6^{\circ}$, small enough to fall into the receptive field of a V1 neuron (Tootell et al., 1997; Kastner et al., 2001; Smith et al., 2001). This small amount of stimulation could well be enough to cause competition within this receptive field. However it is unclear why we did not observe the effect in all early visual areas (V1 to V4).

These studies are directly comparable to the findings of Reynolds et al. (1999). Until now, it has been difficult to replicate these findings in humans due to the non-selectivity of the current neuroimaging methods to individual stimuli in a multiple stimuli display. Reynolds et al. (1999) make use of the response selectivity of neurons in the visual cortex to show sensory interactions. Neurons respond more selectively to certain stimuli, i.e. the preferred stimuli, then to others, i.e. the non preferred stimuli. They measure the response of a neuron which is determined by weighted average of the inputs from neurons reflecting a preferred and non preferred stimulus. These input weights can be influenced by attentional bias. This approach is not applicable to human studies since usually no single cell responses can be measured. However, the study we present here is able distinguish the influence of attention on the weight of the input from neurons coding individual stimuli. Therefore, we are able to show direct evidence for the presence of biased competition as proposed by Desimone and Duncan (1995) in human visual cortex for the first time. 


\section{Chapter 0.6 | Summary}

This doctoral thesis investigates how a change in perception, brought about by task demand (visual masking) and behavioral modulation (attention) manifests itself in the neural dynamics of visual processing. Different approaches to investigate this theme are taken in the studies described in this thesis. The study in chapter 2 investigates how our visual awareness or conscious perception is modulated by the timing and spatial characteristics of visual input. It uses MEG (magnetoencephalography) to measure a change in brain response to masked or unmasked visual stimuli. Early components of visual evoked potentials (VEP) in EEG seem to be unaffected by target visibility in visual masking studies.

Bridgeman's reanalysis of Jeffreys and Musselwhite's (1986) data suggests that a later visual component in the VEP, around $250 \mathrm{~ms}$ reflects the perceptual effect of masking. We challenge this view on the ground that temporal interactions between targets and masks unrelated to stimulus visibility could account for Bridgeman's observation of a U-shaped time course in VEP amplitudes for this later component. In an MEG experiment of metacontrast masking with variable stimulus onset 
asynchrony, we introduce a proper control, a pseudo mask. In contrast to an effective mask, the pseudomask should produce neither behavioral masking nor amplitude modulations of late VEPs. Our results show that effective masks produced a strong U-shaped perceptual effect of target visibility while performance remained virtually perfect when a pseudomask was used. The visual components around $250 \mathrm{~ms}$ after target onset did not show a distinction between mask and pseudomask conditions. The results indicate that these visual evoked potentials do not reveal neurophysiological correlates of stimulus visibility but rather reflect dynamic interactions between superimposed potentials elicited by stimuli in close temporal proximity.

However, we observed a postperceptual component around $340 \mathrm{~ms}$ after target onset, located over temporal-parietal cortex, which shows a clear effect of visibility. Based on P300 ERP literature, this finding could indicate that working memory related processes contribute to metacontrast masking.

The studies in chapters 3 to 5 focus on the effect of visual attention on perception and brain dynamics. Our visual world is so complex that our brain cannot process all visual information that enters the visual system simultaneously. Chapter 3 investigates how objects which are organized in a hierarchical manner are processed. Studies using hierarchical letter stimuli (a large letter composed of smaller letters) suggest that processing of a visual scene is global tolocal, a phenomenon known as the global precedence effect. Elaborating on this global-tolocal hypothesis we tested whether global interference will increase with increasing level of globality. For this, we used triple level hierarchical letter stimuli with a global, middle, and local level. When attending to the local level of the stimulus only the middle level showed an interference effect whereas the global level did not interfere at all. We argue that considering the perceptual and attentional contributions to this effect the hypothesis of global-to-local processing of a visual scene may only hold within a limited spatial attentional window.

In the brain, attentional processing has been related to the modulation of activation in brain areas corresponding to the attended spatial location. The attentional modulation however may hold not only for the spatial organization of visual brain areas, but also for the receptive field size properties of our visual system. Neurons in higher visual areas have large receptive fields usually spanning much of the central visual field. This may lead to processing problems when multiple stimuli fall within a single receptive field. Previous single cell studies in monkeys have suggested that multiple stimuli compete for neural representation and that attentional processes can bias this competition in favor of the attended stimulus. The consequence of this biased competition model of selective attention is that attentional effects are dependent on the relation between stimulus size and receptive field size, i.e. visual area. Visual attention enhances activation in different 
brain areas depending on the spatial scale of the relevant information, but the link of attended spatial scale to receptive field size has not been established. The study in chapter 4 demonstrates that attention to large or small objects in a visual scene increases activation specifically in brain regions with correspondingly large or small receptive field sizes, as measured independently by functional Magnetic Resonance Imaging in humans. Our results are in line with measurements of receptive fields and functional architecture of visual cortex in monkeys. Also, we confirm predictions of models of selective attention, which state that attentional modulation of visual processing critically depends on the receptive field size of neurons across the visual cortex. We conclude that selective visual attention modulates brain areas with specific neuronal receptive field size properties that are most suitable for the task at hand. This adds to the previously described spatially specific attentional effects and further enhances our understanding of visual attention.

The evidence for the biased competition model of selective attention has come mainly from single cell studies in animals. Studies of the human visual cortex show results that could be taken as support for this mechanism, but none of these studies have provided direct evidence of biased competition in human visual cortex. In this MEG study we used frequency tagging for four simultaneously presented stimuli to be able to separate the responses to each individual stimulus. In this way we can assess the effect of attention on the competition between two stimuli assumed to be presented in the same receptive field. Our results show that attention to a target stimulus increases the response to this stimulus compared to when attention was directed away. Moreover, when directing attention to a nearby distracter stimulus presented in assumingly the same receptive field, the response to the target was decreased compared to when attention was directed away. This indicates that attention biases the competition by influencing the output of each competing stimulus and thereby determines which of the outputs dominates the subsequent response. We conclude that these findings are the first ones to show direct evidence of biased competition in human visual cortex. 



\section{Reference list |}

Aalderen-Smeets van, S. I., Oostenveld, R., \& Schwarzbach, J. (2006).

Investigating neurophysiological correlates of metacontrast masking with magnetoencephalography. Advances in Cognitive Psychology, 2, 21-35.

Alpern, m. (1953). Metacontrast. Journal of the Optical Society of America, 43, 648-657.

Amirkhiabani, G. \& Lovegrove, W. J. (1996). Role of eccentricity and size in the global precedence effect. Journal of Experimental Psychology-Human Perception and Performance, 22, 1434-1447.

Amirkhiabani, G. \& Lovegrove, W. J. (1999). Do the global advantage and interference effects covary? Percept.Psychophys., 61, 1308-1319.

Andreassi, J. L., De Simone, J. J., \& Mellers, B. W. (1976). Amplitude changes in the visual evoked cortical potential with backward masking. Electroencephalogr.Clin.Neurophysiol, 41, 387-398.

Bandettini, P. A., Birn, R. M., \& Donahue, K. M. (2000). Functional MRI: background, methodology, limits, and implementation. In J.T.Cacioppo, L. G. Tassinary, \& G. G. Berntson (Eds.), Handbook of Psychophysiology ( Cambridge: Cambridge University Press. 
Bar, M., Tootell, R. B., Schacter, D. L., Greve, D. N., Fischl, B., Mendola, J. D. et al. (2001). Cortical mechanisms specific to explicit visual object recognition. Neuron, 29, 529-535.

Blanca, M. J., Luna, R., Lopez-Montiel, D., Zalabardo, C., \& Rando, B. (2002). Effect of the similarity between target and global and local levels in hierarchical stimuli processing. Psychol.Res., 66, 124-132.

Bles, M., Schwarzbach, J., De Weerd, P., Goebel, R., \& Jansma, B. M. (2006). Receptive field size-dependent attention effects in simultaneously presented stimulus displays. Neuroimage, 30, 506-511.

Boussaoud, D., Desimone, R., \& Ungerleider, L. G. (1991). Visual Topography of Area Teo in the Macaque. Journal of Comparative Neurology, 306, 554575 .

Brefczynski, J. A. \& Deyoe, E. A. (1999). A physiological correlate of the 'spotlight' of visual attention. Nature Neuroscience, 2, 370-374.

Breitmeyer, B. G., Rudd, M., \& Dunn, K. (1981). Metacontrast investigations of sustained-transient channel inhibitory interactions. J Exp.Psychol.Hum. Percept.Perform., 7, 770-779.

Breitmeyer, B. G. (1984). Visual Masking: An integrative Approach. New York: Oxford University Press.

Breitmeyer, B. G. \& Ogmen, H. (2000). Recent models and findings in visual backward masking: a comparison, review, and update. Percept. Psychophys., 62, 1572-1595.

Bridgeman, B. (1975). Correlates of metacontrast in single cells of the cat visual system. Vision Res., 15, 91-99.

Bridgeman, B. (1980). Temporal response characteristics of cells in monkey striate cortex measured with metacontrast masking and brightness discrimination. Brain Res., 196, 347-364.

Bridgeman, B. (1988). Visual evoked potentials: concomitants of metacontrast in late components. Percept.Psychophys., 43, 401-403.

Broadbent, D. (1958). Perception and Communication. London: Pergamon Press.

Cave, K. R. \& Bichot, N. P. (1999). Visuospatial attention: Beyond a spotlight model. Psychonomic Bulletin \& Review, 6, 204-223.

Chen, Y., Seth, A. K., Gally, J. A., \& Edelman, G. M. (2003). The power of human brain magnetoencephalographic signals can be modulated up or down by changes in an attentive visual task. Proc.Natl.Acad.Sci.U.S.A, 100, 35013506.

Collins, D. L., Zijdenbos, A. P., Kollokian, V., Sled, J. G., Kabani, N. J., Holmes, C. J. et al. (1998). Design and construction of a realistic digital brain phantom. IEEE Trans.Med.Imaging, 17, 463-468.

Conner, C. E., Preddie, D. C., Gallant, J. L., \& VanEssen, D. C. (1997). Spatial 
attention effects in macaque area V4. Journal of Neuroscience, 17, 32013214 .

Dehaene, S., Naccache, L., Le Clec'H, G., Koechlin, E., Mueller, M., DehaeneLambertz, G. et al. (1998). Imaging unconscious semantic priming. Nature, 395, 597-600.

Desimone, R. \& Duncan, J. (1995). Neural Mechanisms of Selective VisualAttention. Annual Review of Neuroscience, 18, 193-222.

Ding, J., Sperling, G., \& Srinivasan, R. (2006). Attentional modulation of SSVEP power depends on the network tagged by the flicker frequency. Cereb. Cortex, 16, 1016-1029.

Driver, J. (1995). Object segmentation and visual neglect. Behav.Brain Res., 71, 135-146.

Efron, B. \& Tibshirani, R. J. (1993). An introduction to the bootstrap. Chapman \& Hall/CRC.

Engel, A. K., Fries, P., \& Singer, W. (2001). Dynamic predictions: oscillations and synchrony in top-down processing. Nat.Rev.Neurosci., 2, 704-716.

Engel, A. K. \& Singer, W. (2001). Temporal binding and the neural correlates of sensory awareness. Trends Cogn Sci., 5, 16-25.

Enns, J. T. \& Di, L., V (2000). What's new in visual masking? Trends Cogn Sci., 4, 345-352.

Eriksen, B. A. \& Hoffman, J. E. (1973). The extent of processing of noise elements during selective encoding from visual displays. Percept.Psychophys., 14, 155-160.

Eriksen, B. A. \& Eriksen, C. W. (1974). Effects of Noise Letters Upon Identification of A Target Letter in A Nonsearch Task. Perception \& Psychophysics, 16, 143-149.

Eriksen, C. W. \& St James, J. D. (1986). Visual attention within and around the field of focal attention: a zoom lens model. Percept.Psychophys., 40, 225240.

Felleman, D. J. \& Van Essen, D. C. (1991). Distributed hierarchical processing in the primate cerebral cortex. Cereb.Cortex, 1, 1-47.

Fink, G. R., Halligan, P. W., Marshall, J. C., Frith, C. D., Frackowiak, R. S. J., \& Dolan, R. J. (1996). Where in the brain does visual attention select the forest and the trees? Nature, 382, 626-628.

Fink, G. R., Marshall, J. C., Halligan, P. W., \& Dolan, R. J. (1999). Hemispheric asymmetries in global/local processing are modulated by perceptual salience. Neuropsychologia, 37, 31-40.

Fries, P., Reynolds, J. H., Rorie, A. E., \& Desimone, R. (2001). Modulation of oscillatory neuronal synchronization by selective visual attention. Science, 291, 1560-1563. 
Gandhi, S. P., Heeger, D. J., \& Boynton, G. M. (1999). Spatial attention affects brain activity in human primary visual cortex (vol 96, pg 3314, 1999). Proceedings of the National Academy of Sciences of the United States of America, 96, 7610 .

Gattass, R., Nascimento-Silva, S., Soares, J. G. M., Lima, B., Jansen, A. K., Diogo, A. C. M. et al. (2005). Cortical visual areas in monkeys: location, topography, connections, columns, plasticity and cortical dynamics. Philosophical Transactions of the Royal Society B-Biological Sciences, 360, 709-731.

Grabowska, A. \& Nowicka, A. (1996). Visual-spatial-frequency model of cerebral asymmetry: a critical survey of behavioral and electrophysiological studies. Psychol.Bull., 120, 434-449.

Greaney, J. \& Macrae, A. W. (1992). The Order of Visual Processing - Top-Down, Bottom-Up, Middle-Out, Or None of These. Bulletin of the Psychonomic Society, 30, 255-257.

Grill-Spector, K., Kushnir, T., Hendler, T., \& Malach, R. (2000). The dynamics of object-selective activation correlate with recognition performance in humans. Nat.Neurosci., 3, 837-843.

Gross, J., Kujala, J., Hamalainen, M., Timmermann, L., Schnitzler, A., \& Salmelin, R. (2001). Dynamic imaging of coherent sources: Studying neural interactions in the human brain. Proc.Natl.Acad.Sci.U.S.A, 98, 694-699.

Han, S. H., Jiang, Y., \& Gu, H. (2004). Neural substrates differentiating global/ local processing of bilateral visual inputs. Human Brain Mapping, 22, 321328.

Hayasaka, S. \& Nichols, T. E. (2004). Combining voxel intensity and cluster extent with permutation test framework. Neuroimage, 23, 54-63.

Haynes, J. D., Driver, J., \& Rees, G. (2005). Visibility reflects dynamic changes of effective connectivity between V1 and fusiform cortex. Neuron, 46, 811-821.

Hämäläinen, M. S. (1992). Magnetoencephalography: a tool for functional brain imaging. Brain Topogr., 5, 95-102.

Heinze, H. J., Mangun, G. R., Burchert, W., Hinrichs, H., Scholz, M., Munte, T. F. et al. (1994). Combined Spatial and Temporal Imaging of Brain Activity During Visual Selective Attention in Humans. Nature, 372, 543-546.

Hoffman, J. E. (1980). Interaction Between Global and Local-Levels of A Form. Journal of Experimental Psychology-Human Perception and Performance, 6, 222-234.

Hopf, J. M., Boehler, C. N., Luck, S. J., Tsotsos, J. K., Heinze, H. J., \& Schoenfeld, M. A. (2006). Direct neurophysiological evidence for spatial suppression surrounding the focus of attention in vision. Proc.Natl.Acad.Sci.U.S.A, 103, 1053-1058. 
Hopf, J. M., Luck, S. J., Boelmans, K., Schoenfeld, M. A., Boehler, C. N., Rieger, J. et al. (2006). The neural site of attention matches the spatial scale of perception. Journal of Neuroscience, 26, 3532-3540.

Hubel, D. H. \& Wiesel, T. N. (1968). Receptive Fields and Functional Architecture of Monkey Striate Cortex. Journal of Physiology-London, 195, 215-\&.

Hughes, H. C. \& Zimba, L. D. (1985). Spatial maps of directed visual attention. J Exp.Psychol.Hum.Percept.Perform., 11, 409-430.

James, W. (2006). Principles of Psychology.

Jeffreys, D. A. (1971). Cortical source locations of pattern-related visual evoked potentials recorded from the human scalp. Nature, 229, 502-504.

Jeffreys, D. A. \& Axford, J. G. (1972). Source locations of pattern-specific components of human visual evoked potentials. I. Component of striate cortical origin. Exp.Brain Res., 16, 1-21.

Jeffreys, D. A. \& Musselwhite, M. J. (1986). A visual evoked potential study of metacontrast masking. Vision Res., 26, 631-642.

Kanwisher, N., McDermott, J., \& Chun, M. M. (1997). The fusiform face area: a module in human extrastriate cortex specialized for face perception. $\mathrm{J}$ Neurosci., 17, 4302-4311.

Kastner, S., De Weerd, P., Desimone, R., \& Ungerleider, L. C. (1998). Mechanisms of directed attention in the human extrastriate cortex as revealed by functional MRI. Science, 282, 108-111.

Kastner, S., Pinsk, M. A., De Weerd, P., Desimone, R., \& Ungerleider, L. G. (1999). Increased activity in human visual cortex during directed attention in the absence of visual stimulation. Neuron, 22, 751-761.

Kastner, S., De Weerd, P., Pinsk, M. A., Elizondo, M. I., Desimone, R., \& Ungerleider, L. G. (2001). Modulation of sensory suppression: Implications for receptive field sizes in the human visual cortex. Journal of Neurophysiology, 86, 1398-1411.

Kim, N., Ivry, R. B., \& Robertson, L. C. (1999). Sequential priming in hierarchically organized figures: effects of target level and target resolution. J Exp. Psychol.Hum.Percept.Perform., 25, 715-729.

Kimchi, R. (1992). Primacy of Wholistic Processing and Global Local Paradigm - A Critical-Review. Psychological Bulletin, 112, 24-38.

Kimchi, R. (1998). Uniform connectedness and grouping in the perceptual organization of hierarchical patterns. J Exp.Psychol.Hum.Percept. Perform., 24, 1105-1118.

Kinchla, R. A. \& Wolfe, J. M. (1979). The order of visual processing: “Top-down,” "bottom-up”, or “middle-out”. Percept.Psychophys., 25, 225-231.

Kinchla, R. A., Solis-Macias, V., \& Hoffman, J. (1983). Attending to different levels of structure in a visual image. Percept.Psychophys., 33, 1-10. 
Knösche, T. R. (2002). Transformation of whole-head MEG recordings between different sensor positions. Biomed.Tech.(Berl), 47, 59-62.

Kok, A. (2001). On the utility of $\mathrm{P}_{3}$ amplitude as a measure of processing capacity. Psychophysiology, 38, 557-577.

Kovacs, G., Vogels, R., \& Orban, G. A. (1995). Cortical correlate of pattern backward masking. Proc.Natl.Acad.Sci.U.S.A, 92, 5587-5591.

Kranczioch, C., Debener, S., \& Engel, A. K. (2003). Event-related potential correlates of the attentional blink phenomenon. Brain Res.Cogn Brain Res., $17,177-187$.

Lachter, J., Durgin, F., \& Washington, T. (2000). Disappearing percepts: Evidence for retention failure in metacontrast masking. Visual Cognition, 7, 269-279.

LaGasse, L. L. (1993). Effects of good form and spatial frequency on global precedence. Percept.Psychophys., 53, 89-105.

Lamb, M. R. \& Robertson, L. C. (1988). The processing of hierarchical stimuli: effects of retinal locus, locational uncertainty, and stimulus identity. Percept.Psychophys., 44, 172-181.

Lamb, M. R. \& Robertson, L. C. (1990). The effect of visual angle on global and local reaction times depends on the set of visual angles presented. Percept. Psychophys., 47, 489-496.

Lamme, V. A. F., Super, H., \& Spekreijse, H. (1998). Feedforward, horizontal, and feedback processing in the visual cortex. Current Opinion in Neurobiology, 8, 529-535.

Lamme, V. A. F. \& Roelfsema, P. R. (2000). The distinct modes of vision offered by feedforward and recurrent processing. Trends Neurosci., 23, 571-579.

Logothetis, N. K., Pauls, J., Augath, M., Trinath, T., \& Oeltermann, A. (2001). Neurophysiological investigation of the basis of the fMRI signal. Nature, 412, 150-157.

Luck, S. J., Chelazzi, L., Hillyard, S. A., \& Desimone, R. (1997). Neural mechanisms of spatial selective attention in areas $\mathrm{V}_{1}, \mathrm{~V} 2$, and $\mathrm{V}_{4}$ of macaque visual cortex. Journal of Neurophysiology, 77, 24-42.

Matthews, P. (2001). An introduction to functional magnetic resonance imaging of the brain. In P.Jezzard, P. Matthews, \& S. M. Smith (Eds.), Functional MRI: An introduction to the methods ( Oxford: Oxford University Press.

Maunsell, J. H. (1995). The brain's visual world: representation of visual targets in cerebral cortex. Science, 270, 764-769.

Maunsell, J. H. R. \& Newsome, W. T. (1987). Visual Processing in Monkey Extrastriate Cortex. Annual Review of Neuroscience, 10, 363-401.

McAdams, C. J. \& Maunsell, J. H. (1999). Effects of attention on orientation-tuning functions of single neurons in macaque cortical area V4. J Neurosci., 19, 431-441. 
Miller, E. K., Li, L., \& Desimone, R. (1993). Activity of neurons in anterior inferior temporal cortex during a short-term memory task. J Neurosci., 13, 14601478.

Miller, J. (1981). Global precedence in attention and decision. J Exp.Psychol.Hum. Percept.Perform., 7, 1161-1174.

Milner, A. D. \& Goodale, M. A. (1995). The Visual Brain in Action. Oxford: Oxford University Press.

Moran, J. \& Desimone, R. (1985). Selective attention gates visual processing in the extrastriate cortex. Science, 229, 782-784.

Morgan, S. T., Hansen, J. C., \& Hillyard, S. A. (1996). Selective attention to stimulus location modulates the steady-state visual evoked potential. Proc. Natl.Acad.Sci.U.S.A, 93, 4770-4774.

Morrison, D. J. \& Schyns, P. G. (2001). Usage of spatial scales for the categorization of faces, objects, and scenes. Psychon.Bull.Rev., 8, 454-469.

Motter, B. C. (1993). Focal attention produces spatially selective processing in visual cortical areas $\mathrm{V}_{1}, \mathrm{~V}_{2}$, and $\mathrm{V}_{4}$ in the presence of competing stimuli. Journal of Neurophysiology, 70, 909-919.

Muller, M. M., Picton, T. W., Valdes-Sosa, P., Riera, J., Teder-Salejarvi, W. A., \& Hillyard, S. A. (1998). Effects of spatial selective attention on the steadystate visual evoked potential in the $20-28 \mathrm{~Hz}$ range. Brain Res.Cogn Brain Res., 6, 249-261.

Müller, M. M., Malinowski, P., Gruber, T., \& Hillyard, S. A. (2003). Sustained division of the attentional spotlight. Nature, 424, 309-312.

Müller, N. G., Bartelt, O. A., Donner, T. H., Villringer, A., \& Brandt, S. A. (2003). A physiological correlate of the "Zoom Lens" of visual attention. J Neurosci., 23, 3561-3565.

Müller, N. G. \& Kleinschmidt, A. (2004). The attentional 'spotlight's' penumbra: center-surround modulation in striate cortex. Neuroreport, 15, 977-980.

Müller, N. G., Mollenhauer, M., Rosler, A., \& Kleinschmidt, A. (2005). The attentional field has a Mexican hat distribution. Vision Res., 45, 1129-1137.

Navon, D. (1977). Forest Before Trees - Precedence of Global Features in VisualPerception. Cognitive Psychology, 9, 353-383.

Navon, D. (1981). The Forest Revisited - More on Global Precedence. Psychological Research-Psychologische Forschung, 43, 1-32.

Navon, D. (2003). What does a compound letter tell the psychologist's mind? Acta Psychol.(Amst), 114, 273-309.

Neumann, O. \& Klotz, W. (1994). In C.Umilta \& M. Moscovitch (Eds.), Attention and Performance (15 ed., pp. 124-150). MIT Press, Cambrigde, MA.

Nichols, T. E. \& Holmes, A. P. (2002). Nonparametric permutation tests for functional neuroimaging: a primer with examples. Hum.Brain Mapp., 15, 
1-25.

Nolte, G. (2003). The magnetic lead field theorem in the quasi-static approximation and its use for magnetoencephalography forward calculation in realistic volume conductors. Phys.Med.Biol., 48, 3637-3652.

Nunez, P. L. (2000). Toward a quantitative description of large-scale neocortical dynamic function and EEG. Behav.Brain Sci., 23, 371-398.

O’Craven, K. M., Downing, P. E., \& Kanwisher, N. (1999). fMRI evidence for objects as the units of attentional selection. Nature, 401, 584-587.

Ogawa, S., Tank, D. W., Menon, R., Ellermann, J. M., Kim, S. G., Merkle, H. et al. (1992). Intrinsic signal changes accompanying sensory stimulation: functional brain mapping with magnetic resonance imaging. Proc.Natl. Acad.Sci.U.S.A, 89, 5951-5955.

Orrison, W., Lawine, J., Sanders, J., \& Hartshorne, M. (1995). In Functional Brain Imaging ( Mosby-Year book.

Paquet, L. \& Merikle, P. M. (1984). Global Precedence - the Effect of Exposure Duration. Canadian Journal of Psychology-Revue Canadienne de Psychologie, 38, 45-53.

Pinsk, M. A., Doniger, G. M., \& Kastner, S. (2004). Push-Pull Mechanism of Selective Attention in Human Extrastriate Cortex. Journal of Neurophysiology, 92, 622-629.

Posner, M. I., Snyder, C. R., \& Davidson, B. J. (1980). Attention and the detection of signals. J Exp.Psychol., 109, 160-174.

Posner, M. I. \& Petersen, S. E. (1990). The Attention System of the Human Brain. Annual Review of Neuroscience, 13, 25-42.

Reynolds, J. H., Chelazzi, L., \& Desimone, R. (1999). Competitive mechanisms subserve attention in macaque areas V2 and V4. J Neurosci., 19, 1736-1753.

Ro, T., Breitmeyer, B., Burton, P., Singhal, N. S., \& Lane, D. (2003). Feedback contributions to visual awareness in human occipital cortex. Curr.Biol., 13, 1038-1041.

Robertson, L. C. \& Lamb, M. R. (1991). Neuropsychological contributions to theories of part/whole organization. Cognit.Psychol., 23, 299-330.

Rolke, B., Heil, M., Streb, J., \& Hennighausen, E. (2001). Missed prime words within the attentional blink evoke an N400 semantic priming effect. Psychophysiology, 38, 165-174.

Rolls, E. T., Tovee, M. J., \& Panzeri, S. (1999). The neurophysiology of backward visual masking: information analysis. J Cogn Neurosci., 11, 300-311.

Sasaki, Y., Hadjikhani, N., Fischl, B., Liu, A. K., Marret, S., Dale, A. M. et al. (2001). Local and global attention are mapped retinotopically in human occipital cortex. Proceedings of the National Academy of Sciences of the United States of America, 98, 2077-2082. 
Scherg, M. (1990). Fundamentals of dipole source potential analysis. In F.H.M.R.G.L.Grandori (Ed.), Auditory evoked magnetic fields and electric potentials (pp. 40-69). Basel: Karger.

Schiller, P. H. \& Chorover, S. L. (1966). Metacontrast: its relation to evoked potentials. Science, 153, 1398-1400.

Sereno, M. I., Dale, A. M., Reppas, J. B., Kwong, K. K., Belliveau, J. W., Brady, T. J. et al. (1995). Borders of Multiple Visual Areas in Humans Revealed by Functional Magnetic-Resonance-Imaging. Science, 268, 889-893.

Slotnick, S. D., Hopfinger, J. B., Klein, S. A., \& Sutter, E. E. (2002). Darkness beyond the light: attentional inhibition surrounding the classic spotlight. Neuroreport, 13, 773-778.

Smith, A. T., Singh, K. D., Williams, A. L., \& Greenlee, M. W. (2001). Estimating receptive field size from fMRI data in human striate and extrastriate visual cortex. Cerebral Cortex, 11, 1182-1190.

Stoffer, T. H. (1991). Processing of Hierarchical Stimulus Patterns with 3 LevelsTest of the Navon Perceptual Precedence Hypothesis. Zeitschrift fur Experimentelle und Angewandte Psychologie, 38, 113-148.

Stoffer, T. H. (1994). Attentional Zooming and the Global-Dominance Phenomenon Effects of Level-Specific Cueing and Abrupt Visual Onset. Psychological Research-Psychologische Forschung, 56, 83-98.

Tallon-Baudry, C. \& Bertrand, O. (1999). Oscillatory gamma activity in humans and its role in object representation. Trends Cogn Sci., 3, 151-162.

Tootell, R. B. H., Dale, A. M., Sereno, M. I., \& Malach, R. (1996). New images from human visual cortex. Trends Neurosci., 19, 481-489.

Tootell, R. B. H., Mendola, J. D., Hadjikhani, N. K., Ledden, P. J., Liu, A. K., Reppas, J. B. et al. (1997). Functional analysis of V3A and related areas in human visual cortex. Journal of Neuroscience, 17, 7060-7078.

Tootell, R. B. H., Hadjikhani, N., Hall, E. K., Marrett, S., Vanduffel, W., Vaughan, J. T. et al. (1998). The retinotopy of visual spatial attention. Neuron, 21, 1409-1422.

Treisman, A. (1969). Strategies and Models of Selective Attention. Psychological Review, 76, 282-\&.

Treisman, A. \& Schmidt, H. (1982). Illusory conjunctions in the perception of objects. Cognit.Psychol., 14, 107-141.

Treisman, A. \& Gormican, S. (1988). Feature analysis in early vision: evidence from search asymmetries. Psychol.Rev., 95, 15-48.

Treue, S. \& Maunsell, J. H. R. (1996). Attentional modulation of visual motion processing in cortical areas MT and MST. Nature, 382, 539-541.

VanEssen, D. C., Newsome, W. T., \& Maunsell, J. H. R. (1984). The Visual-Field Representation in Striate Cortex of the Macaque Monkey - Asymmetries, 
Anisotropies, and Individual Variability. Vision Research, 24, 429-448.

Vaughan, H. G., Jr. \& Silverstein, L. (1968). Metacontrast and evoked potentials: a reappraisal. Science, 160, 207-208.

Vogel, E. K., Luck, S. J., \& Shapiro, K. L. (1998). Electrophysiological evidence for a postperceptual locus of suppression during the attentional blink. J Exp. Psychol.Hum.Percept.Perform., 24, 1656-1674.

Vorberg, D., Mattler, U., Heinecke, A., Schmidt, T., \& Schwarzbach, J. (2003).

Different time courses for visual perception and action priming. Proc.Natl. Acad.Sci.U.S.A, 100, 6275-6280.

Ward, L. M. (1982). Determinants of attention to local and global features of visual forms. J Exp.Psychol.Hum.Percept.Perform., 8, 562-581.

Weissman, D. H., Mangun, G. R., \& Woldorff, M. G. (2002). A role for top-down attentional orienting during interference between global and local aspects of hierarchical stimuli. Neuroimage, 17, 1266-1276.

Yovel, G., Levy, J., \& Yovel, I. (2001). Hemispheric asymmetries for global and local visual perception: effects of stimulus and task factors. J Exp.Psychol.Hum. Percept.Perform., 27, 1369-1385.

Zeki, S. M. (1978). Uniformity and Diversity of Structure and Function in RhesusMonkey Prestriate Visual-Cortex. Journal of Physiology-London, 277, 273290. 


\section{Nederlandse samenvatting | Neurale dynamiek van visuele selectie}

Veel mensen gaan er van uit dat wat we zien daadwerkelijk bestaat. Vandaar het gezegde: "eerst zien en dan geloven". Maar dit is niet helemaal waar. Visuele perceptie is geen camera die de buitenwereld passief registreert maar is een actief hersenproces dat de beelden die wij waarnemen creëert. Tijdens dat proces worden bepaalde aspecten van de visuele input benadrukt of juist weggelaten. Door deze actieve constructie van onze waarneming kunnen we omgaan met de overvloed aan visuele informatie in ons dagelijks leven. Dit proces zorgt er bijvoorbeeld voor dat we niet denken dat iemand groeit als het beeld op ons netvlies van die persoon groter wordt. We weten en zien dat die persoon naar ons toe loopt en dichterbij komt. Onze hersenen integreren de visuele input met informatie uit de omgeving en uit het lange termijn geheugen. Hoe de hersenen omgaan met visuele informatie en hoe de verwerking van die informatie verloopt, is het onderwerp van dit proefschrift. De centrale vraag is hoe een verandering in waarneming, veroorzaakt door een gedragstaak (visuele maskering) of door een gedragsverandering (aandachtsverandering), zich terug laat zien in de neurale dynamiek van visuele 
verwerking in de hersenen.

Hoofdstuk 2 onderzoekt een fenomeen dat voortkomt uit dit actieve verwerkingsproces van visuele informatie. Dit fenomeen is visuele maskering en refereert naar de afnemende zichtbaarheid van een doelwit stimulus wanneer er een tweede stimulus wordt aangeboden die zich in tijd en ruimte dicht in de buurt van het doelwit bevindt. Eerder onderzoek heeft duidelijk gemaakt dat ondanks dat de doelwit stimulus niet zichtbaar is, deze wel in staat is om later gedrag te beïnvloeden. Dit impliceert dat de onzichtbare stimulus wel verwerkt wordt. Het is nog onduidelijk hoe de twee stimuli elkaar beïnvloeden zodat de zichtbaarheid van het doelwit afneemt. Wij gebruiken MEG om de verandering in hersenactiviteit te meten als de doelwit stimulus onzichtbaar is in vergelijking met als deze wel zichtbaar is. Vroege componenten van visueel opgeroepen potentialen (VEP) gemeten met EEG lijken niet anders te zijn met meer of mindere zichtbaarheid van het doelwit. Bridgeman suggereert, gebaseerd op data van Jeffreys and Musselwhite (1986), dat een later visuele component in het VEP, rond de $250 \mathrm{ms,}$ de zichtbaarheid van het doelwit reflecteert. Wij plaatsen vraagtekens bij deze conclusie. Temporele interacties tussen de doelwit stimulus en de maskerende stimulus, die niet gerelateerd zijn aan de zichtbaarheid van de stimulus, kunnen ook het effect verklaren wat Bridgeman heeft gevonden. Dit effect is een Uvormig verloop van de VEP amplitude in de tijd van dit latere component. Wij introduceren een passende controle stimulus in een MEG experiment aangaande metacontrast maskering met variabele stimulus aanvang asynchronie, namelijk een pseudo-maskeringstimulus. Deze pseudo stimulus zal, in contrast met de effectieve maskeringstimulus, geen effect hebben op de zichtbaarheid van de doelwit stimulus of op de amplitude van het MEG signaal. De resultaten laten zien dat de effectieve maskeringstimulus een sterk U-vormig waarnemingseffect heeft op de zichtbaarheid van de doelwit stimulus, terwijl de pseudo stimulus daar geen enkel effect op heeft. De late VEP component, rond de $250 \mathrm{~ms}$ na stimulus aanvang, laat geen verschil zien tussen de effectieve en pseudo maskeringstimulus condities. Dit resultaat impliceert dat dit VEP geen neurofysiologisch correlaat is van de zichtbaarheid van de stimulus, maar dat dit VEP de dynamische temporele interacties tussen het doelwit en de maskeringstimulus reflecteert. Echter, we hebben een post-perceptuele component gevonden, rond de $340 \mathrm{~ms}$ na doelwit aanvang en gelokaliseerd in de temporele-parietele hersenkwab, dat een duidelijk effect laat zien van de zichtbaarheid van het doelwit. Gebaseerd op P3oo literatuur zou deze bevinding kunnen impliceren dat er werkgeheugen processen ten grondslag liggen aan het fenomeen van visuele maskering.

Onze bewuste waarneming wordt niet alleen anders door veranderende karakteristieken van de visuele input verandert, maar ook door selectieve aandachtsprocessen. Onze visuele wereld is zo vol met objecten en informatie dat 
we niet alle informatie kunnen verwerken. Selectieve aandacht is het mechanisme dat delen van de input selecteert voor bewuste verwerking. De studies in hoofdstuk 3 tot en met 5 richten zich op het effect dat selectieve aandacht heeft op visuele waarneming en hersendynamiek. Een belangrijk onderwerp binnen aandachtsonderzoek is de allocatie (toekenning) van aandacht aan de structuur van het visuele veld en de delen waaruit deze bestaat. Onze visuele wereld is hiërarchisch georganiseerd, vergelijkbaar met de metafoor van de bomen en het bos (Navon, 1977). De perceptuele relatie tussen het globale niveau van een object (het bos) en het lokale niveau van een object (de bomen) werpt de vraag op wat eerst komt: de verwerking van het globale niveau of de verwerking van het lokale niveau waarbij de afzonderlijke delen later worden samengevoegd tot het globale niveau. Hoofdstuk 3 onderzoekt hoe objecten die uit meerdere niveaus bestaan verwerkt worden. Studies die hiërarchische letter objecten gebruiken (een grote letter die uit kleinere letters bestaat) suggereren dat eerst het globale niveau verwerkt wordt en daarna pas het lokale niveau, een fenomeen dat het globale voorrangseffect genoemd wordt. Verdergaand op deze globaal-naar-lokaal hypothese testen wij of het globale voorrangseffect groter wordt met een groter niveau van globaliteit. Hiervoor gebruikten wij een 3-laags hiërarchische letter stimulus die uit een globaal, een midden en een lokaal niveau bestaat. Waneer aandacht op het lokale niveau gericht wordt zorgt alleen het midden niveau voor een interferentie effect terwijl het globale niveau geen enkele interferentie laat zien. Wij pleiten dat de globaal-naar-lokaal verwerking van een visuele scène alleen plaatsvindt binnen een beperkt spatieel aandachtsgebied.

Zoals eerder gezegd is onze visuele wereld volgestopt met informatie. Daarom focussen we normaal op een beperkt deel van de visuele wereld door hier onze aandacht op te richten. In de hersenen is dit focussen gerelateerd aan de modulatie van activiteit in die hersengebieden die corresponderen met het gebied in het visuele veld waar onze aandacht op gericht is. Deze aandachtsmodulatie is niet alleen afhankelijk van de spatiele organisatie van de visuele hersengebieden, maar ook van de eigenschappen van de receptieve velden in deze hersengebieden. Visuele aandacht verhoogt activiteit in bepaalde hersengebieden afhankelijk van de spatiele schaal van de geselecteerde informatie. Maar deze link tussen de spatiele schaal waar de aandacht op gericht is en de grootte van receptieve velden is nog niet door onderzoek bevestigd. Het onderzoek in hoofdstuk 4 toont met behulp van functionele MRI aan dat aandacht op grote of kleine objecten in een visuele scène de activiteit in specifieke hersengebieden met overeenkomende grote of kleine receptieve velden verhoogt. Deze resultaten komen overeen met de metingen van de maat van receptieve velden en functionele architectuur van de visuele cortex in apen. Verder bevestigen wij voorspellingen die voortkomen uit selectieve aandachtsmodellen. Aandachtsmodulatie van visuele verwerking is sterk 
afhankelijk is van de maat van receptieve velden van neuronen in de visuele cortex. We concluderen dat selectieve visuele aandacht de activiteit in die hersengebieden moduleert die neuronen met receptieve veld eigenschappen bezitten die het meeste passend zijn om de taak te doen. Dit draagt bij aan de voorheen beschreven spatieel-specifieke aandachtseffecten and vergroot ons begrip van selectieve visuele aandachtsprocessen. 


\section{Dankwoord |}

Toen ik in 1996 in Maastricht begon aan de studie biologische psychologie hoopte ik te leren hoe de interactie tussen het lichaam en de geest werkt. Ik was al geruime tijd gefascineerd door dit onderwerp en verwachtte met deze studie antwoord te krijgen op vragen als "Waarom werkt een placebo?" en "Heeft positief denken echt invloed op het genezingsproces en hoe gaat dat in zijn werk?”. Al snel werd me duidelijk dat ik erg naïef was en dat deze vragen niet beantwoord zouden gaan worden in mijn studie. Laat staan of ze ooit beantwoord zullen gaan worden. Enigszins teleurgesteld ging ik toch door en de studie had me al snel in zijn greep. Ik stortte me met hart en ziel me in de boeken. Na mijn afstuderen besloot ik mij verder te gaan verdiepen in de relatie tussen onze hersenen en ons gedrag door promovendus te worden in Maastricht. Zo makkelijk en succesvol als mijn studie was verlopen, zo langzaam, zwaar en moeilijk zou deze aio periode worden. "Driemaal is scheepsrecht", is een gezegde dat mijn promotie-traject goed beschrijft. Na twee doorstarten ben ik nu met de derde poging echt gepromoveerd. Voor u ligt mijn proefschrift. De aanhouder wint. 
Velen voor mij hebben gezegd dat je wetenschap niet alleen bedrijft. Dat beaam ik niet alleen, maar dat wil ik van de daken schreeuwen! Dit proefschrift was er nooit gekomen zonder de samenwerking en de hulp die ik heb gehad. Mark, ik wil je niet alleen bedanken voor de wetenschappelijke bijdrage aan mijn proefschrift, maar vooral voor de talloze gesprekken die we hebben gehad. Alle gesprekken over de leuke en minder leuke kanten van het promoveren en alle gesprekken over alles wat niet met wetenschap te maken heeft. Ik vond het erg fijn om met je samen te werken en vond het leuk je collega te zijn. Jan-Mathijs en Robert O., ook zonder jullie had ik het niet kunnen doen. Ik heb me niet alleen verbaasd over jullie onnoemelijke kennis en kunde, maar ook over het geduld wat jullie met mij hadden bij het uitleggen van de analyse technieken. Mark, Jan Mathijs en Robert, jullie zijn mijn grote helden en redders, bedankt! Nienke Hoogenboom, ik vond het erg leuk om bij jou in de groep te komen. Ik heb bewondering voor je betrokkenheid bij de aio's op het Donders. I would also like to thank Pascal Fries. I am very glad that you "adopted" me in your group. Being part of the neuronal coherence group showed me how motivating, helpful, and pleasant being part of a research group can also be. It reassured me, and gave me new confidence. Great thanks to all members of the neuronal coherence group.

Het FC Donders centrum was een fantastische plek om te werken en te promoveren. Ik wil graag alle collega's en vrienden op het Donders bedanken voor deze tijd. Kamergenoten, Roel, Hubert, Christian en Carinne, ik heb erg prettig met jullie gewerkt. Er was altijd tijd voor een lach of serieus gesprek. En Hubert..., dankjewel dat je altijd in me heb gelooft. Meike, Jasminka, Hanneke, Tineke, Miriam en alle anderen, dankjewel voor alle steun en de gezelligheid! Ook de organisatie en infrastructuur op het Donders waren geweldig. Marek, Dimitri en all andere van de technische groep, zonder jullie had ik alles met de hand moeten berekenen en was ik voorlopig nog niet klaar. Bedankt voor jullie hulp. Bram, ik vond het fijn en vooral gezellig dat je me altijd van mijn werk hebt gehouden, dank je voor al je hulp. Paul, jammer dat ik de laatste tijd niet veel fMRI heb gemeten. Het was altijd gezellig bij jou in de kelder. Ik zal met veel plezier en trots terugdenken aan het centrum en zal de runningclub, de new mom's club, de movieclub, POM's, BBM's en PPM's erg missen!

Rainer, I want to thank you for your always positive attitude, for giving me this aio position and for giving me the chance to finish my $\mathrm{PhD}$ at the FC Donders. Annemie Jeukens, dankjewel voor alle hulp in de administratieve, maar ook in de mentale kwesties. Bernie, dankjewel voor je enthousiaste reactie op mijn zwangerschap en voor je steun tijdens de begeleidingskwestie. Ook wil ik graag alle collega's in Maastricht bedanken. Ik heb altijd veel plezier gehad op de afdeling, en denk nog elke dag aan jullie (dankzij mijn Maastricht koffiemok!, bedankt daarvoor, Michael en Peter). 
Mijn meiden uit Maastricht, Nienke, Milene, Amanda. Voor jullie natuurlijk een speciale dank je wel. Jullie zijn altijd mijn voorbeeld geweest en ik heb zoveel van jullie geleerd (en niet alleen op wetenschappelijk gebied). Ik mis jullie nog steeds en ik hoop dat de mei-vakantie-traditie nog lang door zal gaan. Dank je wel dat jullie er altijd waren en dat we alles met elkaar konden bespreken. Ik ben blij dat ik als hekkensluiter onze promotiecyclus kan afronden. nu vormen we een mooi kwartet.

Kirsten, jammer dat we elkaar zo weinig gezien hebben afgelopen tijd. Hopelijk wordt dat wat meer in de toekomst als je terug komt naar Nederland. Dankjewel dat je er altijd voor mij bent. Sabine, ik zal je missen. Het is zo jammer dat we niet dichter bij elkaar wonen. We hebben zoveel nu waarover we moeten bijpraten en ervaringen uit kunnen wisselen. Ik hoop jou, Peer en Pekka nog vaak te zien. Jayani, ik heb altijd genoten van de verhalen over je werk. Het gaf mij de hoop dat er buiten de wetenschap nog veel meer te vinden is. Ook de GG verdient zijn plekje hier. Wat zou ik me eenzaam gevoeld hebben hier in het oosten van het land als ik niet meteen zo hartverwarmend was opgenomen in dit genootschap. Alle Demmenie-anen, dank jullie voor jullie heerlijke vriendschap en dat jullie me altijd hebben laten zien dat er veel belangrijkere en leukere dingen in het leven zijn dan wetenschap. Stijn, Linda, Richard, Giel en Floor, Marleen, Eylke, en Tjaard en Jess en jullie families, ik hoop dat we nog vele leuke weekenden en vakanties met elkaar gaan doorbrengen!

Joost, ontzettend bedankt voor je ontwerp en je hulp bij het maken van het boekje, ik ben er erg trots op hoe het eruit ziet! Ik hoop dat je op dit moment een fantastische tijd hebt.

Dit alles is niets waard als ik niet mijn fijne familie en gezin zou hebben. Mijn lieve meisje Frida relativeert alle werkgerelateerde problemen. Ze is altijd een feest! Elke dag opnieuw voelt het alsof ik een cadeautje krijg waneer ik opsta en waneer ik 's avonds thuiskom.

Ik wil hier vooral mijn ouders en mijn schoonouders bedanken. Waar zou ik zijn zonder jullie. Zonder jullie onvoorwaardelijke steun, helpende handen en alle uren oppassen zou ik hier nu niet staan. Mijn dankbaarheid is niet in woorden uit te drukken. Al mijn lieve (schoon)zussen: Ilse Daan, Ruth en Marloes, en de mannen: Serge, Ben en Nico, fijn dat jullie er altijd zijn om te helpen of even bij te kletsen over kinderen, klussen, werk, ditjes en datjes. Mijn grootste dank gaat uit naar Robert. Jij zorgt ervoor dat mijn leven altijd fijn en leuk is, wat er ook gebeurt. Bij jou heb ik mijn thuis en dat is alles wat ik wens. 
Hier sta ik dan, ik ben bijna gepromoveerd. Met blijdschap, maar ook met enige weemoed trek ik de deur van de ivoren toren achter me dicht, veel lieve collega's en een fascinerende werkplek achterlatend. De zon verwarmt mijn huid en ik voel de wind in mijn gezicht. Ik kijk uit over een uitgestrekt landschap en voel de kriebels in mijn tenen van een nieuw begin.

Sandra Iris van Aalderen-Smeets

Februari 2007 


\section{Curriculum Vitae |}

Sandra iris van Aalderen-Smeets was born on October 3rd 1976 in Eindhoven, the Netherlands. She attended the van Maerlantlyceum in Eindhoven from 1989 until 1996 where she received her V.W.O diploma. During this period she participated in a youth exchange program for which she spent a year (1992/1993) in Jönköping, Sweden. From 1996 to 2000 Sandra studied Psychology at the Universiteit Maastricht. During this time she participated in teaching activities at the University and worked as a student assistant. Sandra performed her internship and specialization courses in cognitive neuroscience at Penn State University, USA. She graduated Cum Laude in 2000 with a specialization in developmental cognitive neuroscience. Her master thesis investigated mathematical models to describe infant visual habituation under supervision of Dr. L. Blomert and Dr. R. Gilmore. From 2000 to 2007 she was employed as a PhD student and junior lecturer at the Universiteit Maastricht. In 2003 her work office changed to the F.C. Donders centre for Cognitive Neuroimaging in Nijmegen where she conducted the research described in this thesis under supervision of Dr. J. Schwarzbach, Dr. Pascal Fries and Prof. Dr. Rainer Goebel. Currently she is employed at the Departement of Behavioral Science, University of Twente, as a bachelor-master thesis coordinator and lecturer. 



\section{Series | \\ F.C. Donders Centre for Cognitive Neuroimaging}

1. van Aalderen-Smeets, S.I. (2007). Neural dynamics of visual selection. Universiteit Maastricht, Maastricht, The Netherlands.

2. Schoffelen, J. (2007). Neuronal communication through coherence in the motor system. Radboud Universiteit, Nijmegen, the Netherlands. 